\title{
Diversity and renewal of tropical elasmobranchs around the Middle Eocene Climatic Optimum (MECO) in North Africa: New data from the lagoonal deposits of Djebel el Kébar, Central Tunisia
}

\author{
Sylvain Adnet, Laurent Marivaux, Henri Cappetta, Anne-Lise Charruault, \\ El Mabrouk Essid, Suzanne Jiquel, Hayet Khayati Ammar, Bernard Marandat, \\ Wissem Marzougui, Gilles Merzeraud, Rim Temani, \\ Monique Vianey-Liaud, and Rodolphe Tabuce
}

\begin{abstract}
Bulk sampling of an indurated glauconic sandstone horizon from Djebel el Kébar, Central Tunisia, yielded a moderately diversified assemblage of elasmobranchs (sharks and rays), dating from the late Middle Eocene (mid Bartonian). Here, 10 new taxa (nine new species and three new genera) are described among a total diversity of 33 species. These new taxa highlight the rise of mid-large predator lineages of modern nearshore seas and fill a substantial gap in the sporadic fossil record of the late Middle Eocene. Comparisons of this assemblage with other Middle-Late Eocene faunas from the Tethys seaway indicate that this Tunisian fauna shares more similarities with Late Eocene than with early Middle Eocene assemblages. This suggests that the major shift observed in tropical elasmobranch communities from the Late Eocene, with for instance the appearance of large Carcharhinids replacing Lamniforms, began during the late Middle Eocene. Such a biotic shift could be linked to the warm conditions recorded ca. $41 \mathrm{Ma}$, known as the Middle Eocene Climatic Optimum (MECO), which was characterized by a short temperature increase of all marine waters.
\end{abstract}

Sylvain Adnet. Institut des Sciences de l'Evolution (UMR5554, CNRS, UM, IRD, EPHE), Université de Montpellier, Place E. Bataillon, 34095 Montpellier Cedex 05, France. Sylvain.adnet@umontpellier.fr Laurent Marivaux. Institut des Sciences de l'Evolution (UMR5554, CNRS, UM, IRD, EPHE), Université de Montpellier, Place E. Bataillon, 34095 Montpellier Cedex 05, France. laurent.marivaux@umontpellier.fr

Adnet, Sylvain, Marivaux, Laurent, Cappetta, Henri, Charruault, Anne-Lise, Essid, El Mabrouk, Jiquel, Suzanne, Ammar, Hayet Khayati, Marandat, Bernard, Marzougui, Wissem, Merzeraud, Gilles, Temani, Rim, Vianey-Liaud, Monique, and Tabuce, Rodolphe. 2020. Diversity and renewal of tropical elasmobranchs around the Middle Eocene Climatic Optimum (MECO) in North Africa: New data from the lagoonal deposits of Djebel el Kébar, Central Tunisia. Palaeontologia Electronica, 23(2):a38. https://doi.org/10.26879/ 1085

palaeo-electronica.org/content/2020/3110-meco-elasmobranchs 
Henri Cappetta. Institut des Sciences de l'Evolution (UMR5554, CNRS, UM, IRD, EPHE), Université de Montpellier, Place E. Bataillon, 34095 Montpellier Cedex 05, France. henri.cappetta@umontpellier.fr Anne-Lise Charruault. Institut des Sciences de l'Evolution (UMR5554, CNRS, UM, IRD, EPHE), Université de Montpellier, Place E. Bataillon, 34095 Montpellier Cedex 05, France. anne-

lise.charruault@umontpellier.fr

El Mabrouk Essid. Office National des Mines (ONM), 24 rue 8601, 2035 La Charguia, Tunis BP: 215, 1080 Tunis, Tunisia.mab_04@yahoo.fr

Suzanne Jiquel. Institut des Sciences de I'Evolution (UMR5554, CNRS, UM, IRD, EPHE), Université de Montpellier, Place E. Bataillon, 34095 Montpellier Cedex 05, France. suzanne.jiquel@umontpellier.fr Hayet Khayati Ammar. Office National des Mines (ONM), 24 rue 8601, 2035 La Charguia, Tunis BP: 215, 1080 Tunis, Tunisia. khayatihayet@yahoo.fr

Bernard Marandat. Institut des Sciences de l'Evolution (UMR5554, CNRS, UM, IRD, EPHE), Université de Montpellier, Place E. Bataillon, 34095 Montpellier Cedex 05, France. bernard.marandat@umontpellier.fr Wissem Marzougui. Office National des Mines (ONM), 24 rue 8601, 2035 La Charguia, Tunis BP: 215, 1080 Tunis, Tunisia.wi_marzougui@yahoo.fr

Gilles Merzeraud. Géosciences Montpellier (UMR 5243, CNRS/UM/Université des Antilles), Université de Montpellier, Place E. Bataillon, 34095 Montpellier Cedex 05, France. gilles.merzeraud@umontpellier.fr Rim Temani. Office National des Mines (ONM), 24 rue 8601, 2035 La Charguia, Tunis BP: 215, 1080 Tunis, Tunisia. rim.temani@onm.nat.tn Monique Vianey-Liaud. Institut des Sciences de l'Evolution (UMR5554, CNRS, UM, IRD, EPHE), Université de Montpellier, Place E. Bataillon, 34095 Montpellier Cedex 05, France. monique.vianeyliaud@umontpellier.fr

Rodolphe Tabuce. Institut des Sciences de l'Evolution (UMR5554, CNRS, UM, IRD, EPHE), Université de Montpellier, Place E. Bataillon, 34095 Montpellier Cedex 05, France. rodolphe.tabuce@umontpellier.fr

Keywords: Bartonian; faunal turnover; new species; new genera; elasmobranchs

Submission: 7 April 2020. Acceptance: 17 July 2020.

\section{INTRODUCTION}

The Eocene was a crucial time in the Earth's Cenozoic climate evolution. Deep-ocean and highlatitude palaeotemperature proxies demonstrate that the Eocene epoch encompasses the warmest interval of the past 66 million years. The highest temperatures of the Cenozoic were reached during the Paleocene Eocene Thermal Maximum (PETM, $\sim 56 \mathrm{Ma}$ ) and the Early Eocene Climatic Optimum (EECO, 53-49 Ma) and were followed by longterm cooling, which continued through the Middle and Late Eocene (e.g., Zachos et al., 2001, 2008; Katz et al., 2008; Bijl et al., 2010; Westerhold et al., 2018; Hollis et al., 2019). During this global cooling, world lands and seas were in the so-called "doubthouse" climate state, between the "greenhouse" conditions around the EECO and the "icehouse" regime that started with the development of the Antarctic continental ice sheet in the earliest Oligocene (e.g., Miller et al., 1987; Zachos et al., 1996; DeConto and Pollard, 2003; Coxall et al., 2005; Miller et al., 2005; Lear et al., 2008, Liu et al., 2009). During these long "doubthouse" conditions (= Eocene), ephemeral ice sheets may have been present on the Antarctic continent (Miller et al., 2005), while sea ice may have been present in the Arctic Ocean (Stickley et al., 2009).

In the tropical realm of the western Tethys seaway (prefiguring the paleomediterranean sea before its Neogene closure), there is no evidence of major change in inshore marine depositions during the Early Eocene and early Middle Eocene. Combined with a high sea-level, the warm and humid climate at this time may have favoured the local formation of numerous fossiliferous phosphate cores (dated to Early-early Middle Eocene) along the Western and North African coasts (e.g., Notholt et al., 1989) by increasing the rate of continental weathering, and thereby increasing the amount of phosphate transported to the sea (Follmi, 1996; Swezey, 2009). This kind of deposit is well-known by vertebrate palaeontogists because it optimizes the well-preservation of fossil apatite (biogenic calcium triphosphate) that constitutes the main mineral tissue of vertebrate bones and teeth. This is particularly the case with elasmobranchs, a group for which most of the main fossiliferous deposits are located in northern Africa, from 
Morocco to Tunisia, during the early Paleogene (Arambourg, 1952; Noubhani and Cappetta, 1997). The quantity of phosphate in marine deposition (and correlatively fossil-bearing levels with well preserved elasmobranch teeth) decreases along the inshore since the late Middle Eocene. In this context, most of the Late Eocene fossil-bearing localities with elasmobranchs are found to be related to coastal sand body complexes (Adnet et al., 2007, 2010, 2011; Underwood et al., 2011). Among them, some well-exposed coastal complexes in the Western Desert of Egypt (e.g., Wadi al Hitan) have been sometimes interpreted to reflect such global cooling and ephemeral eustatic sea level decrease (possibly related to merging of ice?) during the Late Eocene (Peters et al., 2009, 2010). However, such interpretations are always severely debated (e.g., Underwood et al., 2012; Gingerich et al., 2012; King et al., 2014), and local tectonic events might play an important role in these past sedimentary cycles.
This relatively long transition to globally cooler climates was, however, interrupted by transient warming events, the most prolonged and intense of which was the "Middle Eocene Climatic Optimum" (MECO; e.g., Bohaty and Zachos, 2003). The MECO interrupted the cooling trend of the middlelate Eocene at 40.6-40.0 Ma (Bohaty et al., 2009), during the Bartonian. First identified in sediment cores as a transient oxygen isotopic excursion ( -1.0\%; Bohaty and Zachos, 2003), the MECO was recognized and more precisely dated in isotopic records from different areas. At warming peak, the $\delta^{18} \mathrm{O}$ records indicate warming of $\sim 4-6$ ${ }^{\circ} \mathrm{C}$ of both surface and deep waters (Bohaty et al., 2009; Edgar et al., 2010), with sea-surface temperatures ranging as high as $\sim 31^{\circ} \mathrm{C}$ in the tropical realm (Cramwinckel et al., 2018; see Figure 1). Marine biotic response to the MECO has so far only been studied among plankton or benthic foraminifera, from the Tethys seaway (Luciani et al., 2010; Toffanin et al., 2011; Witkowski et al., 2012; Boscolo Galazo et al., 2013). These studies have

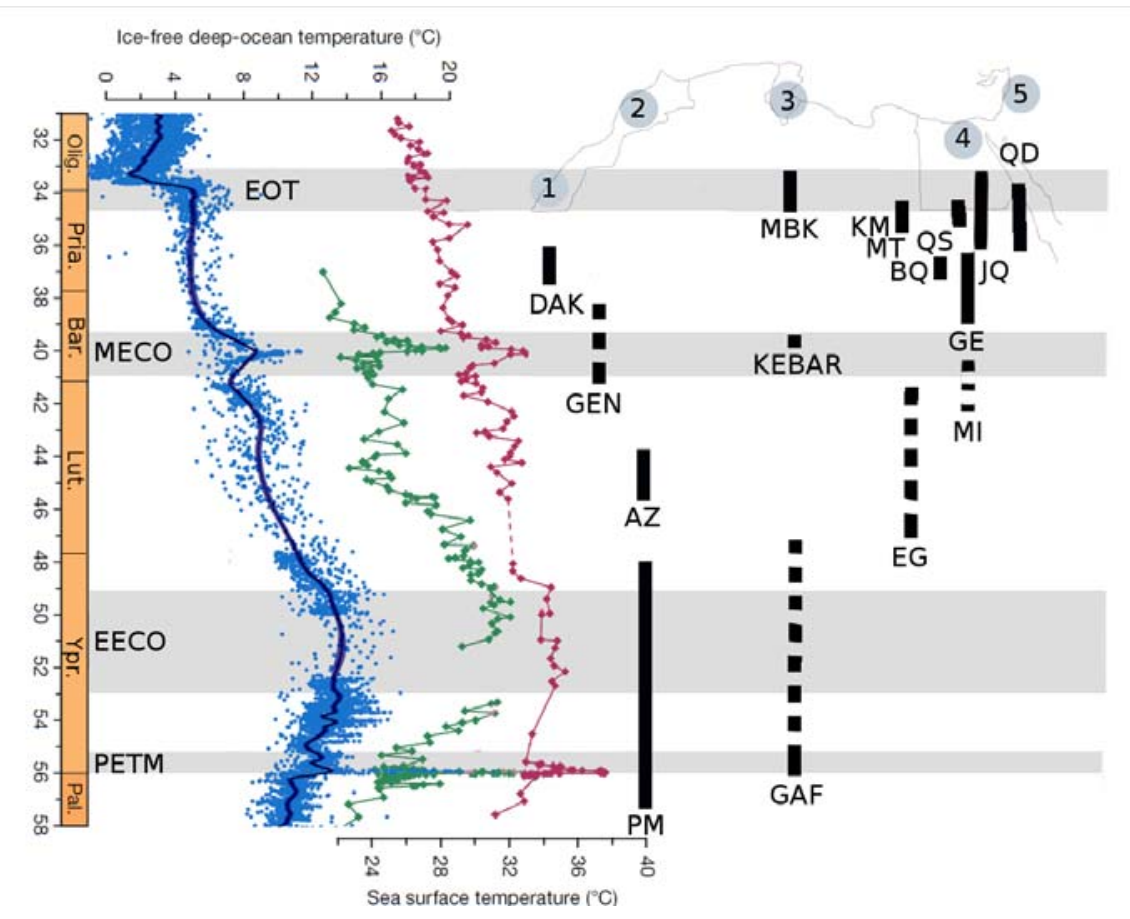

FIGURE 1. Paleotemperatures (ice-free deep-ocean $T^{\circ} /$ tropical sea surface $\mathrm{T}^{\circ}$ ) and Thermic events during the "doubthouse" conditions of Eocene period (from Cramwinckel et al., 2018 modified with events dating from Hollis et al., 2019). Stratigraphically and geographical locations of the main deposits with Elasmobranch associations along the southwestern Tethys. Abbreviations: DAK: Dakhla (Adnet et al., 2010), GEN: Genam (Zouhri et al., 2017, in press); AZ: Aznag (Tabuce et al., 2005) PM: Phosphate ores (see Noubhani and Cappetta, 1997), Morocco; GAF: Gafsa basin (see Arambourg, 1952); KEBAR: Kébar (this work and Adnet et al., 2019); MBK: Mabrouk (see Sweydan et al., 2019), Tunisia; EG: ElGedida (see Strougo et al., 2007); KM: KM11 (see Adnet et al., 2011) MT: Minqar Tabaghbagh (see Zalmout et al., 2012); BQ: Birquet Qarun QS: Quar et Sa; GE: Genahamm Fm.; MI: Midawara FM. from Wadi al Hitan, see Underwood et al., 2011), Egypt; QD: Qa Faydat al Dahikya, Jordania, see Mustafat and Zalmout, 2002). 
highlighted the existence in some cases of rapid assemblage changes in autotrophic and heterotrophic microfossil groups during the MECO.

The evolution of Tethyan seaway elasmobranchs (sharks and rays) during the long "doubthouse" period (including the MECO) has so far remained unknown, even if many authors have suspected a great change in faunal association during the late Middle Eocene (Adnet et al. 2007, 2010, 2018; Underwood et al., 2011; Underwood and Gunter, 2012) with the intense evolution of several dominantly tropical clades as early as the early Late Eocene. Unfortunately, reports of fossilbearing deposits with elasmobranchs from welldated Bartonian sites are relatively scarce along southwestern Tethyan coasts compared to those dating from the Lutetian or Priabonian (Figure 1). These were collected in the Midawara Formation (uppermost Lutetian - lowermost Bartonian NP16/ 17) and those from the lowermost unit of Gehannam Fm. (uppermost Bartonian NP17) in Wadi al Hitan, Egypt (Underwood et al. 2011, 2012, 2013; King et al., 2014). Underwood et al. (2011) noted some differences in both faunal associations from analogous facies, suggesting possible biostratigraphical changes through the MECO. However, the rarity of well-dated Bartonian samples has so far not allowedsupport for such observations.

In the framework of our paleontological program in the early Cenozoic of North Africa, we have (since 2008) focused our field research in Tunisia, notably on the geological outcrops exposed in the center of the country (Figure 2). In the vicinity of the village of Souk-Jedid (Sidi Bouzid Township), the survey of the Eocene shallow marine deposits accessible at the foothill of the southeastern flank of Djebel el Kébar has allowed for the discovery of the vertebrate-bearing KEB-1 locality (Marivaux et al., 2014a-b; Merzeraud et al., 2016). K-Ar dating was carried out on four samples of grains of glauconite from the glauconitic clays embedding the fossils of KEB-1, indicating that KEB-1 is late Middle Eocene in age (Bartonian; datings ranging from $38.7 \pm 1.0 \mathrm{Ma}$ to $40.7 \pm 1.1$ Ma; see Yans in Marivaux et al., 2014a). A few mammal teeth (including a rodent, a hyracoid, and a primate; Marivaux et al., 2014a-b) as well as numerous teeth of elasmobranchs (Merzeraud et al., 2016; Adnet et al., 2019) were recovered by wet-washing of ca. three tons of sediment. Regarding the elasmobranchs, this locality testifies the oldest record of cowtail stingrays (Adnet et al., 2019). In this paper, we complete the study of the KEB-1 elasmobranch assemblage. We provide an update of the former taxonomic list, extending the number of taxa from 29 (in Merzeraud et al., 2016) to 33 (including 22 sharks and 11 batoids). This elasmobranch-bearing locality is particularly critical as it increases substantially our knowledge of the ancient southwestern Tethysian elasmobranch fauna, notably for the still not well-sampled Bartonian stage.
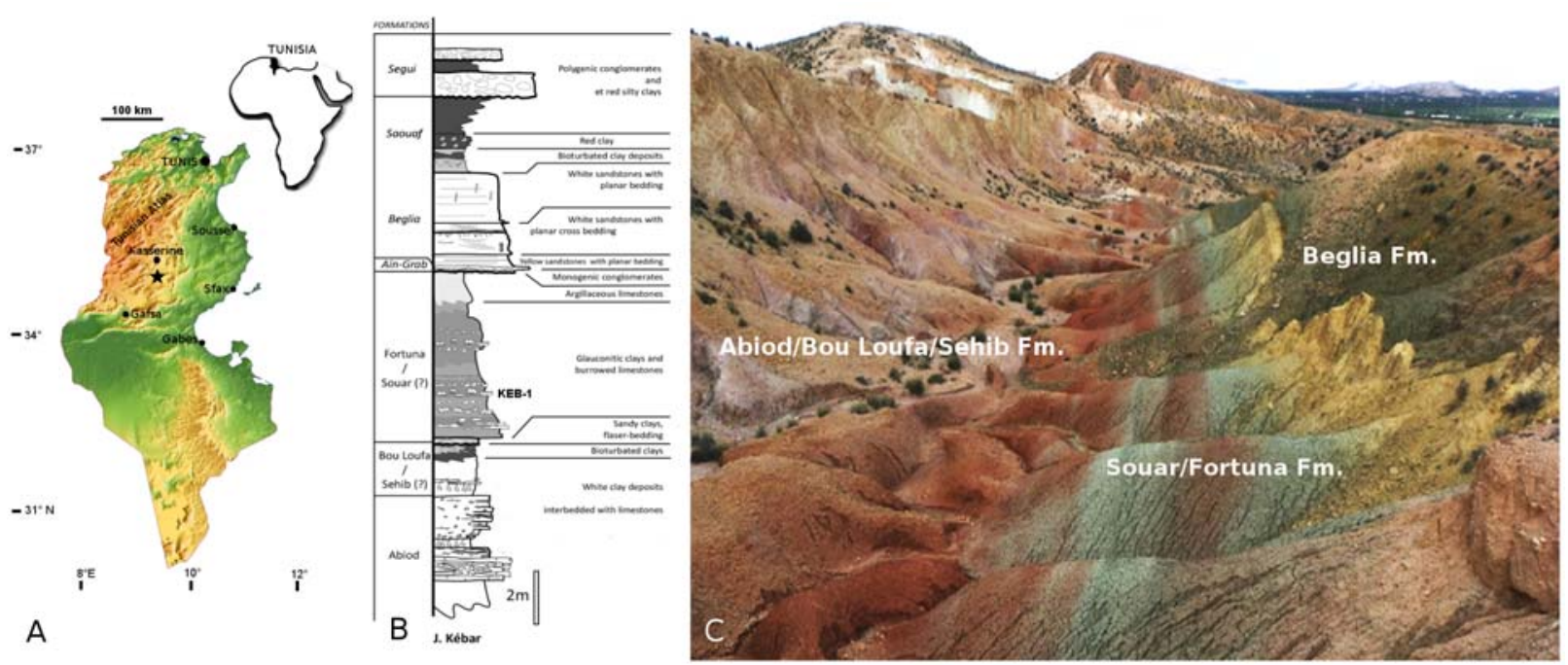

FIGURE 2. Locality of KEB-1, Djebel el Kébar, Kasserine region, Tunisia. A, Simplified topographic map of Tunisia locating the Djebel el Kébar in central Tunisia; B, simplified stratigraphical position of fossiliferous level having yielded the fossil-bearing KEB-1 locality; C, photograph showing the typical badlands of variegated clays from the early Tertiary sequence of Djebel el Kébar. See Merzeraud et al. (2016) for precise details about geological settings. 


\section{GEOLOGICAL SETTING}

The sedimentology, stratigraphy, and dating of the KEB-1 fossil-bearing locality were outlined in Marivaux et al. (2014b) and Merzeraud et al. (2016), and more recently in the first work devoted to some elasmobranch remains (Adnet et al., 2019). Located in central Tunisia, in the Sidi Bouzid area, the Djebel el Kébar is an anticlinal structure of Atlasic direction (Figure 2). The fossil locality (KEB-1; see Marivaux et al. 2014a-b; Merzeraud et al. 2016; Adnet et al., 2019) that yielded the elasmobanch teeth was discovered in a proximal facies associated with several periods of low sedimentation rate of Bartonian deposits in Tunisia. Merzeraud et al. (2016) also interpreted the Kebar sequence as belonging to a very shallow waterdepth carbonate platform (wave dominated and influenced by storms and tide) where the proximal facies of the fossil-bearing KEB-1 locality reflected lagoonal conditions, as indicated by the presence of bioturbated glauconitic clays and continental fossil mammals (Marivaux et al. 2014a-b).

Several thousand elasmobranch teeth were recovered from the KEB-1 fossil-bearing locality by in situ wet washing of sediments (see also, Adnet et al., 2019). Material consists of a very large sample of isolated teeth (more than five thousands) of sharks and rays. However, the elasmobranch species diversity remains relatively low compared to other marine Paleogene localities (see paragraph below) with only 30 species. Among them, a dozen dominant species are abundantly represented by thousands of teeth, including the species of cowtail stingray Pastinachus kebari (Adnet et al., 2019).

\section{Abbreviations}

Numerous Middle-Late Eocene localities with elasmobranchs were recorded along the southwestern coast of Tethys seaway, from Morocco to Qatar. Particularly in Egypt, theses localities are often geographically and stratigraphically close, sometimes leading to confusing reading. To avoid any misunderstanding, we chose to report them with appropriate abbreviation through the text: $\mathrm{BQ}$ : deposits from the Birket Qarum Fm., Fayum, Egypt, dated to ?early Priabonian (NP19-20) in Underwood et al. (2011). BQ2 in Murray et al. (2010) is named after the locality (near Birket Qarun lake) rather than the formation and must be considered as contemporaneous to levels of the Qasr el-Saghr Fm. according to Underwood et al. (2011); EG: El Gedida, Bahariya oasis, Gharaq Fm., Western Desert, Egypt (?Lutetian) in Strougo et al. (2007); GE: deposits from the Gehannam
Fm., Wadi al Hitan, Egypt (as reported in Case and Cappetta, 1990) with details: GE (A-C): Gehannam Fm. Units A-C, Wadi al Hitan, Egypt dated to uppermost Bartonian NP17 (A) - lowermost Priabonian NP18 (B-C) in Underwood et al. (2011, 2012, 2013) and GE (D-G): Gehannam Fm. Units D-G, Wadi al Hitan, Egypt dated to early Priabonian (NP19-20) in Underwood et al. (2011, 2012, 2013); JQ: brackish-freshwater deposits of the Jebel Qatrani Fm. (early Oligocene), Fayum, Egypt (in Murray, 2004); KM: locality Kilometer 11, Qasr el-Saghr Fm, Western Desert, Egypt (late Priabonian) in Adnet et al. (2011); Ml: deposits from the Midawara Fm., Wadi al Hitan, Egypt, dated to uppermost Lutetian - lowermost Bartonian NP16/17 according Strougo (2008) in Underwood et al. (2011, 2012, 2013), and Helal and Holcova (2017); QS: deposits from the Qasr el-Saghr Fm., Fayum, Egypt (late Priabonian - Chr 15n) in Underwood et al. (2011). Underwood et al. (2011) revisited and figured a large part of the elasmobranch fauna from Wadi al Hitan, Egypt, with detailed listing (Underwood et al. 2011, Tab. 1-2) of taxa along the MI, GE, BQ and QS formations. Unfortunately, they left many species in open nomenclature, and figured only a pair of specimens per taxa, which sometimes occur in several levels or diachronic formations. As a result, the morphological comparisons with material figured in Underwood et al. (2011) may seem light. Fresh jaws of Recent species of Leptocharias (Appendix 1), Rhizoprionodon and Sphyrna (Appendix 2) are deposited at Montpellier University with collection number UM REC.

\section{Deposition of Material}

All figured specimens, including the holotypes of new taxa, are housed in the paleontological collections of the museum of the "Office National des Mines" of Tunis, Tunisia, with collection numbers KEB 1-86 to KEB 1-227, coming from the KEB-1 fossil-bearing locality, which was named KEB in forthcoming parts.

\section{SYSTEMATIC PALAEONTOLOGY}

\section{Class CHONDRICHTHYES Huxley, 1880 \\ Sub Cohort NEOSELACHII Compagno, 1977 Order LAMNIFORMES Berg, 1958}

Gathering the largest and most neritic species, well-preserved teeth belonging to common Eocene Lamniform taxa are very scarce in KEB, either by surface collecting during the field or in bulk samples. Several large broken cusps and roots are provisionally attributed to Macrorhizodus cf. praecursor (Leriche, 1905), a large lamnid com- 
monly reported in most of the middle/upper Eocene deposits of the Tethys seaway. Only a pair of complete teeth allowed a better systematic attribution. It concerns those of a fossil thresher shark Alopias sp. Until now, Alopias representatives were primarily known in tropical seas during the Late Eocene in Europe (e.g., Cappetta, 2012), and from southwestern Morocco (Adnet et al., 2011) to Egypt (Case and Cappetta, 1990; Underwood et al., 2011; Zalmout et al., 2012) with the reports of the ambiguous North American Alopias alabamensis White, 1956 (see Ebersole et al. 2019 for discussion). Only represented by a single specimen in MI (Middle Eocene), teeth of Alopias seem to be more abundant throughout all the other open marine rock units of Wadi al Hitan (Case and Cappetta, 1990; Underwood et al. 2011), GE (A-C) included. This report in KEB confirms the occurrence of genus since Bartonian in southwestern Tethys.

Order CARCHARHINIFORMES Compagno, 1977 Family CARCHARHINDAE Jordan and Evermann, 1896

Genus CARCHARHINUS Blainville, 1816

Type species. Carcharhinus melanopterus (Quoy and Gaimard, 1824), extant species.

Carcharhinus kasserinensis nov. sp.

Figures 3, 4A-B

zoobank.org/BBD87F04-3CC9-4B13-9C24-1F37A28DC5D4

2012 Carcharhinus sp. Underwood and Gunter, p.2728, fig. 2.

2016 Carcharhinus sp. Merzeraud et al., p. 14-15, tab. 1.

Etymology. Derived from the name of Kasserine region where the holotype comes from.

Type locality and stratum. KEB 1-087 (Figure 3B), from Souar-Fortuna Formations in Djebel el Kébar, Amamria hamlet near Soug-Jedid village (Sidi Bouzid Township), Tunisia: locality named KEB-1 in Merzeraud et al.(2016) and previously dated (radiometric $\mathrm{K}-\mathrm{Ar}$ datings) as middle Bartonian $(38.7 \pm 1.0 \mathrm{Ma}$ to $40.7 \pm 1.1 \mathrm{Ma}$, covering the NP17) in Marivaux et al. (2014a).

Other material. Additional material, including figured KEB 1-086, KEB 1-088 to 1-099, KEB 1-226, 1-227 (Figures 3A, C-N, 4A-B), mainly consists of several hundred broken upper and lower teeth from the KEB-1 locality, Souar-Fortuna formations, Djebel el Kébar, Tunisia.

Diagnosis. Medium-sized carcharhinid species belonging to the "Bull-group" and only known by isolated teeth. Marked dignathic heterodonty with flat, blade-like cusps in upper teeth and weak erected, asymetrical cusps in lower teeth. Upper teeth display a triangular crown without distinct anterior heel when lateral heel is reduced to oblique cutting edge, partially notched from the principal cusp. Upper mesial edge of the cusp appears to be deflected distally and both cutting edges are fully but irregularly serrated. Root is large and tall, especially in the central part leading to a medially incurved crown-root boundary in labial view. Lower teeth have an erect cusp with irregularly serrated cutting edges from apex to asymmetrical heels, with one developed mesially or distally. Root is peculiarly massive medially with a deep and wide nutritive groove.

\section{Description}

Upper teeth. The specimens reach a maximum 13 $\mathrm{mm}$ in width even if some fragments suggest a larger size (up to $17 \mathrm{~mm}$ ). This tooth size is comparable or larger than the other Middle Eocene representatives of requiem sharks and, thus, was considered as belonging to adults. These teeth, including the holotype (Figure 3B), are very labiolingually flattened with a triangular crown more or less slanted distally, in anterior (Figure $3 \mathrm{~A}$ ) to lateral files (Figure $3 C-G$ ), respectively. The mesial and distal cutting edges are fully serrated from the crown-root boundary to the apex of the cusp. The serrations are mainly simple (mono serrated) but particularly irregular and coarser in its lower part (Figure 3B3). "Typical" double serration (e.g., replication of large serrae boarded by a pair of small serrae) appears locally on the cutting edge, but this pattern is never continuously replicated. This feature could be present on both cutting edges even if it is more strongly marked on the distal one of lateral to posterior upper teeth, near the notch distinguishing the cusp from the distal heel. In lingual and labial views, the mesial cutting edge appears straight in its lower part in more anterior files (Figure $3 A-B$ ) to slightly convex and deflected distally in more lateral files (Figure 3G-I). In the same view, the distal cutting edge is slightly concave to strongly angular in anterior to lateral files, respectively. The distal heel, well-marked by a notch and a coarser serration of its cutting edge, is present in antero-lateral to lateral files (Figure 3D-H). In labial view, the crown-root boundary is reduced in length and medially arched in both anterior and lateral files. The root is massive, tall, and greater in length than that of the crown, except in parasymphyseal files (Figure 3A). The shape of the basal crown border is often medially arched (Figure 3B-C) in anterior and lateral files to straight and disrupted by a median notch in posterior files (Figure 3I). Lateral 


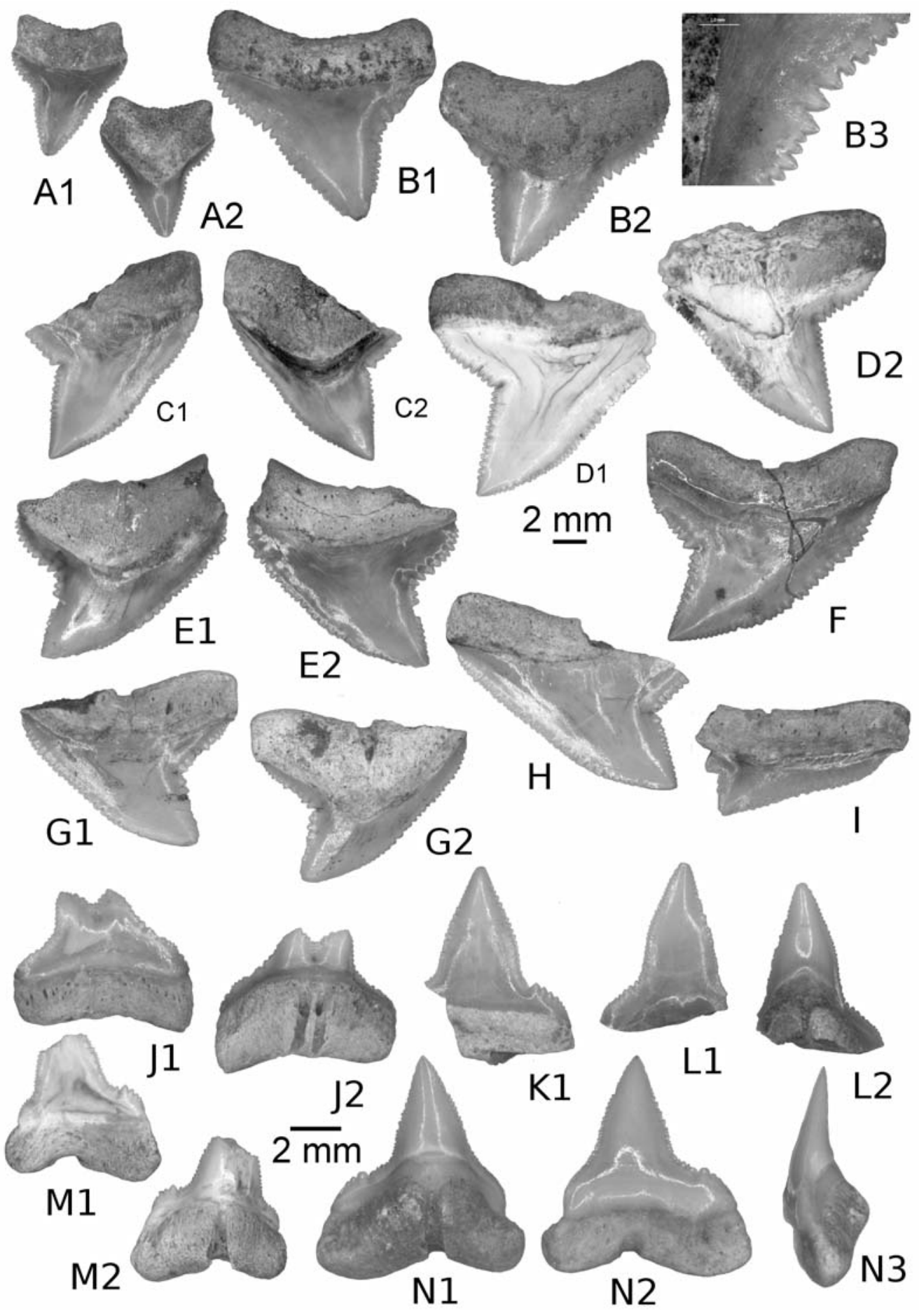

FIGURE 3. A-N: Carcharhinus kasserinensis nov. sp. A. Parasymphyseal upper tooth KEB 1-086, A1. labial view, A2. Lingual view; B. HOLOTYPE Anterior upper tooth KEB 1-087, B1. Labial view, B2. Lingual view, B3. Magnificence of mesial cutting edge; C. Antero-lateral upper tooth KEB 1-088, C1. Labial view, C2. Lingual view; D. Antero-lateral upper tooth KEB 1-089, D1. Labial view, D2. Lingual view; E. Antero-lateral upper tooth KEB 1-226, E1 Lingual view, E2. Labial view; F. Antero-lateral upper tooth KEB 1-227; G. Antero-lateral upper tooth KEB 1-090, G1. Labial view, G2. Lingual view; H. Lateral upper tooth KEB 1-091, labial view; I Posterior upper tooth KEB 1-092, lingual view; J. Symphyseal abnormal lower tooth KEB 1-093, J1. Labial view, J2. Lingual view; K. Anterior lower tooth KEB 1-094, labial view; L. Anterior lower tooth KEB 1-095, L1. Labial view, L2. Lingual view; M. Antero-lateral lower tooth KEB 1096, M1. Labial view, M2. Lingual view; N. Antero-lateral lower tooth KEB 1-097, N1. Lingual view, N2. Labial view, N3. Profile. 
extremities of the root are mainly rounded. The root lobes are well developed and separated in lingual view by a nutritive groove, widely open in lateral to posterior files (Figure $3 \mathrm{C}-\mathrm{I}$ ), and shallow in anterior and antero-lateral files (Figure $3 \mathrm{~A}-\mathrm{C}$ ). The nutritive groove is often relatively reduced in the largest teeth (Figure 3B) and tends to be erased by abrasion. Some smaller teeth (Figure 4A-B), considered as representatives of younger specimens, display similar shapes with adults except for the size of serrations that appears even coarser compared to the tooth size.

Lower teeth. The state of preservation of lower teeth is bad compared to the upper ones. When preserved, lower teeth have a protruding and central cusp, quite symmetrical, with uninterrupted cutting edges from the apex to the basal. If one lateral heel is weakly developed, the other seems always more developed in anterior and lateral files (Figure $3 \mathrm{~K}-\mathrm{N}$ ). If the smallest one is oblique and continuous with cutting edges of cusp, the biggest is notched by a serration locally coarser, forming a kind of small cusplet. As in the upper teeth, irregular serrations are often more strongly developed in the lower part of the cutting edges (and especially on one heel) than near the apex. Labial and lingual faces are slightly sinuous (Figure $3 \mathrm{~N} 3$ ) in profile. The root is well developed with a thick medio-lingual protuberance in lateral view (Figure 3N3). The root lobes, when conserved, have rounded lateral extremities and are separated by a median and nutritive groove (Figure 3N1), which appears deeper and wider than in upper teeth. An abnormal tooth (Figure $3 \mathrm{~J}$ ), possibly from the parasymphyseal file, displays a double cuspided crown and a double nutritive groove as resulting of the fusion of two teeth.

\section{Remarks}

Teeth of living species of Carcharhinus have long attracted attention of many scientists giving the extensive literature with well-done illustrations for comparisons (e.g., Compagno, 1988; Naylor, 1990; Naylor and Marcus, 1992; Voigt and Weber, 2011). Carcharhinus kasserinensis nov. sp. clearly differs from any living species in its diagnosis features and particularly in presence of cutting edges with a very irregular mono serration, announcing the beginnings of double serration, and the asymmetrical crown of the lower teeth. Some living Indonesian species (e.g., C. borneensis, C. dussumieri) display a coarser serration on the distal heel of upper teeth, and asymmetrical lower teeth, but none have the massive aspect of them. Among the rare Paleogene Bull shark group (or whaler sharks) characterized by large serrated upper teeth, the new species $C$. kasserinensis differs from $C$. perseus Adnet et al., 2011 from the Early Oligocene of Pakistan in having a stronger dignathic heterodonty (triangular upper teeth and symmetrical lower teeth) with weaker lower and upper teeth. Given the latter trait, C. kasserinensis nov. sp. reminds those of the large $C$. balochensis Adnet et al., 2011 from the Late Eocene to Early Oligocene of Pakistan and Oman, the medium-sized C. marcinae Ebersole et al., 2019 from mid Bartonian of Alabama, USA, or C. underwoodi Samonds et al., 2019 from the Middle-Late Eocene of Madagascar. However, it differs from the two first in having an irregularly serrated cutting edge when C. balochensis and $C$. mancinae upper teeth share more regular and compound and/or double serration. It differs from the last one in having a clear dignathic heterodonty with unsymmetrical lower teeth, and irregular mono serration of upper teeth that does not decrease drastically in size near the apex of cusps. Samonds et al. (2019) described a Middle-Late Eocene species of Carcharhinus (C. underwoodi) from Madagascar considering that the youngest $C$. balochensis from the Indian Ocean was invalid and should be synonymized with Galeocerdo eaglesomei. However, as noticed by Ebersole et al. (2019), the latter statement is currently unsupported, eluding that $C$. balochensis shares classic dignathic heterodonty of Carcharhinus (contrary to Galeocerdo), a compound serration (never doubly serrate in G. eaglesomei) and does not show the V-shape root morphology (underlined with the concave labial crown-root boundary) of usual Galeocerdo eaglesomei. In fact, $C$. underwoodi (Samonds et al., 2019, Figure 3G-R) probably displays a similar dignathic heterodonty with $C$. balochensis, if we consider the figured lower teeth finely serrated (Samonds et al., 2019, figure 2M-O) incorrectly attributed to Galeocerdo eaglesomei. Whatever, the median sized species $C$. underwoodi is easily distinct from the new species having smaller upper teeth with median and distal cutting edges finely serrated. In the Tethysian realm, the oldest fossil evidence of the "Bull-group" has long been reported from the marine Tertiary sediments of Birket-el-Qurun of Fayum, Egypt (Dames, 1883; Stromer, 1905a under the name C. egertoni) and dated to the late Eocene (Case and Cappetta, 1990). Since then, numerous fossil remains were observed in several Late Eocene deposits of Egypt (BQ, QS and KM) and SW Morocco (Adnet et al., 2010), but the new species $C$. kasserinensis 


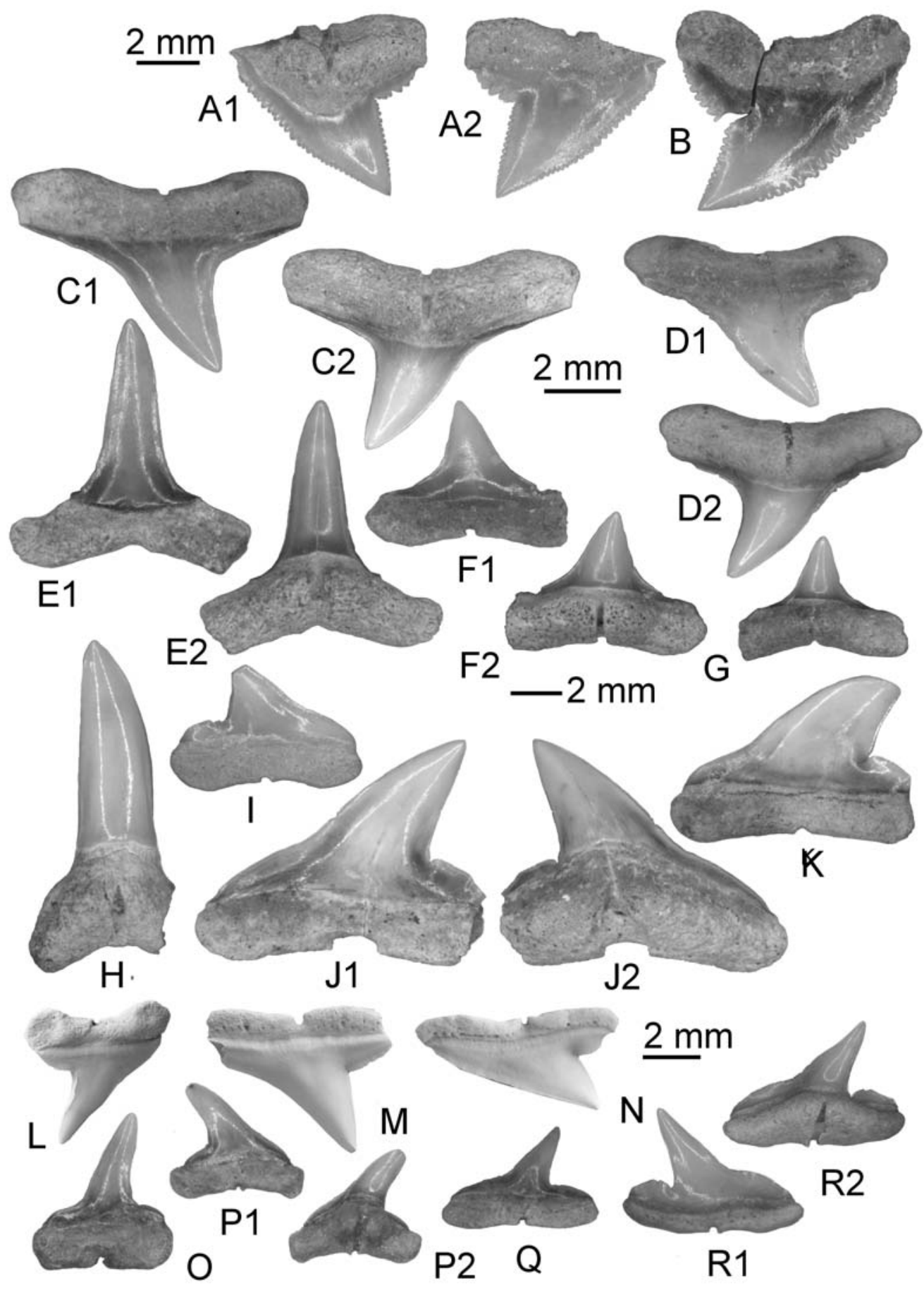

FIGURE 4. A-B: Carcharhinus kasserinensis nov. sp., A. Antero-lateral upper tooth of young specimen KEB 1-098, A1. Lingual view, A2. Labial view; B. Antero-lateral upper tooth of young specimen KEB 1-099, labial view. C-G: Carcharhinus frequens. C. Lateral upper tooth KEB 1-100, C1. Labial view, C2. Lingual view; D. Lateral upper tooth KEB 1-101, D1. Labial view, D2. Lingual view; E. Anterior lower tooth KEB 1-102, E1. Labial view, E2. Lingual view; F. Lateral lower tooth KEB 1-103, F1. Labial view, F2. Lingual view; G. Posterior lower tooth KEB 1-104, lingual view; HK: Misrichtys sp. H. Anterior lower tooth KEB 1-105, lingual view; I. Lateral upper tooth KEB 1-106, labial view; J. Posterior lower tooth KEB 1-107, j1. Labial view, J2. Lingual view; K. Lateral upper tooth KEB 1-108, labial view; L-R: Rhizoprionodon sp. L. Anterior upper tooth KEB 1-126, labial view; M. lateral upper tooth KEB 1-127, labial view; N. Lateral upper tooth KEB 1-128, labial view; O. Anterior lower tooth KEB 1-129, labial view; P. Lateral lower tooth KEB 1-130, P1. Labial view, P2. Lingual view; Q. Posterior lower tooth KEB 1-131, labial view; R. Antero-lateral lower tooth KEB 1-132, R1. Labial view, R2. Lingual view. 
clearly differs in having a smaller size, irregular serrated cutting edges, and lower teeth with asymmetrical heels.

If we exclude Carcharhinus mancinae from the Bartonian (see Ebersole et al., 2019) and Carcharhinus underwoodi dated with uncertainty to the Middle or Late Eocene (see Samonds et al., 2019), Middle Eocene records of Carcharhinus with serrated upper teeth have been sometimes reported but the material remains extremely scarce and often, have been either incorrectly dated or based on misidentification of other genera (Underwood and Gunter, 2012). Among them, a tooth from the GE (upper middle Eocene) was figured under the name Carcharhinus sp.1 by Case and Cappetta (1990, pl. 7, figures 164-165) and resembles those of $C$. balochensis, differing substantially from the latter in showing an important difference in size, a compound serration on the basal part of cutting edges (Adnet et al., 2011). Even if Underwood and Gunter (2012) suspected an error, it may represent a possible variant of $C$. kasserinensis nov. sp. Underwood et al. (2011, p. 57) revised the elasmobranch record of Wadi al Hitan and signaled that requiem sharks of the genus Carcharhinus (e.g., Underwood et al., 2011, Figure $4 \mathrm{~N}$ from $\mathrm{QS}$ ) are only abundant within the upper part of the succession (e.g., BQ, QS), where two species are present, including a large form showing strong serration and thus, affinities with $C$. perseus. However, they noted that rare and often poorly preserved specimens (provisionally referred to the same species in Underwood et al., 2011) were present within all of the underlying units (e.g., MI, GE). Some of them possibly belong to new species $C$. kasserinensis. More interesting, a large unique upper tooth from the Middle Eocene of Jamaica (Underwood and Gunter, 2012, Figure 2), assumed to come from the Chapleton Fm. (Donovan and Gunter, 2001) dated to uppermost Lutetian/lowermost Bartonian (Mitchell, 2016), is similar to the new species in overall shape. Not named, the upper tooth shows similar size and similar irregular serrations with new species. Coming from contemporaneous deposit (unverified), this tooth could represent a western record of these fossil great requiem sharks in the Tethys seaway, when those of Egypt would be the eastern representatives. Adnet et al. (2010) and Underwood and Gunter (2012) suspected that the great Carcharhinus and related genera arose as a dominant tropical marine clade during the Middle-Late Eocene. The new species and the coeval C. mancinae recently described by Ebersole et al. (2019) in contemporaneous deposits of Alabama, USA, confirm and precisely date the rise of the requiem sharks to Bartonian in Western Central Atlantic (Alabama) - Western Tethys seaway (Tunisia) with a sufficient and well-dated material.

As in the great White Shark lineage (see Nyberg et al., 2006; Ehret et al., 2009, 2012), the emergence of the serration on upper teeth observed between the oldest pool (unserrated teeth in Cosmopolitodus hastalis) and living form was quite progressive, from irregular (e.g., Carcharodon hubbeli) to well-developed and regular serration (e.g., living Ca. carcharias). Moreover, Ehret et al. (2012) confirmed that the serrated tooth of pacific Ca. hubbelli was probably adapted for taking marine mammals as prey, compared to the coeval piscivorous Co. hastalis (e.g., Collareta et al., 2017). Even if the comparison is not as robust, the serrations of $C$. kasserinensis nov. sp. are well marked and enlarged basally compared to coeval large carcharhinid sharing unserrated tooth (e.g., Negaprion, other Carcharhinus, Sphyrna) but weaker overall and more irregular than those of coeval C. mancinae (characterized by a compound and/or double serrations) and younger taxa from the Late Eocene/Early Oligocene like C. underwoodi, C. balochensis or C. perseus, and all the extant species recovered since the Neogene. As the evolution of serrations or crenulations in shark would be advantageous for competition with coeval piscivorous taxa in exploring new prey (e.g., marine mammals and/or prey that needs to be sliced up and cannot be swallowed whole), it is not surprising that more than one taxa (e.g., among Carcharhinus, Hemipristis, Galeocerdo, and Otodus/Carcharocles) would acquire serrations during the Middle Eocene along the tropical coasts where several marine mammals (e.g., archaeocetes, sea cows) raised, too.

Specimens repositories. Holotype and Paratypes are deposited in the paleontological collections of the museum of the "Office National des Mines" of Tunis, 24 rue 8601, 2035 La Charguia, 1080 Tunis, Tunisia

Temporal range. ?Early Bartonian (Jamaica) to middle Bartonian (Tunisia).

$$
\text { cf. "Carcharhinus" frequens (Dames, 1883) }
$$

Figure 4C-G

1883 Carcharias (Aprionodon) frequens Dames; Dames, p143-144, tab.3, figs. 7a-p

1905a Carcharias sp.; Stromer, p. 176-177, tab. 16(14), figs. 16-19, 21, 23-17, 28

1908 Carcharias (Aprionodon) aff. frequens Dames; Priem, p. 414 , pl. 15 , figs. 6,7 
1971 Aprionodon frequens Dames; Casier, p. 2, pl.1, fig. 6.

1990 Carcharhinus frequens (Dames); Case and Cappetta, p. 12-13, pl. 5, figs. 102-107, pl. 7, fig. 143-148, 151-159.

2010 Carcharhinus frequens (Dames); Adnet et al., p. 863-864, tab. 1.

2011 Carcharhinus aff. frequens (Dames); Adnet et al., p. 32, fig. 3G-H.

2011 Negaprion sp.; Underwood et al., p. 52-62, tab. 1, fig. 5T-U.

2012 Negaprion frequens (Dames); Zalmout et al., p.80, fig. 5A-D.

2017 Negaprion frequens (Dames); Van Vliet et al., p. 10, fig. $12 \mathrm{G}$.

2019 cf. "Carcharhinus" frequens (Dames); Sweydan et al., p. 198, fig. 3IJ

Material. Material consists of a fifty broken upper and lower teeth from KEB-1 locality, Souar-Fortuna formations, Djebel el Kébar, Tunisia, and including the figured material KEB 1-100 to 1- 104 (Figure 4C-G).

\section{Description}

With rather moderate dignathic heterodonty, teeth of this carcharhinid species are somewhat gracile and of small size (up to $1 \mathrm{~cm}$ ). There is no serration on both mesial and distal cutting edge as well as on the heels of upper and lower teeth.

Cutting edges are continuous from heels to top of cusps and never notched, including in the more posterior files. For both upper and lower jaws, the labial face of the tooth crowns is flat, whereas the lingual face is convex. Upper teeth (Figure 4C-D), have a cusp rather large at its base, triangular, and more or less slanted distally depending on their position on the jaw. Lower teeth (Figure 4E-G) have a higher cusp, straight and slender compared to the previous ones. Crown heels are lesser marked in anterior lower files. The root is developed, low, and separated into two distinct lobes by a shallow nutritive groove. The root lobes in lower teeth are shorter than those of the upper teeth and always separated by a nutritive groove.

\section{Remarks}

Frequently attributed to the genus Negaprion (see synonyms list), Sweden et al. (2019) summarized the discussions around the unresolved generic status of this taxa. Material from Tunisia, too scarce, does not allow improvement. Despite a general size twice or three times smaller compared to the Late Eocene representatives from Egypt where this species was formally described (e.g.,
Dames, 1883; Case and Cappetta, 1990), there is no real difference in tooth morphology. Often misidentified (see also Sweyden et al., 2019), this species was previously known in EG (Strougo et al., 2007) and since then in GE (A-C), Fayum - Egypt (Underwood et al., 2011; see Sweydan et al., 2019 for a review). Relatively rare in GE, this species is considered as the most abundant carcharhinid in the younger fossil assemblages of $B Q$, Fayum (Dames, 1883; Case and Cappetta, 1990). Subsequently reported from many other Late Eocene localities, cf. "Carcharhinus" frequens seems to have been a frequent medium-sized carcharhinid that frequented all the western Tethys seaway, from Southwestern Morocco to Qatar (Dames, 1883; Strömer, 1905a; Casier, 1971; Case and Cappetta, 1990; Murray et al., 2010; Adnet et al., 2011; Underwood et al., 2011; Zalmout et al., 2012; Sweyden et al., 2019) until its disappearance after the Rupelian in Egypt (Murray et al., 2014; Van Vliet et al., 2017). Here we report the oldest welldated occurrence of that taxon, which demonstrate that this common Late Eocene tropical carcharhinid actually occurs since the middle Bartonian. Clearly different from $C$. kasserinensis nov. sp. in having slender upper teeth, cf. "C." frequens possibly represents the ancestral pool of piscivore Carcharhinus that now includes the living finetooth shark C. isodon (Müller and Henle, 1839) and the smoothtooth blacktip shark C. leiodon Garrick, 1985.

Genus MISRICHTHYS Cappetta and Case, 1990

Type species. Misrichthys stromeri Cappetta and Case, 1990

Misrichthys sp.

Figure 4H-K

2016 Misrichthys sp.; Merzeraud et al., p. 14-15, tab. 1.

Material. The material consists only of three isolated teeth (KEB 1-105 to 1-108; Figure 4F-K), and numerous fragmentary crown, broken from KEB-1 locality, Souar-Fortuna formations, Djebel el Kébar, Tunisia.

\section{Description}

Teeth are medium sized, reaching $14 \mathrm{~mm}$ height. The enameloid of crown is totally smooth both on lower and upper teeth. The upper teeth (Figure 4J-K) have a high triangular cusp, distally inclined in antero-lateral and posterior files. The mesial cutting edge is unserrated, convex, and not distinct from the mesial heel on our material. The distal cutting edge is also unserrated and concave 
but well separated from the short, rounded distal heel, sometimes angular, by a notch. Root is high with divergent lobes and a very large median groove in lingual view. The lower anterior tooth (Figure $4 \mathrm{H}$ ) has a high and narrow cusp, the cutting edges are well marked but never reach the shortly and abrupt distal heel. The root is massive with a well-developed lingual protuberance bearing a very deep nutritive groove and two short lobes.

\section{Remarks}

Misrichthys was long considered as a Late Eocene monospecific genus having the ability to tolerate brackish to fresh waters (Murray et al., 2010) of Egypt, where it was often recorded (e.g., Case and Cappetta, 1990; Murray et al., 2010; Adnet et al., 2011; Underwood et al., 2011; Zalmout et al., 2012) until it was observed elsewhere (Adnet et al., 2010). This new report in Tunisia confirms that this genus was widely distributed along the Tethys seaway, and indicates that its occurrence is much older than the Late Eocene. Underwood et al. (2011) already reported rare specimens of a small and gracile species of Misrichthys (Underwood et al., 2011, figure 5Q) in MI (Late Lutetian - Early Bartonian), and suggested that an unnamed species of the genus was present in Wadi al Hitan before the Priabonian. Our report confirms the presence of a small species of Misrichthys since the Middle Bartonian, at least in Tunisia, but the scarcity of referred material and the tenuous distinction with the unique species $M$. stromeri (except a smaller size) are insufficient to describe a new species.

Genus RHIZOPRIONODON Whitley, 1929

Type species. Rhizoprionodon acutus (Rüppell, 1837), extant species

\section{Rhizoprionodon sp. Figure 4L-R}

2016 Rhizoprionodon sp.; Merzeraud et al., p. 14-15, tab. 1.

Material. A hundred broken upper and lower teeth from the KEB-1 locality, Souar-Fortuna formations, Djebel el Kébar, Tunisia (including those figured, KEB 1-126 to 1-132; Figure 4L-R).

\section{Description}

Teeth are relatively small (5 $\mathrm{mm}$ in length), labial face of root is slighlty concave and the basal edge of root is well rounded, except near the nutritive notch. The main cusp is relatively high (especially in most anterior lower teeth; Figure 4O) and without serration. Finely serrated, the distal heel of the crown is interrupted by a small notch in lateral teeth, sometimes marking a low cusplet (Figure 4R).

\section{Remarks}

First recorded in the Early Eocene of Morocco (Arambourg, 1952), Cenozoic evidence of the genus Rhizoprionodon is relatively common in tropical deposits of the Tethys seaway during the Late Eocene, from the Caribbean sea to the Jordanian coast (e.g., Case, 1981; Mustafa and Zalmout, 2002), leading some authors to propose that the current distribution of the seven recent species, today unknown in Mediterranean sea, is most likely a result of a former widespread distribution along Tethyan mangroves in the mid-Cenozoic, affected by successive vicariance events (Briggs, 1995; Musik et al., 2004; Gallo et al., 2010). It is noteworthy that certain extant species of Rhizoprionodon are possibly known since Late Eocene deposits but distinctive specific characters on teeth suffer from a conservative dental morphology among genera, as observable in the literature devoted to those taxa (Springer, 1964; Compagno, 1988; Herman et al., 1991). By combination of a pointed cusp out with the lack of serrated cutting edges, this unnamed fossil species seems quite different from several extant species, but resembles the Ypresian Rhizoprionodon gantourensis (Arambourg 1952), the Neogene Rhizoprionodon fisheuri (Joleaud, 1912), frequently recorded in Miocene deposits of Mediterranean or the extant Rhizoprionodon lalandii (appendix 2 Fig. D) and Rhizoprionodon acutus (appendix 2 Fig. C), recorded since the Zanclean deposits of south and north Mediterranean coasts (e.g., Cappetta and Cavallo, 2006; Pawellek et al., 2012). Besides the fact that tooth morphology of fossil Rhizoprionodon is quite conservative, dignatic and gynandric heterodonties are frequently observed in fresh jaws of Recent representatives. Its use in systematics appears highly uncertain.

Family SPHYRNIDAE Gill, 1872

Genus SPHYRNA Rafinesque, 1810

Type species. Sphyrna zygaena (Linnaeus, 1758), extant species

Sphyrna guinoti nov. sp.

Figures 5, 6A-C

\section{zoobank.org/779694E6-E3B1-4A5A-9C1A-4CB401DE852D}

?2011 Rhizoprionodon sp; Underwood et al., p. 52-62, tab. 1, figs. 50-P.

Etymology. In recognition of Guillaume Guinot for his great contribution in the study of extinct hammerhead shark-like taxa. 


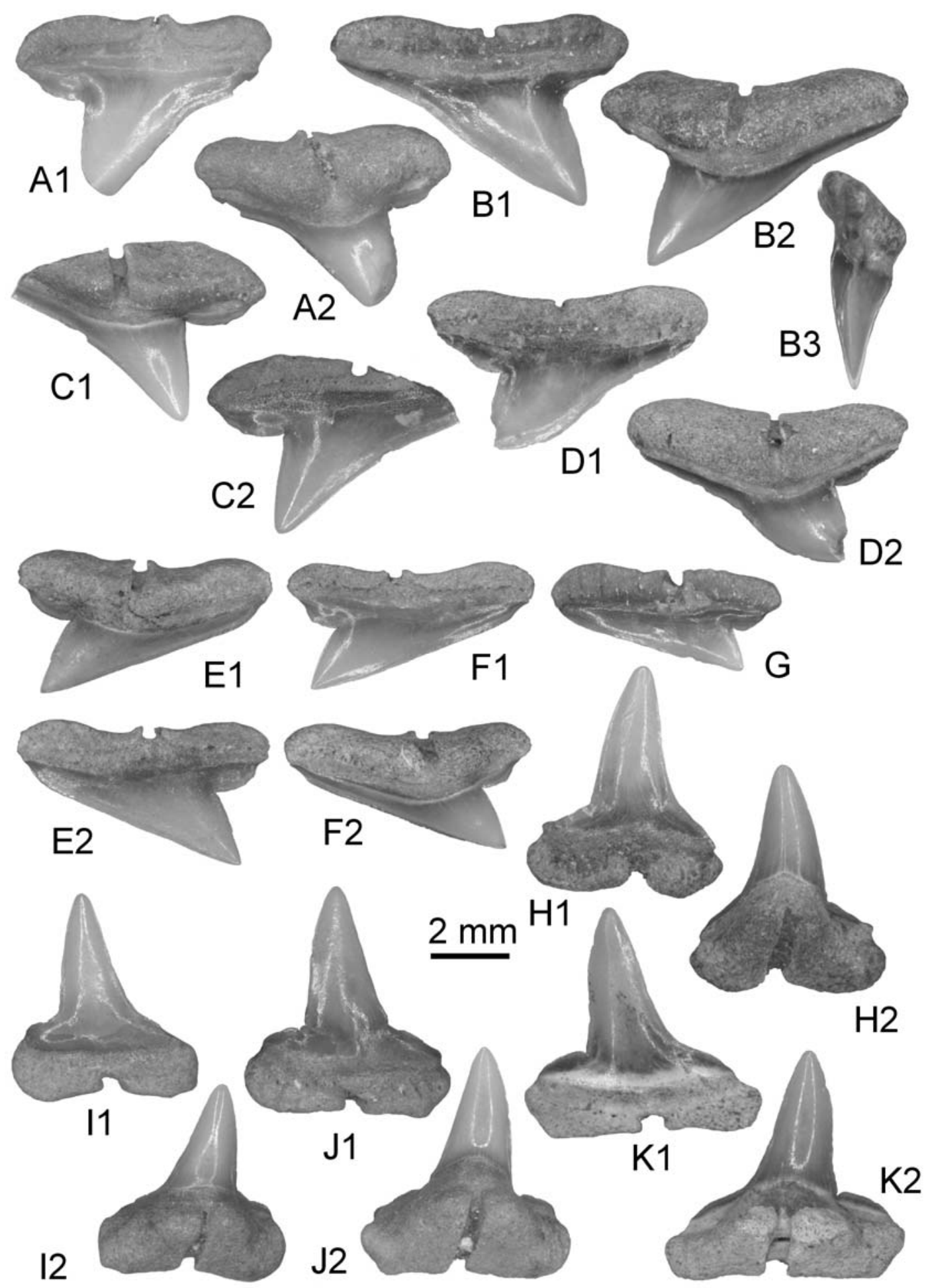

FIGURE 5. A-K: Sphyrna guinoti nov. sp. A. Anterior upper tooth KEB 1-109, A1. Labial view, A2. Lingual view; B. Lateral upper tooth KEB 1-110, B1. Labial view, B2. Lingual view; C. Anterior upper tooth KEB 1-111, C1. Lingual view, C2. Labial view; D. Lateral lower tooth KEB 1-112, D1. Labial view, D2. Lingual view; E. lateral upper tooth KEB 1-113, E1. Lingual view, E2. Labial view; F. Lateral upper tooth KEB 1-114, F1. Labial view, F2. Lingual view; G. Posterior upper tooth KEB 1-115, lingual view; H. Anterior lower tooth KEB 1-116, H1. Labial view, H2. Lingual view; I. Antero-lateral lower tooth KEB 1-117, I1. Labial view, I2. Lingual view; J. (HOLOTYPE) Antero-lateral lower tooth KEB 1-118, J1. Labial view, J2. Lingual view; K. Lateral lower tooth KEB 1-119, K1. Labial view, K2. Lingual view. 


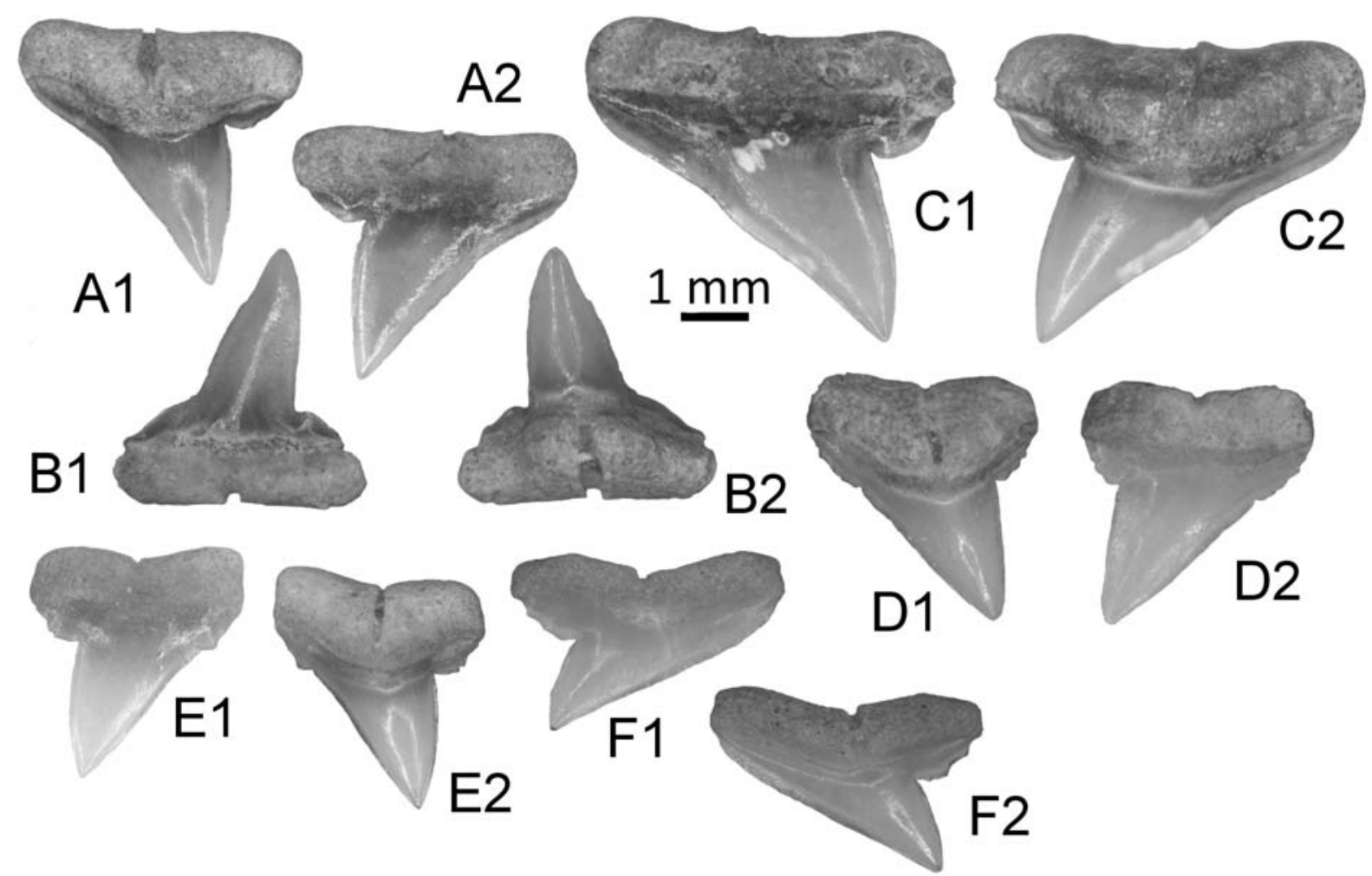

FIGURE 6. A-C: Sphyrna guinoti nov. sp. A. Anterior upper tooth of Young specimen KEB 1-120, A1. Lingual view, A2. Labial view; B. Lateral lower tooth of Young specimen KEB 1-121, B1. Labial view, B2. Lingual view; C. Lateral upper tooth KEB 1-122, C1. Labial view, C2. Lingual view; D-F: ?Sphyrna sp. 4. D. ?Antero-lateral upper tooth KEB 1-123, D1. Lingual view, D2. Labial view; E. ?Antero-lateral upper tooth KEB 1-124, E1. Labial view, E2. Lingual view; F. Lateral upper tooth KEB 1-125, lingual view.

Type locality and stratum. KEB 1-118 (Figure 5J) from Souar-Fortuna formations in Djebel el Kébar, Amamria hamlet near Soug-Jedid village (Sidi Bouzid Township), Tunisia: locality named KEB-1 in Merzeraud et al. (2016) and previously dated (radiometric K-Ar datings) to middle Bartonian $(38.7 \pm 1.0 \mathrm{Ma}$ to $40.7 \pm 1.1 \mathrm{Ma}$, covering the NP17) in Marivaux et al. (2014a).

Other material. Additional material, including figured KEB 1-109 to 1-117, 1-119 to 1-122 (Figures $5 \mathrm{~A}-\mathrm{F}, 5 \mathrm{H}-\mathrm{K}, 6 \mathrm{~A}-\mathrm{C})$, consists of several hundred of upper and lower teeth from the KEB-1 locality, Souar-Fortuna formations, Djebel el Kebar, Tunisia.

Diagnosis. Medium sphyrnid species only known by isolated teeth reaching $8 \mathrm{~mm}$ in width with a well-marked dignathic heterodonty which is reflected in bended blade-like cusps in upper teeth and high, erected cusps in lower teeth. Cutting edges of cusp and heels are totally smooth in both jaws. If upper teeth are reminiscent to those of all other upper teeth of fossil Sphyrna, lower teeth have a particularly well erected cusp and root is peculiarly massive medially with a deep and wide nutritive groove as observed in Recent $S$. tudes but the asymmetrical root lobes and heel distinct $S$. guinoti from this last.

\section{Description}

Upper teeth. The cusp is relatively thick and short in the mesio-distal long axis; the cutting edges lack serration and the mesial cutting edge is straight (Figure 5A-B, E-G) to slightly concave (Figure 5C$D)$. The apex of cusp never exceeds the distal extremity of heel in lingual and labial views, even in the more posterior teeth (Figure 5G). The distal heel is well developed, well separated from cusp by a notch, rounded and entirely unserrated. The mesial heel is less individualized from cusp, its cutting edge being more or less aligned with that of cusp. Crown and root are not strongly labio-lingually compressed in profile (Figure 5B3), the basal face of root making always an angle with the cusp. The crown-root boundary is reduced and limited to the fin enamel junction, which is relatively straight in labial view. The root is slightly broader 
than the crown, both in antero-lateral (Figure 5A-C) and lateral teeth (Figure 5E); root lobes are well aligned, horizontal and separated by a straight and deep nutritive groove in lingual view (e.g., Figure 5B2, C1, D2). Small but distinct protuberances are sometimes located in the medio-basal part of the lingual face of the root, and can be observed on labial view (Figure 5A1, F1) or lingual view (Figure $5 A 2, F 2$ ). These protuberances are in fact marked by the erecting of root lobe extremities, close to the median nutritive groove, but they can disappear totally on several upper teeth (Figure 5B, C).

Lower teeth. Compared with upper teeth, the lower teeth, holotype included (Figure 5J), are slightly narrower mesio-distally and thicker labiolingually. Contrary to the upper teeth, the cusp of lower teeth is strongly erected, as observable in the holotype (Figure 5J). The cusp is relatively high (twice higher than the root) and its axis is quite vertical (Figure $5 \mathrm{H}$ ) in anterior teeth to slightly bended distally in more lateral teeth, like in the holotype (Figure 5K). Its mesial cutting edge remains however very concave in lingual or labial views, and its distal cutting edge convex. Cutting edges of the cusp and heels are also unserrated. As for the upper teeth, the distal heel is well developed and distinct from the cusp, when the mesial heel is faintly marked. The root is relatively thick and the medio-lingual protuberance is particularly well marked in some teeth (Figure $5 \mathrm{~J}-\mathrm{K}$ ), with a large nutritive groove where a central foramina opens (Figure 5J2, K2). Root lobes are often asymmetric, the mesial being shorter than the distal one contrary to what is observed in upper teeth.

\section{Remarks}

Nowadays, the representatives of this genus exhibit rather different dentitions and tooth morphologies, inasmuch as these living species are characterized by clutching-crushing type (Sphyrna tiburo) to cutting type with serrated teeth (e.g., living Sphyrna mokarran). In addition, the dignathic heterodonty may be weak (e.g., S. tiburo), moderate (e.g., Sphyrna lewini, S. mokarran, and Sphyrna zygaena) to strong (e.g., Sphyrna media and Sphyrna tudes), where lower teeth share straightened cusp with a mesial cutting edge very concave (e.g., like in some Rhizoprionodon) when upper teeth are reminiscent to those of other large carcharhinid (e.g., Negaprion). Sphyrna guinoti nov. sp. belongs to the last morphological group exhibiting strong heterodonty and thus an overall morphology of both dentitions very close to those observed in living and fossil species of the genus
Rhizoprionodon. This explains that when the Paleogene material is scarce and restricted to a couple of teeth, confusion with Rhizoprionodon is possible. But in general, the teeth of Rhizoprionodon (see also Appendix 2C-E) have a narrower crown, with lower teeth having a straightened but short cusp with a mesial cutting edge more concave in labial view. This morphology is less usual on lower teeth of Sphyrna (see also Cappetta and Case, 2016) where the cusp tends to become higher than the width of crown, as observed in $S$. guinoti nov. sp.

Frequently reported from Neogene deposits, with occurrences of extant species (e.g., Sphyrna zygaena, including fossil Sphyrna laevissima (Cope, 1869) considered as synonym by Purdy et al., 2001) or of extinct Sphyrna arambourgi Cappetta, 1970, the earliest appearance of the hammerhead sharks is quite discrete and sometimes dated to the Lutetian (Cappetta and Case, 2016, see also Ebersole et al. 2019 for discussion about affiliation). If the record of the genus in the Lutetian of Nigeria (White, 1926) seems to be erroneous (Cappetta, 2012), isolated Sphyrna teeth become more commonly recovered in Tethys and Atlantic deposits from the Late Eocene - Early Oligocene (Genault, 1993; Cicimurri and Knight, 2009; Adnet et al., 2010; 2011) with teeth often larger than for those of the present new species Sphyrna guinoti. Moreover, none of the fossil tooth set attributed to Sphyrna (including the unique fossil species $S$. arambourgi) shows such a strong heterodonty. However and because of their morphological resemblances with teeth of Rhizoprionodon, the medium-sized teeth of Sphyrna are probably misidentified in the fossil record. A careful examination of other Middle-Late Eocene assemblages could reveal a more widespread occurrence of small and medium-sized species of Sphyrna, Sphyrna guinoti nov. sp. included. For Instance, Underwood et al. (2011) did not report the occurrence of Sphyrna in the Fayum area, but they mentioned two morphs attributed to Rhizoprionodon in their text, figuring the more robust one (Underwood et al., 2011, Figure 50-P from $B Q$ ), the morphology of which is reminiscent to that of the tooth of a hammerhead shark tooth.

At the present state of comparison, only the extant species Sphyrna media or Sphyrna tudes (see also Appendix 2A-B) have unserrated teeth that display the same heterodonty and morphology than Sphyrna guinoti nov. sp. However, lower teeth of $S$. media (Appendix 2A) seemly have finer and more elongated cusp (more than $66 \%$ of the tooth 
height) than in the $S$. guinoti nov. sp where the elongated cusp represents no more than $66 \%$ of tooth height. The upper teeth of S. media (Appendix 2A2) have also more gracile cusps with a more sigmoid mesial cutting edge in labial view. Distinction with $S$. tudes (Appendix 2B) is more tenuous. S. guinoti nov. sp. have upper teeth with similar erected cusp compared to that of $S$. tudes but the mesial heel is lesser individualized and shorter than the distal one; where both are quite equal and more similar in shape in S. tudes. This characteristic, added to the corresponding asymmetry of root lobes, was not observed on the teeth in the Recent S. tudes jaw.

Specimens repositories. Holotype and paratypes are deposited in the paleontological collections of the museum of the "Office National des Mines" of Tunis, 24 rue 8601, 2035 La Charguia, 1080 Tunis, Tunisia

Temporal range. Middle Bartonian (Tunisia) and possibly to Priabonian (Egypt).

\section{?Sphyrna sp. \\ Figure 6D-F}

Material. KEB $1-123$ to $1-125$ (Figure 6D-F) consists of 10 upper and lower teeth from the KEB-1 locality, Souar-Fortuna formations, Djebel el Kebar, Tunisia.

\section{Description}

Upper teeth are relatively small $(3.5 \mathrm{~mm}$ in length). The cusp is relatively fine and high in the mesio-distal axis; the mesial cutting edge is straight (Figure 6D) to slightly concave (Figure 6E$F$ ), and bears fine serrations on its more mesial part, marking sometimes a small notch. The distal heel is well developed, rounded and also finely serrated. The root is broader than the crown, both in antero-lateral (Figure 6D-E) and lateral teeth (Figure $6 \mathrm{~F}$ ); root lobes are well aligned, horizontal and separated by a straight nutritive groove.

\section{Remarks}

Compared with the former described species, a few teeth of small size were provisionally attributed to another species of Sphyrna. The latter, illustrated by upper teeth, presents a dental pattern that reminds those of small individuals of Sphyrna guinoti nov. sp. (Figure 5A), except that the crown sometimes shows mesial and distal heels with a short and fine serration. Teeth are moreover more labiolingually compressed and lesser expended mesiodistally compared with those usually reported for $S$. guinoti nov. sp. Alternatively, they could document to a tooth morphol- ogy of juvenile of $S$. guinoti nov. sp. due to the scarcity of the material, this species was left in open nomenclature.

Family HEMIGALEIDAE Hasse, 1879 Genus HEMIPRISTIS Agassiz, 1843

Type species. Hemipristis elongata (Klunzinger, 1871), extant species

Hemipristis curvatus Dames, 1883, Figure 7A-C

Material. Consists of four teeth (including KEB 1133 to 1-135; Figure 7A-C) and several broken upper and lower teeth from the KEB-1 locality, Souar-Fortuna formations, Djebel el Kébar, Tunisia.

\section{Description}

Although the fossil material is scarce or poorly preserved, upper teeth have a relatively high crown, which is compressed labio-lingually and slanted distally. The mesial cutting edge is convex with, in its median part, two very small denticles. The distal cutting edge is straight and forms an angle with an oblique distal heel. The latter is high and bears several well-developed denticles. The lingual face of the crown is convex, the root, partially unpreserved, bears a well-developed lingual protuberance, incised by a shallow groove. In labial view, the convex crown forms a bulge at its base, and strongly overhangs the low root. The anterior lower tooth has a relatively high, slender and straight cusp with sharp cutting edges that never reach its lower part. There is no denticle on the available material. The root, although incomplete, is massive, with short but well-developed lobes separated by a deep median nutritive groove.

\section{Remarks}

The morphology of teeth is similar to that of those from the Late Eocene of Fayum attributed to Hemipristis curvatus by Case and Cappetta (1990, figures 4, 80-81). Hemipristis curvatus is primarily known from all tropical seas during the late MiddleLate Eocene, from the Tethys seaway (e.g., Case and Cappetta, 1990; Mustafa and Zalmout, 2002; Underwood et al., 2011) to the Western Central Atlantic (Case and Borodin, 2000; Ebersole et al., 2019). However, Underwood et al. (2011) reported this species in $\mathrm{Ml}$ (but not illustrated), when it is typically more common throughout the remainder of the Wadi al Hitan succession (see also Underwood et al. 2011, figure 5B and 5C from $B Q$ ), and especially since the GE (A-C) (around the Bartonian/Priabonian boundary). This new occurrence confirms the late Middle Eocene appearance of the 


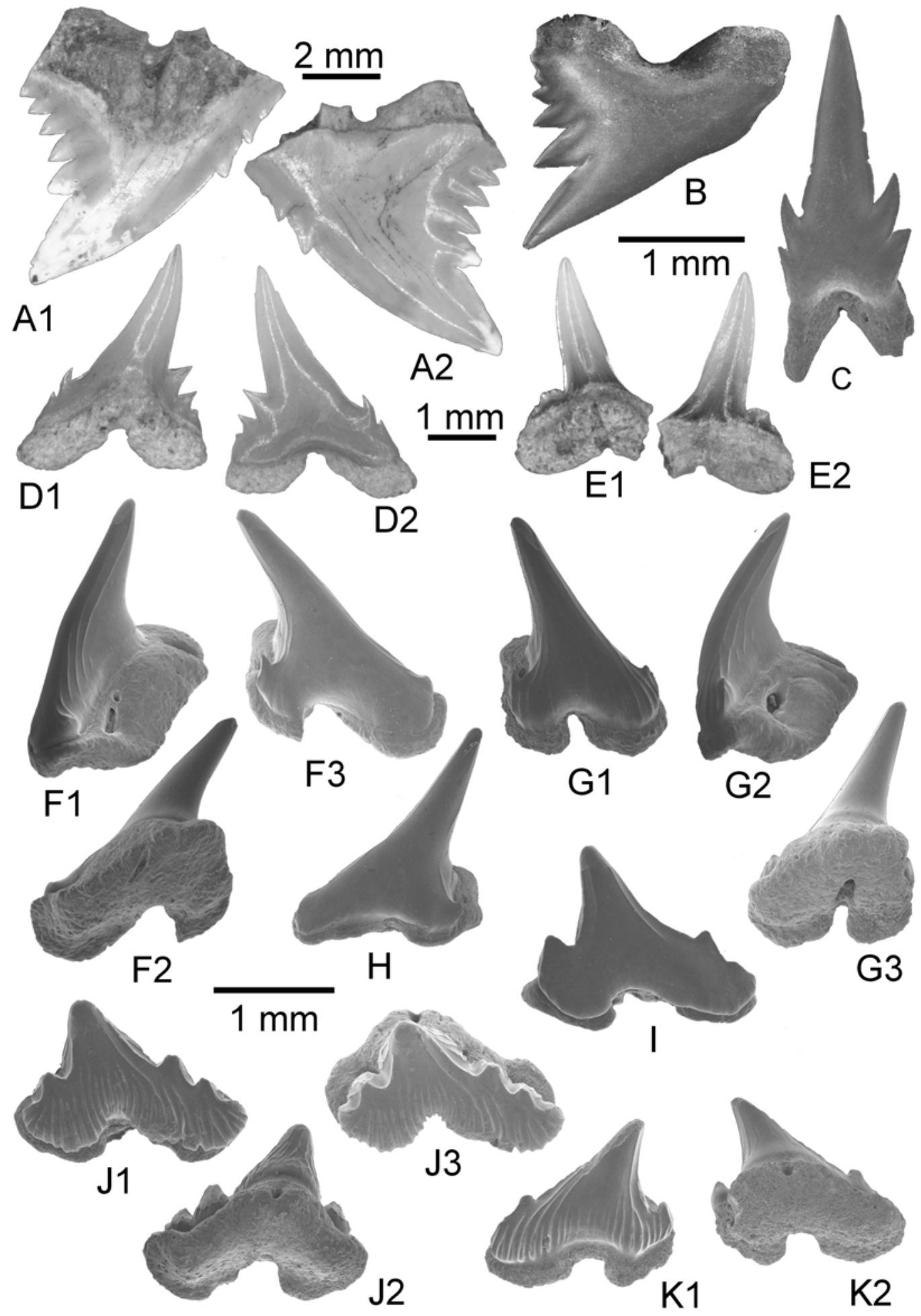

FIGURE 7. A-C: Hemipristis curvatus. A. Antero-lateral upper tooth KEB 1-133, A1. Lingual view, A2. Labial view; B. Lateral upper tooth of young specimen KEB 1-134, labial view; C. Anterior lower tooth of young specimen KEB 1-135, labial view; D-E: Moerigaleus sp. D. Lateral upper tooth KEB 1-136, D1. Lingual view, D2. Labial view; E. Lateral upper tooth KEB 1-137, E1. Lingual view, E2. Labial view; F-K: Leptocharias tunisiensis nov. sp. F. (HOLOTYPE) Antero-lateral lower tooth KEB 1-138, F1. Profile, F2. Lingual view, F3. Labial view; G. Antero-lateral upper tooth KEB 1-139, G1. Labial view, G2. Profile, G3. Lingual view; H. Anterro-lateral lower tooth KEB 1-140, labial view; I. Lateral lower tooth KEB 1-141, labial view; J. More lateral tooth KEB 1-142, J1. Labial view, J2. Lingual view, J3 occlusal view; K. Posterior tooth KEB 1-143, K1. Labial view, K2. Lingual view. 
genus Hemipristis in the Tethys seaway, and this material then represents one of the oldest figured report (with those of Ebersole et al., 2019 from the Bartonian of Alabama) of this famous lineage highlighted by its descendent, $H$. serra, reported since the Early Oligocene (e.g., Adnet et al., 2007; Van Vliet et al., 2017) until the Pleistocene of Alabama (Ebersole et al., 2017).

\section{Genus MOERIGALEUS Underwood and Ward,} 2011

Type species. Moerigaleus vitreodon Underwood and Ward, 2011

\section{Moerigaleus sp. Figure 7D-E}

2007 "Galeorhinus" sp.; Strougo et al., p. 88-94.

2016 ?Moerigaleus sp.; Merzeraud et al., p. 14-15, tab. 1.

Material. Two teeth KEB 1-136 and 1-137 (Figure 7D-E) and rare broken upper and lower teeth from the KEB-1 locality, Souar-Fortuna formations, Djebel el Kébar, Tunisia.

\section{Description}

The crown is either unornamented on the two specimens. Teeth are strongly compressed labiolingually and the cusp is relatively high compared with the root. The upper anterolateral tooth (Figure 7D) bears a pair of short but sharp and divergent lateral denticles on its distal cutting edge, and a pair of minute hook-shaped denticles on its mesial cutting edge. The second tooth (Figure 7E), possibly from the lateral lower file, is quite similar except the lack of marked cusplets in both sides of the main cusp. The rare material available here reminds those of the unique species $M$. vitreodon from the Late Eocene, but as it is also present in other faunas close to the Lutetian-Bartonian boundary and still under study (Underwood and Ward, 2011, p. 708), we preferred to leave it in open nomenclature waiting for supplementary figurations.

\section{Remarks}

Representing one of the earliest records of the Hemigaleidae with Hemipristis, the dentition of Moerigaleus differs from that of other members of the family in the dignathic heterodonty, which is far less well developed but monognathic heterodonty is at least as extreme. This genus was described from BQ (Underwood and Ward, 2011), but occurred from the Fayum region ranging in age from the Lutetian-Bartonian to late Priabonian (Underwood and Ward, 2011). Some teeth recovered in EG (pers. observ. SA, HC) and probably attributed to "Galeorhinus" sp. in Strougo et al. (2007) belong in fact to this genus. This new report, even unnamed, therefore adds to the known geographical range of this taxon.

\section{Family LEPTOCHARIIDAE Gray, 1851}

This family of barbeled houndshark is currently monotypic with the living Leptocharias smithii Müller and Henle, 1838, which inhabits the tropical eastern Atlantic coasts from Mauritania to Namibia. The Leptochariidae are recorded since the Late Cretaceous (Underwood and Ward, 2008) but the tooth morphology of its first representatives is quite different from that of the living species (illustrated by Herman et al., 1991). In contrast, the MiddleLate Eocene representatives share very similar tooth morphology and heterodonty with the living representative.

\section{Genus LEPTOCHARIAS Smith, in Müller and Henle, 1838}

Type species. Leptocharias smithii Müller and Henle, 1838, extant species

\section{Leptocharias tunisiensis nov. sp. Figure $7 \mathrm{~F}-\mathrm{K}$}

zoobank.org/075E7036-4A5C-4E78-B634-F3F8F141C788

2002 Microscyliorhinus leggeti Case; Mustafa and Zalmout, p.83, pl. 1, figs.12-14.

2007 Scyliorhinus sp.; Strougo et al., p. 88-94.

2011 Leptocharias sp.; Underwood et al., p. 52-62, tab. 1, figs. 6F-G.

2011 Crassescyliorhinus sp.; Underwood et al., p. 52-62, tab. 1.

2011 Scyliorhinus sp.1; Adnet et al., p. 33, fig. 3R

2016 Scyliorhinus sp 1 and 2; Merzeraud et al., p. 1415, tab. 1.

Etymology. From Tunisia where the type material originates.

Type locality and stratum. KEB-1-138, Figure 7F from the KEB-1 locality, Souar-Fortuna formations, Djebel el Kébar, Tunisia.

Other material. Additional material, including figures KEB 1-139 to 1-143 (Figure 7G-K), mainly consists of about 60 upper and lower teeth from the KEB-1 locality, Souar-Fortuna formations, Djebel el Kébar, Tunisia.

Diagnosis. Fossil species of Leptocharias characterized by a disjunctive monognathic heterodonty with partial overlapping of alternate files as observed in the living representative Leptocharias smithii. Antero-lateral teeth with high cusp curved distally and slightly a folded enameloid, twice as large as anterior teeth. Posteriors are quite symmetrical resembling those of scyliorhinid with pli- 
cate enameloid. This fossil species is, however, distinct in having lateral teeth with more stocky design, a well-marked overlapping surface on the labial part of the root, a lesser ornamented enamel of the crown in posterior teeth, and in a hemiaulacorhize vascularization of the root.

\section{Description}

The holotype is an antero-lateral lower tooth (Figure 7F), probably from the third position following the dentition pattern of the living representative (Leptocharias smithii). Lower antero-lateral teeth are larger, more robust and highly asymmetrical compared with similar files of upper jaw (Figure $7 G$ ). The main cusp is straight, robust, elongated beyond the distal root extremity, and strongly inclined toward the jaw commissure. A single pair of lateral cusplets is present but poorly developed and slightly turned off lingually. The two cutting edges are well developed from base to apex of the main cusp, the mesial one being slightly sigmoidal (Figure 7F, H) to straight (Figure 7G), probably depending of sex (Herman et al., 1991). In anterolateral files, the labial ornamentation of crown is absent (on the holotype) or weak, and limited to the lateral extremities of the crown (on upper anterolateral teeth; Figure 7G1). The lingual face of the principal cusp is strongly convex in profile (Figure $7 F 1$ ), and the ornamentation is fine, more regular with some ridges reaching the cusp apex. The root is very bulky, high and moderately wider than the crown. The root vascularization is always at a hemiaulacorhize stage in the available material, i.e., the medio internal foramen opens on the posterior part of the bulging lingual protuberance, offset relative to cusp, when the medio-external foramen opens on edge between basal and labial faces of the root. The root lobes are clearly asymmetrical and have strongly angular profile (Figure 7F1) with several foramina, sometimes very large, opening on both side of the lingual protuberance. The labial part of the root is thinned compared with the rest, delimiting in fact a labial overlapping surface, which probably interlocked on the lingual protuberance of tooth from previous row.

In the more anterior files (e.g., Figure 7G), near the parasymphyseal, teeth show a morphology that reminds that of the laterals (see below); except that the crown is without any labial ornamentation, as it does in living representatives. In the lateral and posterior teeth (Figure $7 \mathrm{~J}-\mathrm{K}$ ) from both jaws, the crown has a medium to low principal cusp depending position of tooth in jaw, which is more or less inclined toward the commissure. A pair of well-developed mesial and distal cusplets is present, with sometimes a poorly developed second cusplet in the mesialmost region. Both cutting edges are well developed as in anterior files. The labial face of the crown, fully ornamented and bifid, largely overhangs the root lobes at both ends, as observable in occlusal view (Figure 7J3). The ornamentation strengthens as more the tooth is located toward the jaw commissure (Figure 7K). The lingual faces are always finely ornamented, as in antero-lateral files. The root vascularization is at a hemiaulacorhize stage (e.g., Figure 7J2), and shows two long and broad lobes, quite symmetrical, which are angular at the base. The overlapping surface, as observed in more anterior teeth, is less developed and reduced with respect to the extreme labial edge of the root basal face (Figure $7 \mathrm{~J} 2$ ). As in more anterior files, some large foramens open on both side of a large lingual protuberance.

\section{Remarks}

Herman et al. (1991) described in details the tooth morphology of this monotypic family. They noted that "except for the parasymphysial rows, a disjunct monognathic heterodonty is presented by anterior teeth, with a high principal cusp strongly oriented obliquely toward the commissure and much smaller lateral and posterior teeth with a slightly oblique principal cusp" (Herman et al., 1991, p. 76). In addition, Underwood and Ward (2008) suggested that large, angular, and highly asymmetrical root of Leptocharias could be then regarded as a character unique to this genus. In fact, as previously reported by Herman et al. (1991), this concerns only the antero-lateral teeth, and especially on the lower jaw of male leading to a very important disjunctive monognathic heterodonty (Herman et al., 1991; Cappetta, 2012). As the most lateral and posterior teeth are less asymmetrical with cusps slightly oblique, their distinction from scyliorhinid becomes more delicate. However, based on the tooth morphology and heterodonty of numerous fresh specimens available in our collections (e.g., Appendix 1), the genus is also characterized by a slight overlapping of its tooth rows, marked by a depressed labial part of the root compared to the lingual part, and especially to the robust lingual protuberance (= angular root of Herman et al., 1991 and Underwood and Ward, 2008). If we can observe this dental trait on the lateral teeth of both jaws of living Leptocharias, this feature tends to disappear on teeth near the jaw commissure. Confusion with scyliorhinids is obvious, 
especially in the fossil record that has proven to be scarce.

Strougo et al. (2007) reported at least two species of Scyliorhinus in GE. A re-examination of the material (pers. observ. SA.), led us to consider that a part of the material, unfortunately badly preserved, could actually belong to Leptocharias tunisiensis nov. sp. Underwood et al. (2011, text only) reported in the same levels of Wadi al Hitan (from $\mathrm{Ml}$ to lower QS), the presence of typical antero-lateral teeth of Leptocharias (Underwood et al., 2011, Figure 6F-G from BQ) and robust teeth with a scyliorhinid pattern that they attributed to the Cretaceous genus Crassescyliorhinus Underwood and Ward, 2008 (in text only). The authors probably confused the latter with lateral and posterior teeth of Leptocharias as illustrated here. If confirmed, the material from Wadi al Hitan attributed to Crassescyliorhinus and Leptocharias are likely to be conspecific and could be assigned to $L$. tunisiensis nov. sp. considering the tooth morphology of figured antero-lateral teeth. Mustafa and Zalmout (2002) reported in Late Eocene of Jordan the occurrence of Microscyliorhinus leggetti Case 1994, an Early Eocene species from Mississipi, USA, based on large scyliorhinid teeth (up to 5 $\mathrm{mm}$ ). By the characters described in their text and despite a low-quality illustration, this record can be assigned to Leptocharias as well.

Leptocharias tunisiensis nov. sp. clearly differs from the unique fossil species of Leptocharias, Leptocharias cretaceus Underwood and Ward, 2008 in its own teeth bearing a strong ornamention of the crown, low cusp (compared to the width of the root), even in antero-lateral files, and in a flatter basal face of the root (sometimes at anaulacorhize stage). If the latter undoubtedly represents the oldest record of the Leptochariidae with the presence of a depressed labial part of the root ("root lobes with 'corners' projecting labially and linguolaterally" in Underwood and Ward, 2008, p. 529), both the morphology and ornamentation of the crown (especially in antero-lateral tooth files) is, however, sufficiently different from other Leptocharias representatives to belong to another, unnamed genus. A distinction between $L$. tunisiensis nov. sp and the living species Leptocharias smithii is more tenuous, because both taxa share the same peculiar heterodonty pattern, the same antero-lateral teeth morphology and the same variability in crown ornamentation. However, L. tunisiensis nov. sp. possesses teeth that are distinct in being more robust in aspect, in showing a labial face of the crown more bifid, with fainter ornamentation on lateral to posterior teeth.

Specimens repositories. Holotype and Paratypes are deposited in the paleontological collections of the museum of the "Office National des Mines" of Tunis, 24 rue 8601, 2035 La Charguia, 1080 Tunis, Tunisia.

Temporal range. Uppermost Lutetian-lowermost Bartonian (Egypt), middle Bartonian (Tunisia), and possibly to late Priabonian (Egypt, Jordan).

Order ORECTOLOBIFORMES Applegate, 1972

Family GINGLYMOSTOMATIDAE Gill, 1862

Genus NEBRIUS Rüppell, 1837

Type species. Nebrius ferrugineus (Lesson, 1831), extant species

\section{Nebrius sp.}

Figure 8A-C

2016 Nebrius cf. obliquus; Merzeraud et al., p. 14-15, tab. 1.

Material. About 30 teeth from the KEB-1 locality, Souar-Fortuna formations, Djebel el Kébar, Tunisia are identified, including the figured specimens KEB 1-144 to KEB 1-146 (Figure 8A-C).

\section{Description}

Anterior teeth are almost symmetrical and broader than high (Figure 8A). In labial view (Figure $8 \mathrm{~A} 1$ ), the mesial and distal cutting edges are virtually straight to slightly convex and indented by seven to eight well-separated serrations. The main cusp is clearly more developed than the marginal serrations but not as protruding. In profile (Figure $8 \mathrm{~A} 3$ ), the labial face is almost straight and the lingual one clearly concave. The base of the labial face of the crown bears a salient and symmetrical apron. The root is thick, with a cloverleaf-shaped outline in basal view (Figure 8B2). A broad and deep elliptical foramen opens in the centre of the face. In more lateral teeth (Figure 8B), the morphology of the crown is quite similar to the previous, except the distal cutting edge that bears serrations, which are more erected than those of the mesial edge. The apron is more developed, asymmetrical, and longer in labial view. In posterior teeth (Figure $8 \mathrm{C}$ ), the crown is much more inclined distally, the mesial cutting-edge bears nine to ten serrations whereas the distal one, much shorter and straight, bears only four serrations.

\section{Remarks}

Nebrius obliquus (Leidy, 1877) and Nebrius thielensis (Winkler, 1874) are common carpet sharks recovered in the Middle-Late Eocene tropi- 

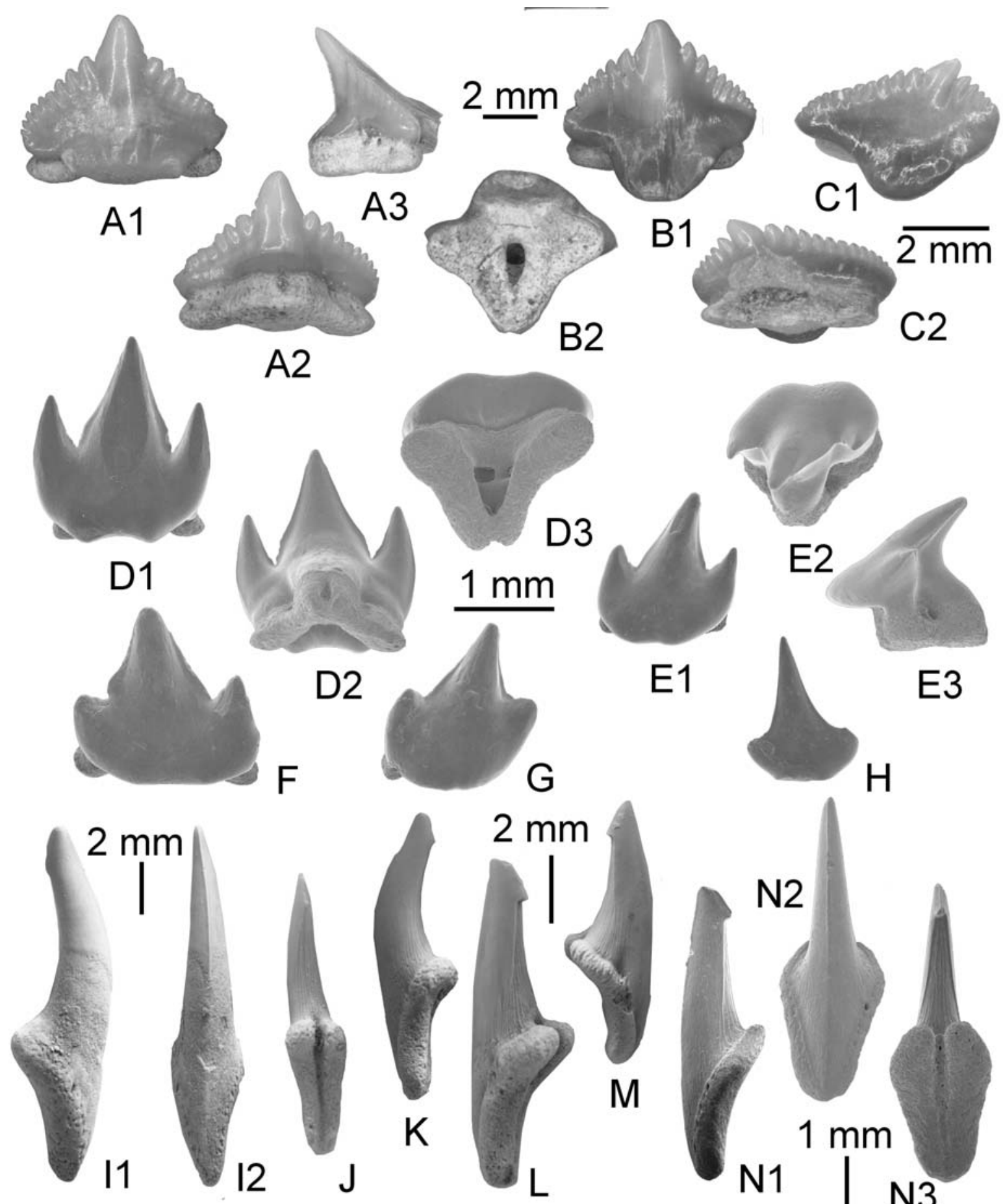

FIGURE 8. A-C: Nebrius sp. A. Anterior tooth KEB 1-144, A1. Labial view, A2. Lingual view, A3. profile; B. Antero-lateral tooth KEB 1-145, B1. Labial view, B2. Basal view; C. Lateral tooth KEB 1-146, C1. Labial view, C2. Lingual view; D-G: Stegostoma tethysiensis nov. sp. D. (HOLOTYPE) Anterior tooth KEB 1-147, D1. Labial view, D2. Lingual view, D3. Basal view; E. Antero-lateral tooth KEB 1-148, E1. Labial view, E2. Occlusal viex, E3. profile; F. Lateral tooth KEB 1-149, labial view; G. Posterior tooth KEB 1-150, labial view; H: Hemiscyllium sp. 8. Antero-lateral tooth KEB 1-151, labial view; I-N: Odontorythys pappenheimi I. ?Anterior tooth KEB 1-152, I1. Profile, I2. Labial view; J. ?Latero-posterior tooth KEB 1-153, lingual view; K. ?Latero-posterior tooth KEB 1-154, profile; L. ?Latero-posterior tooth KEB 1-155, profile; M. ?Latero-posterior tooth KEB 1-156, profile; N. ? lateral or posterior tooth KEB 1-157, N1. Profile, N2. Labial view, N3. Lingual view. 
cal nearshores deposits from the paleo-Caribbean (Leidy, 1877; Kruckow and Thies, 1990; Cappetta and Case, 2016, Ebersole et al., 2019) to Pakistan (Case and West, 1991; Adnet et al., 2007) including Aznag in Morocco (Tabuce et al., 2005) and KM, Egypt (Adnet et al., 2011) for instance. Among the other Eocene species assigned to the genus Nebrius, two come from the Middle/Late Eocene of Egypt, Nebrius blanckenhorni (Stromer, 1903) and Nebrius fourtaui (Priem, 1905). If Noubhani and Cappetta (1997) already synonymized $N$. fourtaui with $N$. obliquus, the teeth of $N$. blanckenhorni have a morphology reminiscent to that of $N$. obliquus, and as such both species are probably synonymous (e.g., Cappetta and Case, 2016), even if this first is always signalled in Late Paleogene deposits (Samonds et al., 2019). Ebersole et al. (2019) recently discussed about the tooth differences between $N$. obliquus and $N$. thielensis and suggested that they seem rather a reflection of heterodonty than separate species, at least concerning the post Ypresian representatives. Considering these recent observations and the doubt about systematics validity, this Nebius representative from Bartonian is left in open nomenclature. Underwood et al. (2011) also reported the presence of Nebrius from MI to QS. Strougo et al. (2007) do not reported the presence of Nebius at EG, but a reexamination of the material from this locality (pers. observ.) allows us to confirm the presence of Nebrius in EG.

Family STEGOSTOMATIDAE Gill, 1862

Genus STEGOSTOMA Müller and Henle, 1837

Type species. Stegostoma fasciatum (Hermann, 1783), extant species

Stegostoma tethysiensis nov. sp.

Figure 8D-G

zoobank.org/328467AB-1AFC-4825-BF60-65628BA4AF05

2007 Chiloscyllium sp. 2; Strougo et al., p. 88-94, pl. 1, fig. 6.

2011 ?Stegostoma sp.; Underwood et al., p. 52-62, fig. 6C-D.

2016 Stegostoma sp.; Merzeraud et al., p. 14-15, tab. 1.

Etymology. Derived from the "Tethys" sea where the species inhabited.

Type locality and stratum. KEB 1-147, Figure 8D from the KEB-1 locality, Souar-Fortuna formations in Djebel el Kébar, Tunisia.

Other material. Additional material, including figured KEB 1-148 to 1-150 (Figure 8E-G), consists of 20 teeth from the KEB-1 locality, Souar-Fortuna formations, Djebel el Kébar, Tunisia.
Diagnosis. Extinct species of Stegostoma only known by isolated teeth that are characterized, compared to those of the unique and living species S. fasciatum, by teeth slightly lower and showing a light but gradual monognathic heterodonty; a pair of lateral cusplets that are more separated from the main cusp, especially in anterior files.

\section{Description}

The holotype (Figure 8D) is an anterior tooth which measures $1.7 \mathrm{~mm}$ mesiodistally. The tooth is quite symmetrical; the crown, relatively slender, bears a sharply-pointed main cusp, which is slightly angled distally. The main cusp is flanked by a pair of lateral cusplets. The latter are strong, high, erected and well-individualized from the main cusp. The height of the mesial cusplet is about $70 \%$ of that of the main cusp, whereas the distal lateral cusplet is only about $60 \%$. Both lateral cusplets are similarly sharply pointed and all of the cusps possess sharp cutting edges, which descend the lateral margins of the cusp mesially and distally. The lateral cusplets are sub-parallel to the main cusp. In profile, the cusplets are slightly flattened labio-lingually, as the main cusp. A moderate bifid apron is developed on the crown margin, beneath the central cusp base, and substantially overhangs the root (Figure 8D1). The enameloid of the crown is entirely smooth. A short uvula is developed on the lingual face, above the median protuberance of the root, which is marked by a small collar (Figure 8D2). The root has a V-shaped basal surface (Figure 8D3), and an oval lingual foramen is present beneath the uvula. The lateral foramina are sometimes present under the crownroot boundary (Figure 8D2). The mesial and distal lobes of the root are fine and extend slightly beyond the mesial and distal heels of the crown. A large basal nutritive foramen opens on the basal face, in the large notch built by two root lobes (Figure 8D3).

Several antero-lateral to lateral teeth show less prominent labial aprons with much straighter labial margins and less marked overhanging of the root (Figure 8E-F). The base of the central cusp is somewhat inflated mesiodistally. In some specimens, the pair of lateral cusplets may be less prominent (Figure $8 \mathrm{~F}$ ) or quite similar (Figure $8 \mathrm{E}$ ) with respect to the condition found in the holotype. In both cases, one cusplet is always lesser developed than the other, either on the mesial or on the distal side. More lateral teeth (Figure $8 \mathrm{G}$ ) have a much squatter, triangular, shorter main cusp than in anterior teeth. The mesial and distal cutting 
edges are nevertheless consistently and strongly developed. The main cusp is also flanked by a pair of lateral cusplets, which are much shorter and possess a less acuminate, more rounded outline than is the case in more anterior teeth. The labial apron is here rounded in labial view (Figure 8G). There is clearly a light gradual monognathic heterodonty between the anterior and lateral teeth of this new species. Changes taking place distally through the dentition include a gradual asymmetry of teeth, with posterior teeth slightly bended distally (Figure 8E, G); a long, slender main cusp flanked by a pair of high lateral cusplets in anterior teeth generates a more squat, triangular central cusp flanked by relatively shorter, more rounded lateral cusplets in lateral teeth; a labial apron, although quite variable, regardless of the tooth position, that tends to be more bifid in anterior teeth (Figure 8D) and more rounded in lateral teeth (Figure $8 \mathrm{G}$ ).

\section{Remarks}

Only known in the fossil record by Eocene teeth from Antarctica (Long, 1992) and recently revised and placed within the Hemiscylliidae (Engelbrecht et al., 2016), the genus Stegostoma is rarely cited in the paleontological literature, unlike some specimens from the Eocene of Northern Africa belonging to this genus (Cappetta, 2012, p. 168). Contrary to most orectolobiforms (Hemiscylliidae included), there is no well-marked heterodonty in jaws of the living representative $S$. fasciatum, as illustrated by Herman et al. (1992). Upper and lower teeth are virtually similar (even in the same jaw), and anterior and posterior teeth share a similar crown pattern with long symmetrical cusp and pair of cusplets. Engelbrecht et al. (2016) erected the new genus Notoramphoscyllium from supplementary material formerly attributed to Stegostoma cf. fasciatum by Long (1992) due to the presence on their new large sample of teeth with a marked gradient of monognathic heterodonty, an asymmetrical main cusp with low and also asymmetrical lateral cusplets. With this suite of characters, the latter authors assigned Notoramphoscyllium to the family Hemiscylliidae because of their general resemblance with the teeth of Chiloscyllium/Hemiscyllium, in which the monognathic heterodonty is particularly noticeable. The KEB-1 material shows symmetrical anterior teeth (Figure 7D) as well as asymmetrical lateral teeth with sometimes reduced cusplets in posterior teeth (Figure 7G), a feature that is seemingly inconsistent with an attribution to Stegostoma. However, and contrary to what is observed in all recent and fossil species of hemiscyllids, the lateral cusplets are always present and usually well-developed, even in the most posterior teeth. If the gradual and light monognathic heterodonty observed in the KEB-1 material recalls that of some brachaelurid taxa (e.g., Brachaelurus, Eostegostoma), the latter are clearly distinguishable by their teeth that have a rounded and elongated apron, which overlaps the root. The genus was nevertheless previously reported in Priabonian deposits of Egypt, from the upper GE, BQ to lower QS (?Stegostoma sp., Underwood et al., 2011), and the figured tooth (Underwood et al., 2011, figure 6C-D from BQ) appears to be similar to lateral teeth of Stegostoma tethysiensis nov. sp. We also corroborate its occurrence in EG (pers. observ. SA, HC) even if affiliated material only consists of rare broken teeth without root, except those figured by Strougo et al. (2007, plate 1, figure 6) as Chiloscyllium sp. 2.

Specimens repositories. Holotype and Paratypes are deposited in the paleontological collections of the museum of the "Office National des Mines" of Tunis, 24 rue 8601, 2035 La Charguia, 1080 Tunis, Tunisia.

Temporal range. Uppermost Lutetian - Lowermost Bartonian (Egypt) to middle Bartonian (Tunisia), and possibly up to Priabonian (Egypt).

Family HEMISCYLLIIDAE Gill, 1862

Genus HEMISCYLLIUM Müller and Henle, 1838

Type species. Hemiscyllium ocellatum (Bonnaterre, 1788), extant species

\section{Hemiscyllium sp. \\ Figure 8H}

Material. Less than 10 teeth and fragmentary cusp from the KEB-1 locality, Souar-Fortuna formations, Djebel el Kébar, Tunisia, and including the figured specimen KEB 1-151 (Figure 8H).

\section{Description}

The teeth are small (less than $2 \mathrm{~mm}$ in length), symmetrical to slightly asymmetrical (Figure $8 \mathrm{H}$ ) depending of the file position. The crown always possesses a long and wide sharply-pointed central cusp, which is angled slightly distally in lateral tooth files. The main cusp is never flanked by pairs of lateral cusplets but by oblique straight heels. A moderate labial apron is developed on the crown margin and substantially overhangs the root. There is no ornamentation of the crown enameloid. The mesial and distal lobes of the root do not extend beyond the mesial and distal heels of the crown. 


\section{Remarks}

With teeth weakly asymmetrical, possessing a flat labial face of crown, a large cusp and no developed lateral triangularly-shaped cusplets, these teeth belong preferentially to Hemiscyllium rather than to Chiloscyllium according to Herman (1977) and Herman et al. (1992). Few fossil species are known during the Paleogene, such as Hemiscyllium bruxelliensis (Herman 1977) and Hemiscyllium tailledisensis Adnet, 2006, from Early-Middle Eocene deposits of the North Atlantic. Teeth of both contemporaneous species are clearly distinguishable from those of KEB-1 by their peculiar lower main cusp and sometimes, the presence of well-defined lateral cusplets in anterior teeth (e.g., $H$. bruxelliensis). However, the material is too scarce to precise the species attribution. Strougo et al. (2007) and Underwood et al. (2011) have also reported the rare presence of this genus in $E G, M I$ and $B Q$ in Egypt.

\section{Sub Cohort NEOSELACHII incertae ordinis Genus ODONTORHYTIS Böhm, 1926}

Type species. Odontorhytis pappenheimi Böhm, 1926

\section{Odontorhytis pappenheimi Böhm, 1926 Figure 8I-N}

Material. More than 300 teeth from the KEB-1 locality, Souar-Fortuna formations, Djebel el Kébar, Tunisia, and including the figured specimens (KEB 1-152 to KEB 1-157; Figure 8I-N).

\section{Description}

Teeth are very numerous from the KEB-1 locality, exceeding a hundred specimens. The tooth-size ranges between 5 and $14 \mathrm{~mm}$ in crown elevation. The teeth are nearly symmetrical, mesiodistally compressed, and have a high, sharp, and slanted lingually cusp with an apico-lingual barb observable in lateral view (Figure 8I1, K, M, N1). The tooth crowns do not seem to change in general morph according size, except the cusp that tends to be shorter and more massive in lateral teeth (Figure 8L-N) compared to the most slender ones, considered here as most anterior (Figure 8I$\mathrm{K})$. The enameloid of crown is primarily smooth, except on the basal part of the lingual face, under the barb, where fine folds are often visible. The labio-median cutting edge, when observable, does not reach the base of the crown face (Figure 812 , N2). The root is always high, relatively thick and always concave in profile view (Figure 8K, L, M, N1). It bears a well-marked protuberance incised by a median groove (Figure 8J, N3).

\section{Remarks}

The generic attribution to this uncertain shark, only known from the Paleogene (see Cappetta, 2012; Sambou et al., 2020), is noticeable considering its peculiar tooth morphology. Attribution to the Namibian species Odontorhytis pappenheimi is also sustainable, the latter being characterised by the lack of lateral cusplets, a labio-median cutting edge, and by an apico-lingual barb (Case and Cappetta, 1990; Adnet et al., 2011; Cappetta, 2012) even if Case and Cappetta (1990) and Cappetta (2012) noticed that there were probably several species remaining so far undescribed. Recently, Salame and Asan (2019) described a new species, Odontorhytis bahariensis, from EG, Baharyia Oasis, Egypt. It differs from O. pappenheimi in being smaller (less than $7 \mathrm{~mm}$ height), less massive, with a crown relatively higher and in having a labial cutting edge that does not extend to the basal edge of the cusp, as is the case in $O$. pappenheimi. The smallest teeth documenting this taxon from the KEB-1 locality are quite comparable to those of 0 . bahariensis (e.g., Figure 7K, N) but the largest ones are also comparable to that of $O$. pappenheimi (e.g., Figure 7I). In fact, the distinction of both species is somewhat tenuous, thereby suggesting that both species are present in KEB-1. Alternatively, we suspect that both species illustrate in fact different ontogenetic stages (see also Sambou et al., 2020) of a unique species. We currently retain the attribution to the formal species $O$. pappenheimi, pending further studies focused on the heterodonty of this peculiar genus.

Until now, Middle-Late Eocene Odontorhytis pappenheimi and its relatives (e.g., Odontorhytis bahariensis) were known to be widely distributed in African coastal deposits of late Middle/Late Eocene, particularly well-represented in Egypt (Case and Cappetta, 1990; Murray et al., 2010; Underwood et al., 2011; Adnet et al., 2011). However, it also frequented the Tunisian coast (Sweydan et al., 2018) until to Pakistan area (Case and West, 1991). Underwood et al. (2011) reported the occurrence of $O$. pappenheimei in MI (Lutetian/ Bartonian boundary) but not in GE (A-C) (Bartonian/Priabonian boundary). As this taxa seems to have preferentially frequented the near shore deposits with fresh water influence (as observed in BQ2 or in interdune lag of QS; Underwood et al., 2011), it is not surprising to have an uncontinuous fossil record for this taxa.

Order RHINOPRISTIFORMES Naylor et al., 2012 Family PRISTIDAE Bonaparte, 1838 Genus PROPRISTIS Dames, 1883 


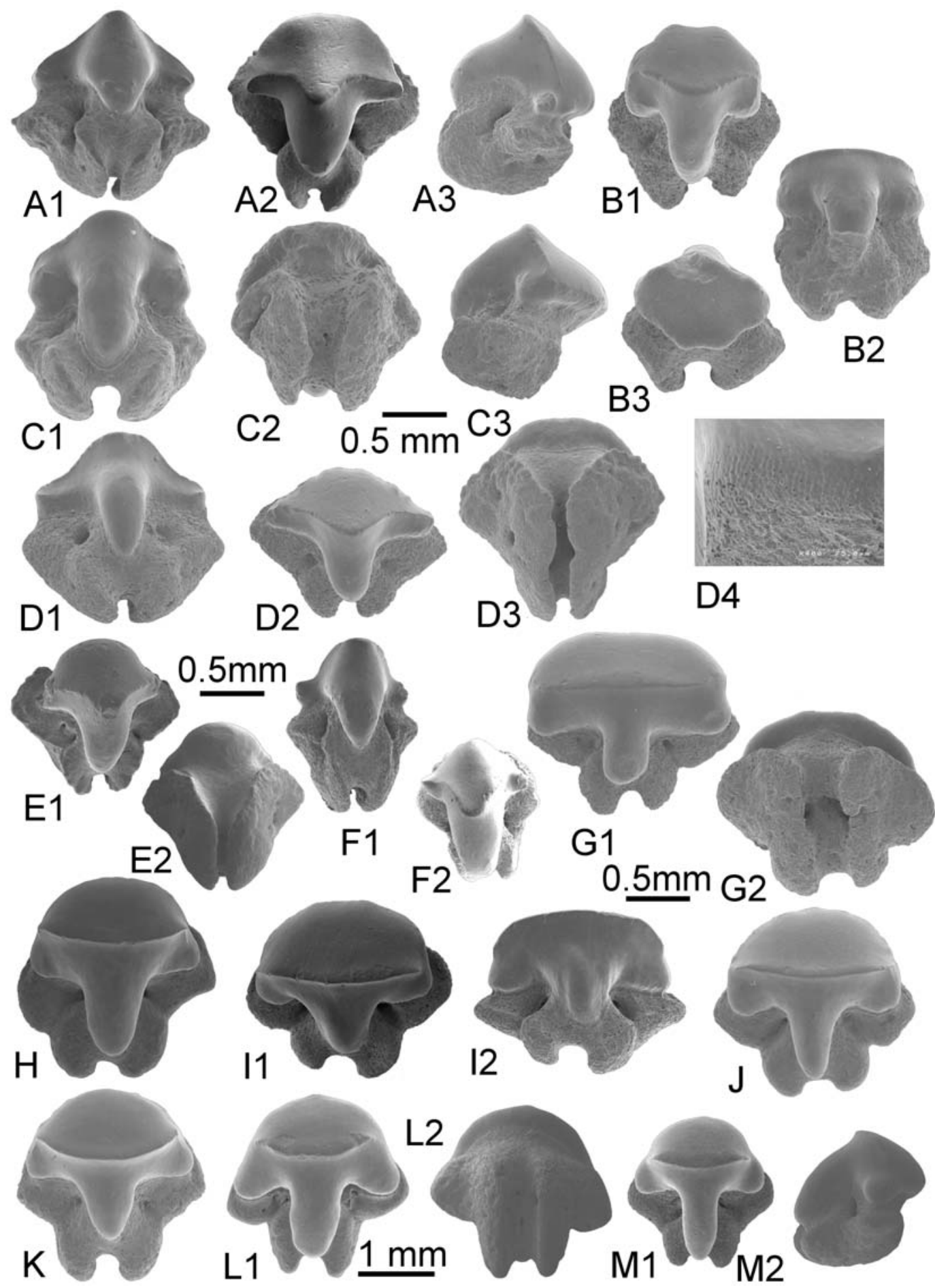

FIGURE 9. A-F: Propristis cf. schweinfurti, A. Anterior oral tooth KEB 1-166, A1. Lingual view, A2. Occlusal view, A3. profile; B. Antero-lateral oral tooth KEB 1-167, B1. Occlusal view, B2. Lingual view, B3. Labial view; C. Anterior oral tooth KEB 1-168, C1. Lingual view, C2. Basal view, C3. Profile; D. lateral tooth KEB 1-169, D1. Lingual view, D2. Occlusal view, D3. Basal view, D4. Magnificence of crown-root boundary of D3; E. ?male lateral tooth KEB 1-170, E1. Occlusal tooth, E2. Basal view; F. ?male anterior tooth KEB 1-171, F1. Lingual view, F2. Occlusal view; G-L: Pristis sp. G. porterior tooth KEB 1-158, G1. Occlusal view, G2. Basal view; H. anterior tooth KEB 1-159, occlusal view; I. lateral tooth KEB 1-160, I1 occlusal view, I2., lingual view. J lateral tooth KEB 1-161, occlusal view; K. anterior tooth KEB 1-162, occlusal view; L. lateral tooth of ?juvenile KEB 1-163, L1. Occlusal view, L2. Basal view; M. lateral tooth of juvenile KEB 1-164, M1. Occlusal view, M2. Profile. 


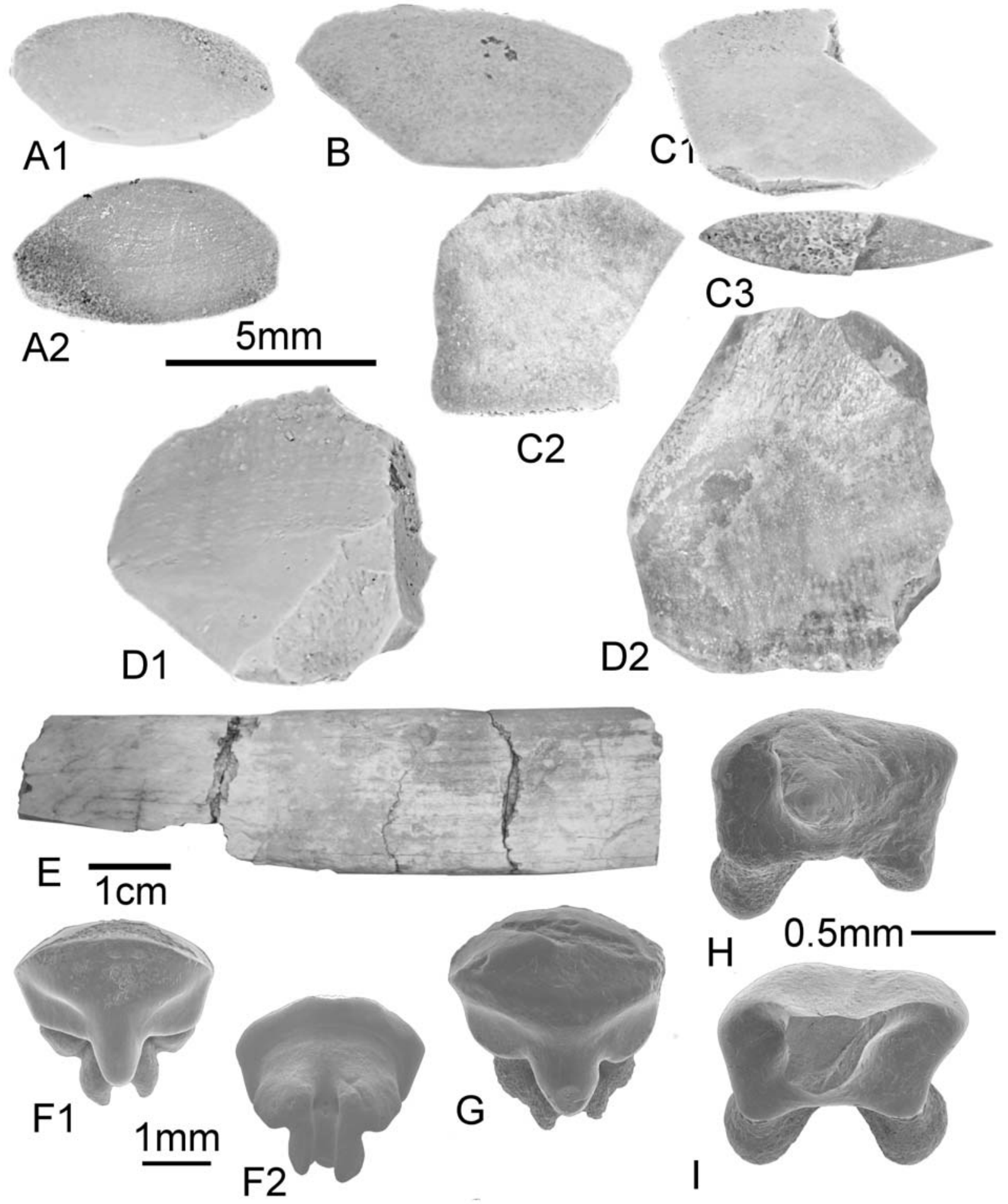

FIGURE 10. A-D: Propristis cf. schweinfurti. A. Rostral denticle KEB 1-172, A1. Profile, A2. dorsal view; B. Rostral denticle KEB 1-173, Profile; C. Rostral denticle KEB 1-174, C1. Profile, C2. Dorsal view, C3. basal view; D. Rostral denticle KEB 1-175, D1. profile. D2. dorsal view; E: Pristis sp. Rostral denticle, KEB 1-165, dorsal view; F-G. Rhynchobatus cf. vincenti. F. anterior tooth KEB 1-176, F1. Occlusal view, F2. Basal view; G anterior tooth KEB 1-177, occlusal view; $\mathrm{H}-\mathrm{I}$.? Torpedo sp. $\mathrm{H}$. lateral tooth KEB 1-178, occlusal view, I. lateral tooth KEB 1-179, occlusal view. 
Type species. Propristis schweinfurthi Dames, 1883

\section{Propristis cf. schweinfurthi}

Figures 9A-F, 10A-D

2016 Propristis sp.; Merzeraud et al., p. 14-15, tab. 1. Material. More than 200 oral teeth (including the figured specimens KEB 1-166 to 1-171; Figure 9A$\mathrm{F}$ ), and four badly preserved rostral denticles (KEB 1-172 to 1-175; Figure 10A-D) from the KEB-1 locality, Souar-Fortuna formations, Djebel el Kébar, Tunisia.

\section{Description}

Rostral denticles. The rare rostral denticles, mainly broken, are virtually as long as high, and are flattened dorso-ventrally, reaching a size up to $1.5 \mathrm{~cm}$ (estimated) high in the largest specimen (Figure 10D). The basal edge is convex (Figure $10 \mathrm{~A} 2$ ) to straight (Figure 10C2, D2) in dorsal or ventral view. The apical angle is wide to round in the best preserved smallest specimen (Figure 10A). The two cutting edges are salient and no posterior carena is observable as in rostral denticles of Pristis. The posterior cutting edge is convex whereas the anterior one is angular due to the presence of a more or less prominent process (Figure 10C2, D2). Without enameloid and due to functional wear, the ventral and dorsal faces of the dentine bear nearly parallel folds that fade out near the apex.

Oral teeth. These teeth are very small, reaching up to $1.5 \mathrm{~mm}$ maximal size. The heterodonty is not very marked with teeth more compressed mesiodistally according to files and/or ontogenetic stades (Figure 9E, F). The teeth are broader than long; their crown is relatively high, always bearing a cusp, more or less erected, characterized by a sharp transversal crest and two short lateral lingual uvulae. The latter do not overlap the root in occlusal view. The median lingual uvula is well developed, prominent and rounded in profile (Figure 9A3, C3). The labial face of the crown is short and its labial edge is sometimes truncated (Figure 9B3). The root is thick, also compressed mesiodistally but always longer than the crown length. The margino-lingual faces are flat, regular, and form a small (Figure 9A2) to inconspicuous (Figure 9B1, D2) lingual extension, under the median uvula of the crown. A pair of large nutritive foramina opens laterally to the medio lingual extension of the root. The basal face of the root is large and long with two root lobes separated by a deep groove. The two basal faces of the root lobes, flat (Figure 9C1,
D1, B2) to convex (Figure 9A1, F1) in lingual view, form an acute angle from $30^{\circ}$ (Figure 9F1) in the most anterior teeth to $90^{\circ}$ (Figure 9D1) in the most posterior teeth.

\section{Remarks}

Even fragmentary, rostral denticles are unequivocal representatives of Propristis, an Eocene sawfish only known by long rostrum with peculiar flat and rounded rostral denticles, without any enameloid on the dental crown surface. Firstly recovered in the Late Eocene of Fayum (Dames, 1883; Priem, 1897b, Stromer, 1905b) with Propristis schweinfurthi Dames, 1883, the genus was subsequently recorded widely in the Middle-Late Eocene deposits from Atlantic and Tethysian coasts (see Case and Cappetta, 1990; Cappetta, 2012) including in MI, KM and BQ in Egypt (Underwood et al., 2011). Until now, oral teeth of this fossil genus were unknown or at least, have never been clearly associated to this genus in localities where unambiguous rostral denticles were found. Oral teeth are similar to those figured as ?Pristis sp. from EG (Strougo et al., 2007, plate 2, figures 4-5), to those figured as ?Propristis or ?Pristis in $\mathrm{KM}$ (Adnet et al., 2012, figure 4A-B). Adnet et al. (2011) and Cappetta (2012) already considered that these peculiar pristid oral teeth might represent oral teeth of Propristis. We definitively confirm this previous hypothesis, considering that the oral tooth morphology is clearly different from that of the teeth of Anoxypristis or Pristis (e.g., Herman et al., 1997). As morphology of rostrum and rostral denticles usually differ greatly from one individual to the next among living pristids, as the rostral denticles are especially badly preserved and, as no oral teeth of $P$. schweinfurthi was until now reported, we remain cautious about attributing our numerous specimens to the type representative of genus.

\section{Genus PRISTIS Linck, 1790}

Type species. Pristis pristis (Linnaeus, 1758), extant species

\section{Pristis sp. Figures 9G-M, 10E}

2016 Pristis sp; Merzeraud et al., p. 14-15, tab. 1.

Material. More than 200 oral teeth (including the figured specimens KEB 1-158 to 1-164; Figure 9G$\mathrm{M}$ ), and some fragmentary rostral denticles (e.g., KEB 1-165; Figure 10E) from the KEB-1 locality, Souar-Fortuna formations, Djebel el Kébar, Tunisia. 


\section{Description}

Rostral denticles. These structures are badly preserved, often broken and strongly smoothed. The largest one (Figure 10E) probably reached 8 up to $10 \mathrm{~cm}$ long. They are thick, elongated and curved ventrally. Dorsal and ventral surfaces are only weakly convex. When preserved, the anterior edge is very convex. In contrast, the posterior edge bears a deep sulcus running along the length of the tooth, and there is a distinct ridge on both the dorsal and ventral margins, contrary to what is observed in rostral denticles of Anoxypristis. Most of rostral denticles exhibit clear signs of wear, with the distal half of each specimen being smooth.

Oral teeth. As rostral denticles, oral teeth of Pristis are conservative, exposing a dental pattern close to that observed in living species (e.g., Pristis pristis). As a consequence, there is no report in the literature of oral teeth belonging strictly to Pristis lathami Galeotti, 1837, the species commonly recovered in Eocene deposits from rostral denticles. In fact, all the oral teeth of Middle-Late Eocene Pristis are left in open nomenclature (e.g., Underwood et al., 2011; Cappetta and Case, 2016) and Case and Cappetta (1991) suggested that $P$. lathami possessed rather different oral teeth compared to living species. The re-examination of the material from EG (pers. observ. SA, HC.) suggests that the material attributed with uncertainty to ?Rhinobatos sp. (Strougo et al., 2007, plate 2, fig. 3 ) belongs in fact to oral teeth of Pristis, and are besides rather comparable to those figured here.

\section{Remarks}

Pristis lathami is the common representative of Pristis that frequented the tropical Atlantic and Tethys during the Middle-Late Eocene. Numerous records of rostral denticles, sometimes still imbedded in the rostrum (e.g., Cicimuri, 2007), are reported in the literature (Cappetta, 2012) contrary to the oral teeth that seemingly did not attracted particular attention until now. Given that the largest specimens of pristid teeth from KEB-1 share similar sizes and morphologies, we can expect that they are associated with the largest rostral denticles. For the first time, the oral teeth and the rostral denticles from an Eocene sawfish are figured together, however, and for the similar reasons advocated for the previous species, we remain cautious about attributing these materials to $P$. lathami and preferred to leave it in open nomenclature.

Family RHYNCHOBATIDAE Garman, 1913 Genus RHYNCHOBATUS Müller and Henle, 1837
Type species. Rhynchobatus djiddensis (Forsskål, 1775), extant species

Rhynchobatus cf. vincenti Jaekel, 1894

Figure 10F-G

2016 Rhynchobatus sp.; Merzeraud et al., p. 14-15, tab. 1.

Material. More than 100 oral teeth from the KEB-1 locality, Souar-Fortuna formations, Djebel el Kébar, Tunisia, and includes the figured specimens KEB 1-176, 1-177 (Figure 10F-G).

\section{Description}

Teeth are medium to large sized, reaching more than $3 \mathrm{~mm}$ long. The ornamentation of the lingual face, when the latter is not totally abraded by functional wear, is extremely variable, being usually smooth (Figure 10G) or having fine enameloid pitting under the transverse keel (Figure 10F1).

\section{Remarks}

Relatively common in most of the Eocene elasmobranch associations, Rhynchobatus displays a tooth morphology particularly conservative, explaining why only three worldwide species are recognised in the fossil record, the Neogene Rhynchobatus pristinus (Probst 1877) and Rhynchobatus rudolffischeri Laurito Mora, 1999, and the Paleogene Rhynchobatus vincenti Jaekel 1894. The latter probably corresponds to the frequent species with pitted enameloid occurring along the Fayum series from $\mathrm{Ml}$ to $\mathrm{BQ}$ (Underwood et al., 2011) and often attributed or affiliated to $R$. vincenti in the Eocene of Tethysian realm (e.g., Cappetta, 2012; Ward and Wiest, 1990; Averianov and Udovinchenko, 1993; Mustafa and Zalmout, 2002; Tabuce et al., 2005; Strougo et al., 2007).

Order TORPEDINIFORMES de Buen, 1926

Family TORPEDINIDAE Bonaparte, 1838

Genus TORPEDO Duméril, 1806

Type species. Torpedo torpedo (Linnaeus, 1758), extant species

\section{?Torpedo sp. Figure $10 \mathrm{H}-\mathrm{I}$}

2016 Torpedo sp.; Merzeraud et al., p. 14-15, tab. 1.

Material. Two rare and fragmentary teeth from the KEB-1 locality, Souar-Fortuna formations, Djebel el Kébar, Tunisia (KEB 1-178 and 1-179; Figure 10HI).

\section{Description}

These two teeth of ?Torpedo sp. have broken cusps, reducing the reliability of systematics deter- 
mination among the Torpediniformes. The teeth measure less than $2 \mathrm{~mm}$ in width. The crown is laterally elongated and seems well cuspidate. Labial and lingual ornamentations are missing on the whole enameloid surface of the crown. The labial face of the crown is slightly convex from the base of cusp to the labial visor that largely overlaps the root-crown boundary in profile. The labial visor marks a transversal rounded bulge. The transversal crest between the lingual and labial faces is lacking, except near the broken cusp where it appears sharped toward the cusp apex (Figure 10I). The lingual face is sub-rectangular, its marginal edges being quite vertical and its basal edge being slightly concave in lingual view (Figure $10 \mathrm{H}$ I). A narrow collar is visible on both views. The root is high with flattened lobes separated by a broad groove. The nutritive foramen is oriented lingually in the median groove, opening just below the crown/root boundary.

\section{Remarks}

Cappetta (1988) has figured teeth of most of the extant genera of Torpediniformes. The tooth morphology observed in the scarce sample from the KEB-1 locality (with the presence of a sub-rectangular lingual face, lack of salient transversal crest along the entire crown length, singular orientation of nutritive foramen) reminds the morphology usually observe in torpedinins like Torpedo or Tetronarce rather than that characterizing narcinins/ narkinins like Narcine, Narke, Temera, and Tetronarcine for instance. Torpedo is known in the Priabonian of the Fayum area (BQ and upper $\mathrm{QS}$; Underwood et al., 2011) and was signalled since the Palaeocene elsewhere (Cappetta, 2012). Benoit et al. (2013) reported the presence of a unique torpediniform tooth (? Narcine sp.) in the Ypresian - early Lutetian fossil mammal-bearing locality of Djebel Chambi in Tunisia, a fossiliferous locality close to those of Djebel el Kébar. The specimen from Chambi resembles in some aspect to the material reported by Cappetta (1988) as Narcine $\mathrm{sp}$. from the late Ypresian of Ouled Abdoun, Morocco, and besides it is different from those recovered in youngest deposits of Djebel el Kébar.

Order MYLIOBATIFORMES Compagno, 1973

GYMNURIDAE Fowler, 1934 incertae sedis

Genus OULEDIA Cappetta, 1986

Type species. Ouledia sigei Cappetta, 1986

Ouledia lacuna nov. sp.

Figure $11 \mathrm{~A}-\mathrm{C}$

zoobank.org/626F6DD8-45BE-4245-A07F-456550BFE876
2007 Ouledia sp.; Strougo et al., p. 88-94, pl.3, figs. 6-7.

?2008a Ouledia sp.; Adnet et al., p. 338, figs. 2.3-4.

?2011 Ouledia sp.; Underwood et al., p. 53-62, fig. 7J

2011 Ouledia sp.; Adnet et al., p. 35, fig. 4L-N.

2016 Ouledia sp.; Merzeraud et al., p. 14-15, tab. 1.

Etomology. Derived from Latin "lacuna" for lagoon that the new species preferentially frequented.

Type locality and stratum. KEB 1-180 (Figure $11 \mathrm{~A}$ ), from Souar-Fortuna Formations in Djebel el Kébar, Amamria hamlet near Soug-Jedid village (Sidi Bouzid Township), Tunisia: locality named KEB-1 in Merzeraud et al. (2016) and previously dated (radiometric $\mathrm{K}-\mathrm{Ar}$ datings) as middle Bartonian $(38.7 \pm 1.0 \mathrm{Ma}$ to $40.7 \pm 1.1 \mathrm{Ma}$, covering the NP17) in Marivaux et al. (2014a).

Other material. Additional material, including figured KEB 1-181 to 1-182 (Figure 11B-C), mainly consists of about 100 teeth from the KEB-1 locality, Souar-Fortuna formations, Djebel el Kébar, Tunisia.

Diagnosis. Fossil species of Ouledia known by uncupsided teeth with combination of characters that distinct the new species from $O$. sigei and $O$. casieri: a crown extremely narrow above the neck in uncuspided teeth with an occlusal surface never marked by a large mesio-distal furrow, a smooth enamel excepted on the lingual face of crown with the frequent development of fine alveolar network, a root always longer mesiodistally to the crown with two rounded lobes, hardly separated by a narrow groove.

\section{Description}

Teeth (including holotype) are small, not reaching more than $1.5 \mathrm{~mm}$ in height and width. There is no evidence of any dental sexual dimorphism in our large sample, having only female design (or male during non breeding period) without slender cusp. Crown and root are well differentiated by a slightly constricted neck. The root is always wider than crown. Teeth bear a thin, ovate crown in occlusal view (Figure 11A1, B1), which is always much longer labiolingually than it is wide mediodistally. The unique mesio-distal crest is sharp edged, rectilinear (Figure 11A1, B1) in occlusal view, and slightly concave in lingual or labial views (Figure 11A2, B2, C1), separating the labial face from the lingual face of the crown. The lateral angles of the crown are more or less sharp. The enamel is smooth, except behind the crown-root boundary where it may be slightly ornamented with alveolar net of folds on the lingual face (Figure 11A3). The root is bilobate, displaced lingually (Fig- 


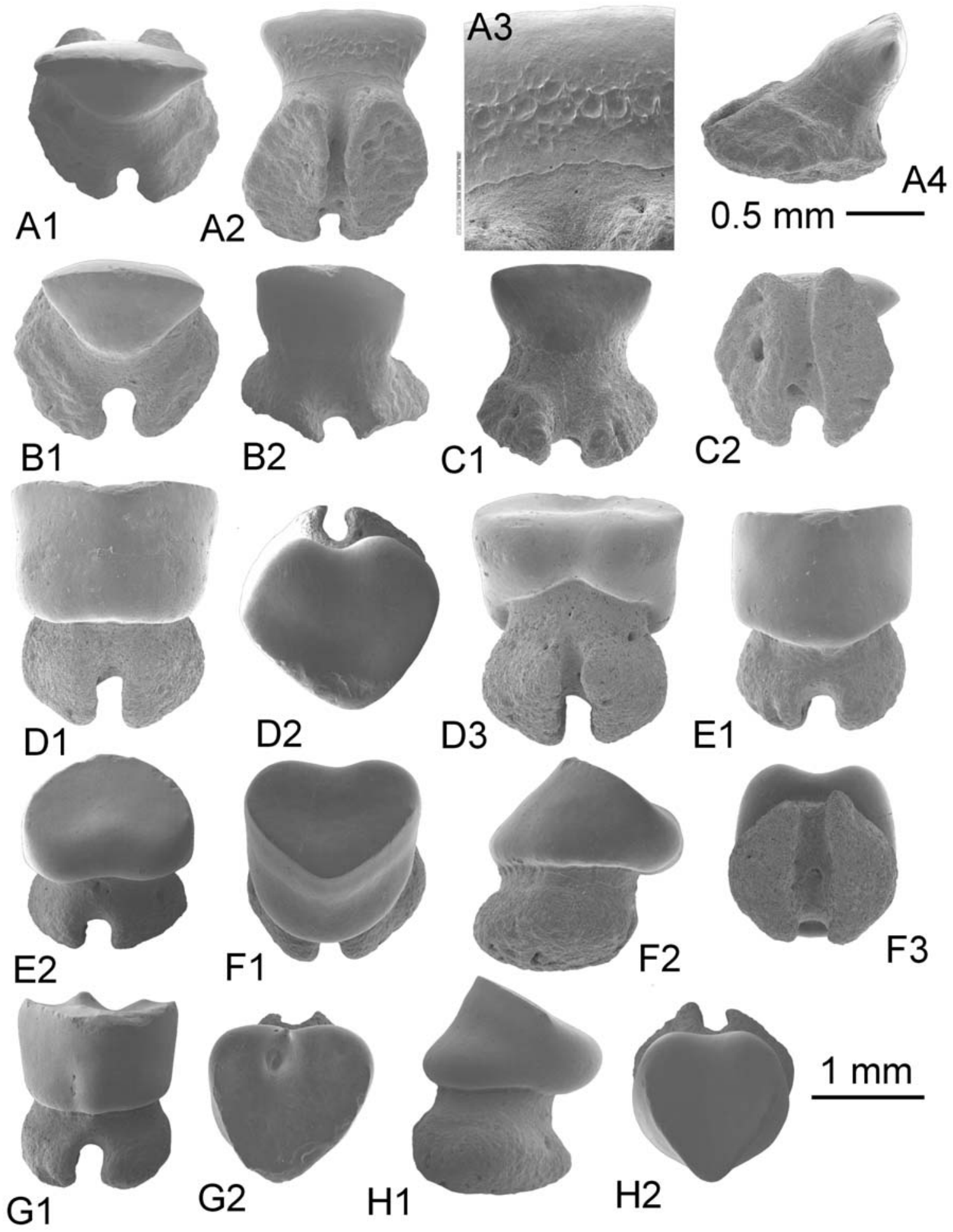

FIGURE 11. A-C. Ouledia lacuna nov. sp. A. ?Anterior tooth KEB 1-180, A1. Occlusal view, A2. Lingual view, A3. Magnificence of crown-root boundary in A2, A4. profile; B. ?lateral tooth KEB 1-181, B1. Occlusal view, B2. labial view, C. ?Anterior tooth KEB 1-182, C1. Labial view, C2. Basal view; D-H. Pachygymnura attiai nov. gen. D. Anterior tooth KEB 1-183, D1. Lingual view, D2. Occlusal view, D3. Labial view, D4. Basal view; E. Antero-lateral tooth KEB 1-184, E1. Lingual view, E2. Near labial view, F. lateral tooth KEB 1-185, F1. Occlusal view, F2. Profile, F3. Basal view; G. lateral tooth KEB 1-186, G1. Lingual view, G2. Occlusal view; H. Anterior tooth KEB 1-187, H1. Profile, H2. Occlusal view. 
ure 11A4), as long as wide and massive. The root lobes are suboval or subrounded with a lingual face much more widely expanded than the labial face. The basal face is flat to slightly rounded, with a narrow medial groove preferentially marked on its lingual edge (Figure 11B2, C1), and bears a well-defined and large notch on its labial edge (Figure $11 \mathrm{~A} 1, \mathrm{~B} 1, \mathrm{~B} 3)$.

\section{Remarks}

Widely distributed despite its low abundance in most of the fossil-bearing localities, only two species have been described in Early Eocene deposits where specimens are more numerous. Regardless of the absence of typical teeth of male with cusp in our sample, this new species is nevertheless distinct from the type species Ouledia sigei Cappetta, 1986, from the late Ypresian of Morocco, in showing a crown narrower above the neck in female teeth, a root always longer mesiodistally to the crown with two rounded lobes, hardly separated by a narrow groove. It is also distinct from Ouledia casieri (Kumar and Loyal, 1987) from the Ypresian of the lower Subathu Fm., India (Kumar and Loyal, 1987), in having an occlusal surface of the crown never marked by a large mesio-distal furrow, making a confined depressive basin in female teeth, and in having smooth enamel on the occlusal surface. Underwood et al. (2011) reported that rare examples of teeth of Ouledia are present throughout the section of Wadi al Hitan, Egypt, becoming more common only in the youngest deposits of QS. The latter authors figured only one tooth (Underwood et al., 2011, figure 7J from BQ) that corresponds to a "female" design, comparable to those observed in all specimens of Ouledia lacuna nov. sp. Being particularly worn, figure of Egyptian specimen does not allow to confirm the presence, or not, of the unusual ornamentation of the enameloid as observed in the material from KEB-1. From a close locality KM, Adnet et al. (2011, figure 4L-M) figured male and female teeth of Ouledia sp. Unfortunately, the scarce specimens from KM, also comparable to female teeth observed in EG and KEB, do not permit to conclude about the tooth morphology of the male teeth. Strougo et al. (2007) reported the presence of Ouledia at EG. The material from EG is as abundant as the Kebar sample (pers. observ. SA), and teeth with female design are entirely comparable to the material from KEB-1. Very scarce teeth (1\%) with male design (cuspided crown) were observed in EG. There is no doubt that the specimens of Ouledia from EG belong to the same KEB-1 new species. Without considering the diagnostic morphology of the occlusal surface of the crown of $O$. casierii, and despite the surprising lack of tooth with breeding male design in KEB samples, this species of Ouledia (as those from Myanmar in Adnet et al., 2008b, and those of southwestern Morocco in Adnet et al., 2010) is rather strongly reminiscent to the Indian species compared to Moroccan species $O$. sigei.

This ambiguous gymnurid genus, sometimes considered as an extinct filter feeder (Underwood et al., 2011) and/or tolerant to fresh water inflow (Adnet et al., 2008), seems to represent a diverse component of the nearshore ecosystems of all equatorial seas during the Paleocene (Cappetta, 2012; Louterbach et al., 2014) and Eocene, from Peru (Louterbach et al., 2014) to Myanmar (Adnet et al., 2008b). Absence of cuspid teeth usually attributed to (breeding) male in KEB remains unaccountable unless this could reflect a strong spatial segregation of male outside lagoons, at least during the breeding season.

Genus PACHYGYMNURA nov. gen. zoobank.org/343C7885-43ED-4D1C-A498-2F5034A8BE7D

Type species. Coupatezia attiai Cook in Murray et al. (2010) - DPC 23279, DPC 23777, DPC 23778 from the BQ-2 locality, Fayum, Egypt - Late Eocene.

Etymology. Derived from the Greek Pachy (thick) relative to the peculiar massive teeth of this gymnurid taxon.

Temporal range. Middle Eocene of West and North Africa to Latest Priabonian (Egypt).

Diagnosis. Genus only known by minute isolated teeth, the root and crown of the teeth being as massive and similar in size. The enameloid of the crown surface is entirely smooth and free of ornamentation or keel. In occlusal view, the crown is heart-shaped with a concave labial visor and convex lingual extremity. The marginal angles are particularly rounded. The lingually directed transverse crest that separates the lingual from the labial face extends from the lateral angles to form a sharp, medially but no individualized cusp. The occlusal part of the labial face is flat, the labial visor is rounded, and the lingual face is sub-rectangular in lingual view. In profile, the lingual face is steepsided, and only slightly shorter than the labial face. Both faces are remarkably straight in this view. The bilobate root is very massive with a height equalling or surpassing the height of the crown. It is as wider than the crown width. The root lobes are particularly labiolingually elongated and extend beyond the labial margin of the crown in occlusal 
view. The asymmetrical root lobes are crescentshaped in basal view, and separated by a welldeveloped nutritive groove that bears sometimes a large median foramen and regularly many marginal foramina.

Pachygymnura attiai (Cook in Murray et al., 2010) nov. comb.

Figure 11D-H

zoobank.org/9E15A4B6-1623-4CD3-83A6-5BCBF7A3ED96

2010 Coupatezia attiai Cook in Murray et al.; Murray et al, p. 669, figs. 1G, $2 A$.

2011 ?Jacqhermania attiai (Cook in Murray et al.); Underwood et al., p. 53-62, fig. 7 F-G.

2011 ?Jacqhermania attiai (Cook in Murray et al.); Adnet et al., p. 35-36, fig. 40.

2016 "Jacqhermania" attiai (Cook in Murray et al.); Merzeraud et al., p. 14-15, tab. 1.

Material. One hundred teeth from the KEB-1 locality, Souar-Fortuna formations, Djebel el Kébar, Tunisia, including those figured KEB 1-183 to 1187 (Figure 11D-H).

\section{Description}

Cook in Murray et al. (2010) proposed the first description of Coupatezia attiai, the type species of the new monotypic genus. Compared to their scarce material, the KEB-1 material counts several hundreds of teeth. However, the morphologies of teeth are quite similar, thereby testifying the very faint heterodonty in this taxon. No sexual nor dignathic heterodonty is clearly identified in this large KEB-1 sample. Some teeth (Figure 11D-F) are more laterally positioned based on the slight increase in mesiodistal width. Conversely, the most anterior teeth (e.g., Figure 11G-H) are slightly longer than wide, forming sometimes some asymmetrical folds on the labial face (e.g., Figure 11G). As observed by Murray et al. (2010), the nutritive groove also contains multiple smaller foramina rather than a single large foramen in some teeth.

\section{Remarks}

Formerly recognized as Coupatezia attiai Cook in Murray et al., 2010, this new taxon can be differentiated from Coupatezia inasmuch as it possesses a smooth and flat occlusal crown surface, without any ornamentation nor transversal labial crests, a lack of individualised cusp, and two rounded root lobes that are asymmetrical and labially extended. Nevertheless, as previously remarked by Murray et al. (2010), this morphology is quite comparable to that of Coupatezia laevis Noubhani and Cappetta, 1993, from the Danian of
Imin Tanout, Morroco. Differing from $C$. laevis in possessing a labial face that is completely flat, a lingual face that approaches the length of the labial face in profile view, and in a root more massive with root lobes more convex, Murray et al. (2010) already suggested that Pachygymnura attiai (formally C. attiai) and C. laevis should be removed from the genus Coupatezia. Underwood et al. (2011) and Adnet et al. (2011) later reported similar teeth in the Middle-Late Eocene of Egypt that were considered to have more affinities to the fossil gymnurid Jacquhermania Cappetta, 1982. Affinities to gymnurids are supported by: a root morphology that is extended mesiodistally in both fossil (e.g., Ouledia, Jacquhermania) and living gymnurids (see also Herman et al., 1998; Guinot et al., 2018), the crown faces with smooth enameloid only separated by a long cutting transverse crest, and the concave labial visor, which is particularly rounded in profile. However, the type species Jacquhermania duponti (Winkler 1874) recovered from the Early-Middle Eocene of the North Atlantic (Kent, 1999; Cappetta and Case, 2016) has larger teeth with more mesiodistally enlarged roots, and a strongly cuspidate crown, thereby justifying the description of a new genus. The systematic affinity of Pachygymnura nov. gen. remains unclear, and as such it is provisionally placed in Gymnuridae. Abundant in Djebel el Kébar, this species was also recovered from Priabonian deposits of Egypt (BQ, QS, KM), including coastal deposits with fresh water influence in BQ2 (Murray et al., 2010). This genus is likely to be known since the Middle Eocene of West Africa (Sambou et al., 2020) and Pachygymnura attiai nov. gen. was also observed in material from $E G$ (pers. observ. $S A, H C$ ).

\section{Family DASYATIDAE Jordan and Gilbert, 1879}

The recent revision of Last et al. (2016) about dasyatids has profoundly shaken our understanding of the systematics of fossil teeth with modern dasyatid design that have long been attributed to Dasyatis alone, or more recently to Himantura. To date, no available study of tooth morphologies within and between the most diversified subfamilies (Dasyatinae, Neotrygoninae, and Urogymininae) is available due to incompleteness of tooth figuration (Guinot et al., 2018). Only Hypolophinae (gathering all the species of Pastinachus) have a tooth morphology that is atypical enough to be clearly identified among fossil and living dasyatids (see also Adnet et al., 2019). However, and despite a very partial knowledge of the morphological diversity within each of the rare figured genera (e.g., Herman et al. 1998, 1999, Hovestadt and 
Hovesdtat-Euler, 2010; Cappetta, 2012; Marrama et al., 2018), it seems that most of the subfamily dasyatins sensu Last et al. [2016; e.g., Dasyatis pastinaca (Linnaeus, 1758), D. sabina (Lesueur, 1824), Bathytoshia centroura (Mitchill, 1815), Pteroplatytrygon violacea (Bonaparte, 1832)] and neotrygonins sensu Last et al. [2016; e.g., Neotrygon kuhlii (Müller and Henle, 1841), Taeniura lymma (Forsskal, 1775)] have jaws presenting a marked sexual heterodonty with male (and sometimes female) teeth displaying a long, tapered cusp in all or some tooth files.

Conversely, urogynminins sensu Last et al. (2016) have numerous species with a tooth morphology without well-detached cusp [e.g., Fontitrygon margarita (Günther, 1870), Fontitrygon margaritella Compagno and Roberts, 1984, Himantura uarnak (Gmelin, 1789), Urogymnus asperrimus (Bloch and Schneider, 1801), Fluvitrygon signifier (Compagno and Roberts, 1982)]. Only a complete revision of the dental morphology of living taxa reviewed in this recent phylogenetic framework could allow a better and more accurate fossil identification of dasyatid genera. However, the presence of a cusp in the fossil dasyatid tooth sample can tentatively help for identification at the subfamily rank despite the knowledge of periodic shifts in male dentition from a female-like molariform to a recurved cuspidate form only during the reproductive season (Kajiura and Tricas, 1996).

Sub family NEOTRYGONINAE Last et al., 2016 Genus MECOTRYGON nov. gen.

zoobank.org/F3C2C37C-A6C7-4225-BC7E-85D3F56AD72C

Type species. Mecotrygon asperodentulus nov. sp.

Etymology. From the acronym "MECO" (Middle Eocene Climatic Optimum) and Latin "trygon" that means stingray from the MECO event.

Temporal range. Uppermost Lutetian - lowermost Bartonian (Egypt) to middle Bartonian (Tunisia).

Diagnosis. Genus only known by isolated teeth with typical dasyatid design. Characterized by the presence of rugose crown marked by a sinuous transversal keel and secondary crests that tend to form an inner basin on the labial face. Cuspidate teeth have a small and thick cusp with a flat top extremity. The root could be high in anterior teeth with reduced rounded root lobes in lingual view.

Mecotrygon asperodentulus nov. sp. Figure 12A-C

zoobank.org/E23FAB91-7091-45F7-9A3A-6E878BCC583E

2007 Dasyatis sp. 1; Strougo et al., p. 88-94.
2016 Dasyatis sp. 1; Merzeraud et al., p. 14-15, tab. 1.

Etymology. Derived from the Latin "aspero" and "dentulus", meaning rugose small teeth.

Type locality and stratum. KEB 1-190 (Figure 12C) from the KEB-1 locality, Souar-Fortuna formations in Djebel el Kébar, Tunisia.

Other material. Additional material, including figured KEB 1-188 and 1-189 (Figure 12A, B), consists of several hundred oral teeth from the KEB-1 locality, Souar-Fortuna formations, Djebel el Kébar, Tunisia.

Diagnosis. As that of the monotypic genus.

\section{Description}

The dentition shows a gradual monognathic heterodonty with high-crowned teeth, which decrease in size toward the commissure. The majority of available teeth have a small, thick cusp on the crown, holotype included (Figure 12C). This cusp is mainly medio-lingually oriented (Figure $12 \mathrm{~A} 2, \mathrm{~B} 3, \mathrm{C} 4)$, its top is peculiarly flat, parallel to the crown base and connected to the transversal keel separating the smooth lingual face from the crested labial face of crown. Cusps are often displaced distally (Figure 12B2, C2). The crown of cuspidate teeth are often asymmetric in occlusal view (Figure 12B2), and the transversal keel is particularly irregular in these specimens, forming sometimes a pair of pseudo cusplets laterally (Figure 12B1). Other teeth have a minute or no median cusp, the transversal keel being erected to low according to their position in jaw. The lateral edges of the lingual face are straight (Figure 12A1) to concave (Figure 12B1, C1) in lingual view, and converge toward the rounded lingual visor. The lingual face is concave, except in its median part below the cusp. The marginal angles are pointed (Figure 12C2). The labial face is also mainly concave. It is delimited by the salient and irregular transversal keel and some secondary inner crests that sometimes merge with the previous one laterally. Most of the non cuspidate teeth have a labial face without any secondary crest, this face being rounded near the labial visor. In some antero-lateral teeth (of males?) with salient cusp (Figure $12 \mathrm{~B}$ ), this merging forms a narrow basin in occlusal view (Figure 12B2). More posterior teeth (Figure 12C), holotype included, show an occlusal face more elongated mesio-distally with inner irregular crests transversally oriented (Figure 12C1). Some minute enameloid peaks could appear along the transverse keel and near the labial visor, thereby forming sometimes rare anastomosed ridges. The 


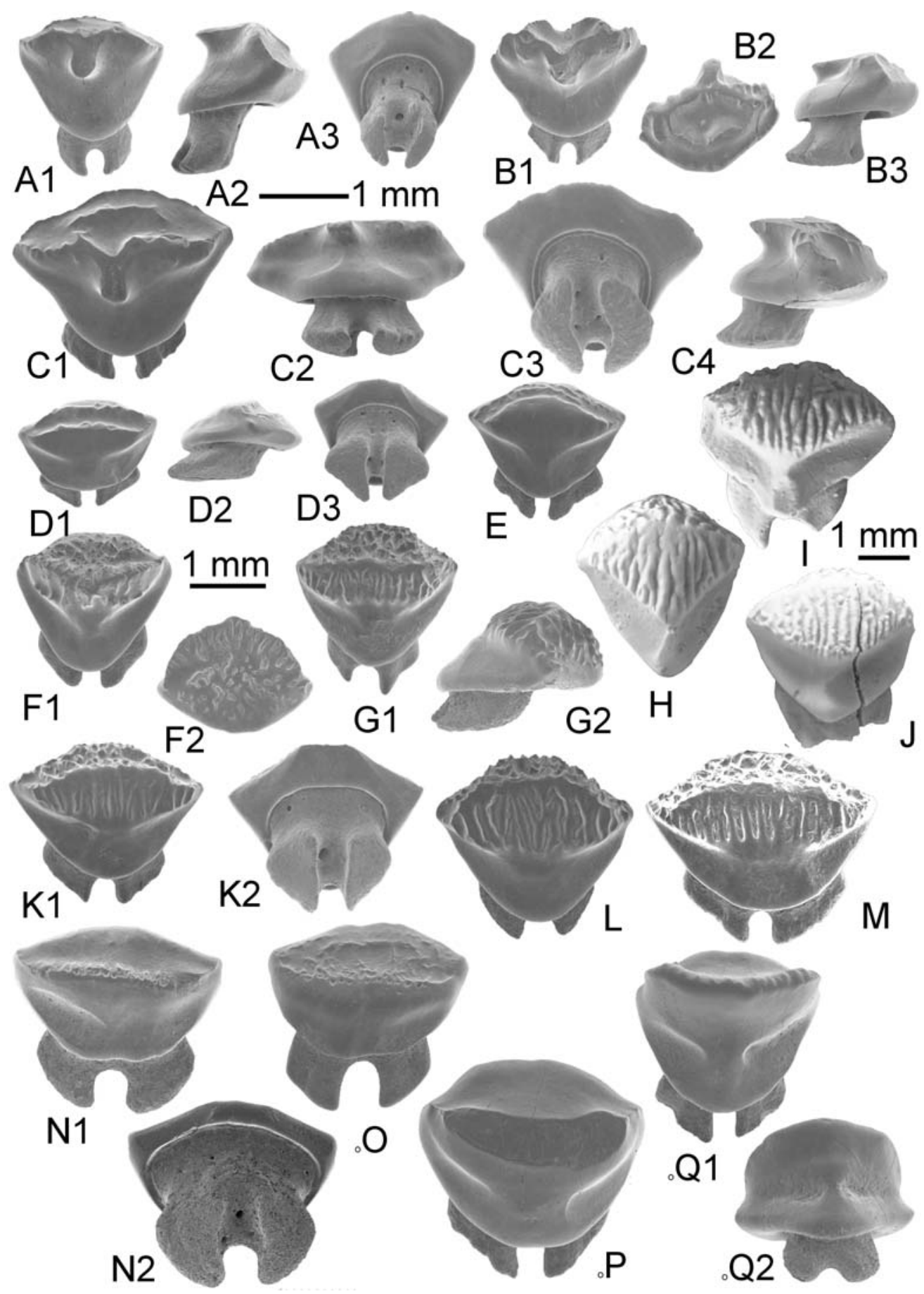

FIGURE 12. A-C. Mecotrygon asperodentulus nov. gen nov. sp. A. anterior tooth KEB 1-188, A1. occlusal view, A2. Profile, A3. Basal view; B. lateral tooth KEB 1-189, B1. occlusal view, B2. labial view, B3. Profile; C. lateral tooth KEB 1-190, HOLOTYPE, C1. Occlusal view, C2. Lingual view, C3. Basal view, C4. Profile; D-M. Himantura souarfortuna nov. sp. D. ?posterior tooth KEB 1-191, D1. Occlusal view, D2. Profile, D3. Basal view; E. antero-lateral tooth KEB 1192, occlusal view; F. anterior tooth KEB 1-193, F1. Occlusal view, F2. Labial view; G. antero-lateral tooth KEB 1-194, G1. Occlusal view, G2. Profile; H. anterior tooth KEB 1-195, occlusal view; I. lateral tooth KEB 1-196, occlusal view; J. A. anterior tooth KEB 1-197, occlusal view; K. lateral tooth KEB 1-198, K1. Occlusal view, K2. Basal view; L. A. anterior tooth KEB 1-199, occlusal view; M. lateral tooth KEB 1-200, occlusal view. N-O. Dasyatoid indet. N. antero-lateral tooth KEB 1-201, N1. Occlusal view, N2. Basal view; O. A. antero-lateral tooth KEB 1-202, occlusal view; P-Q. Arechia sp. P. lateral tooth KEB 1-203, occlusal view; Q. A. anterior tooth KEB 1-204, Q1. Occlusal view, Q2. Lingual view. 
lower face of the labial visor, overhanging the root, is particularly well developed (Figure 12A3, C3), extending from one side to the other marginal angle. The root is relatively narrow compared to the crown in lingual or labial views. Several small foramina are visible on its labial face, near the crown/root junction. The root is relatively high in profile of anterior teeth (Figure 12A2), and is lingually oriented without exceeding largely the visor. The root is of holaulacorhizous type with two lobes comparatively short and separated by a nutritive groove where one (Figure 12A3) to several foramens (Figure 12C3) emerge. The basal face of root lobes, which tend to converge each over, are semi-circular in basal view.

\section{Remarks}

The numerous teeth belonging to this new taxon have a variable morphology, with crowns rugose and typically asymmetric with short to minute cusp revealing a dentition assignable to the Neotrygoninae (e.g., Taeniura) among dasyatids. For instance, Herman et al. (1999) and Cappetta (2012) abundantly figured teeth of Taeniura lymma. Monognathic and sexual heterodonties figured by Herman et al. (1999, pl. 7) are comparable to the variability observable in the KEB-1 sample, male teeth (during the breeding season) having short cusp more or less displaced laterally when female or male teeth (outside the breeding season) are less cuspidate, except along one lateral file (Herman et al., 1999, text, plate 1). However, none of the figures of Taeniura lymma shows teeth with such an irregular transverse keel nor labial face marked by numerous secondary crests that often form an inner concave basin as observable in some specimens of Mecotrygon asperodentulus nov. gen nov. sp. (e.g., Figure 12B2). However, we can note some similarities with other taxa. For instance, the irregular transverse keel of $M$. asperodentulus reminds that of the Ypresian "Dasyatis" tricuspidatus Casier, 1946, a taxon, which presents a peculiar tricuspidate transversal keel and a secondary crest on the labial crown face. Possibly reported from the Middle Eocene (Case et al., 1996, as Dasyatis sp.) until the Priabonian (Cicimurri and Knight, 2019), "D." tricuspidatus is distinct from $M$. asperodentulus nov. gen. in having teeth with long, wide root lobes and a lingual visor more or less bifid. Neotrygonins are relatively scarce in the fossil record, especially in MiddleLate Eocene deposits of the Tethys area. Adnet et al. (2011) and Underwood et al. (2011) reported the presence of Taeniura sp. in MI, BQ, KM and QS,
Egypt. The rare figurations of them (Adnet et al., 2011, from KM / Underwood et al., 2011, from BQ) are seemingly different from the KEB-1 specimens in having a more rugose and discontinuous transversal keel. However, we do not exclude that some material attributed to the Middle Eocene Taeniura (e.g., from $\mathrm{MI}$ ) could in fact belong to a distinct new taxa. Otherwise, the material from EG attributed to Dasyatis sp. 1 and characterized by a cuspidate crown with a cutting crest on the sides of the lingually directed cusp and a labial face without trace of enamel ornamentation (Strougo et al., 2007) belongs definitively to the new taxon (pers. observ. SA, HC). Murray et al. (2014, figure 4J) also reported the presence of Taeniura in JQ, earliest Oligocene of Fayum with a tooth that could represent a female design (or male outside the breeding season) seemingly differing from new taxa.

Specimens repositories. Holotype and Paratypes are deposited in the paleontological collections of the museum of the "Office National des Mines" of Tunis, 24 rue 8601, 2035 La Charguia, 1080 Tunis, Tunisia

Temporal range. Uppermost Lutetian - lowermost Bartonian (Egypt) to middle Bartonian (Tunisia).

Sub Family UROGYMNINAE Last et al., 2016

Genus HIMANTURA Müller and Henle, 1837

Type species. Himantura uarnak (Gmelin, 1789), extant species

\section{Himantura souarfortuna nov. sp. Figure 12D-M}

\section{zoobank.org/7B76AC15-5452-454A-801A-603CF5C9C6AC}

2016 Himantura sp.1; Merzeraud et al., p. 14-15, tab. 1.

Etymology. Derived from Souar-Fortuna formations where the holotype comes from.

Type locality and stratum. KEB 1-194 (Figure 12G) from the KEB-1 locality, Souar-Fortuna formations in Djebel el Kébar, Tunisia.

Other material. Additional material, including figured KEB 1-191 to 1-193 and KEB 1-195 to 1-200 (Figure 12D-F, H-M), consists of 100 male and female teeth from the KEB-1 locality, Souar-Fortuna formations, Djebel el Kébar, Tunisia, including the specimens figured.

Diagnosis. Fossil Himantura only known by isolated teeth reaching a large size (4 $\mathrm{mm}$ long). The heterodonty is weak with only molariform teeth without cusp. It differs from the others representatives of urogymnins known to date by having teeth with a globular crown marked by a transversal keel, rarely cutting, and often bombed and striated by numerous regular vertical ridges, a finely rugose 
labial face, and a low root with well-separated lobes.

\section{Description}

The dentition is characterized by a gradual monognathic heterodonty, with high-crowned teeth which decrease in size toward the commissure. Evidence of dignathic heterodonty was not detected, all teeth being non cuspidate. Teeth can be relatively massive and can reach a large size with a maximum of $4.2 \mathrm{~mm}$ long (Figure $12 \mathrm{H}-\mathrm{J}$ ). The holotype (Figure 12G) is probably an anterolateral tooth, considering the root shape of the selected specimen, with elongated root lobes. In occlusal view, the crown is sub-hexagonal in shape. The crown has an inward bent, rounded (Figure 12G-J) to salient (Figure 12F), transverse keel, which divides the crown into distinct labial and lingual faces. None of the teeth identified in this taxon have well-detached cusp, the few anterior teeth exempt of wear having only a more or less prominent cutting transversal keel (Figure $12 F)$. The lingual face of the crown is partially smooth, except in its occlusal extremity, domed, where several vertical deep ridges are equally distributed under and across the transverse keel (Figure $12 \mathrm{~F}-\mathrm{M}$ ). The labial face is convex and covered by numerous wrinkles of enameloid that often anastomose into irregular small crests and pits (Figure 12G2). These peaks gradually fade towards the labial visor. The lower part of the labial visor is without ornamentation (Figure 12G2, K2). The root is narrow with respect to the crown, whereas being relatively long. It is also relatively short compared to the crown in profile (Figure 12D2, G2), and extends lingually beyond the lingual visor of the crown in occlusal view. The root is of holaulacorhizous type (Figure 12D3, K2), with two lobes separated by a large nutritive groove where a circular foramen opens labially (Figure 12K2).

Some small teeth (Figure 12D, E) have been provisionally attributed to this taxon. Their crown morphologies are quite different with the smallest one (Figure 12D) being non cuspidate, with a unique secondary crest parallel to transversal keel. The largest teeth (Figure 12E) exhibit a slight ornamented enameloid on their labial face, but no ridge across the bombed transversal keel.

\section{Remarks}

By the lack of well-detached cusp, the presence of an enameloid ornamentation over the occlusal part of the lingual face and over the entire labial face of crown, the presence of a short root with well-detached root lobes where an unique labial foramen opens, this morphology reminds the dental condition characterizing Himantura uarnak (Cappetta, 2012, figure 411; non Herman et al., 1998, pl. 8-9) or some large species of Pateobatis (e.g., Pateobatis bleekeri), which were previously included into Himantura (Last et al., 2016). Cappetta (2012, figure 411) and Herman et al. (1998, pl. 8-9) both figured teeth of Himantura uarnak with very different design, the second showing minute teeth with few ornamented crowns and a secondary transverse crest (as in Figure 12D) when the first remind the tooth morphology of adults of Himantura souarfortuna nov. sp. (Figure 12F-J). As noticed by Cappetta (2012, p.418), teeth illustrated by Herman et al (1998) probably correspond to the morphology of a juvenile of $H$. uarnak, thereby indicating a relative strong developmental heterodonty. We could suspect that some teeth (e.g., Figure 12D-E) represent similar ontogenetic stages in $H$. souarfortuna nov. sp. Marrama et al. (2018) figured embedded teeth from a skeleton of Protohimantura vorstmani (de Beaufort, 1926) from the Miocene of Indonesia. Juveniles of $H$. souarfortuna nov. sp. and $H$. uarnak share the same semi-ovoid or subhexagonal crown, with a second transverse keel that partially characterizes this Miocene urogymnin too. Himantura (and other new urogymnin genera sensu Last et al., 2016) are particularly scarce in the fossil record compared to Dasyatis, probably due to its misidentification with the former (see also the review of the fossil record of urogymnins by Marrama et al., 2018). Only two fossil species are known, they concern the Neogene Himantura menoni (Sahni and Mehrotra, 1981) and Protohimantura vorstmani. Sahni and Mehrotra (1981) always suggested that teeth of their Himantura menoni were similar to those of the living Indian species Pateobatis bleekeri (formerly Himantura bleekeri), except that the transversal keel in the extinct $H$. menoni does not run up to the lateral edges, and the lingual and labial faces are different in size. By this, $H$. menoni appears different from $H$. souarfortuna nov. sp. even if the latter has teeth that also resemble those of $P$. bleekeri (pers. observ. SA).

This new species testifies the occurrence of urogymnins sensu Last et al. (2016) since the Middle Eocene in western Tethys. Besides, it confirms the spatial and temporal dynamics of Urogymninae, substantiating an eastward movement of the fossil occurrences from the Tethys during the Eocene to the tropical Indo-Australian Archipelago 
after the Oligocene, where they are particularly well-represented today (Marrama et al., 2018). We provisionally referred this new species to the "'informal" genus Himantura pending more accurate figurations from neontologists because several species of Himantura have been recently attributed to other genera (e.g., Pateobatis) by Last et al. (2016).

Specimens repositories. Holotype and Paratypes are deposited in the paleontological collections of the museum of the "Office National des Mines" of Tunis, 24 rue 8601, 2035 La Charguia, 1080 Tunis, Tunisia

Temporal range. Middle Bartonian (Tunisia).

Family DASYATIDAE incertae sedis Dasyatoid indet.

Figure $12 \mathrm{~N}-\mathrm{O}$

2016 Dasyatis sp. 2; Merzeraud et al., p. 14-15, tab. 1.

Material. A dozen teeth, including those figured KEB 1-201, 1-202 (Figure 12N-O) from the KEB-1 locality, Souar-Fortuna formations, Djebel el Kébar, Tunisia.

\section{Description}

Teeth are relatively large compared to previous taxa, reaching $2.5 \mathrm{~mm}$ long for the largest one. Showing a typical dasyatoid design, the dentition exhibits a gradual monognathic heterodont with high-crowned teeth, which decrease in size toward the commissure. Evidence of a dignathic heterodonty was not detected, the whole teeth being non cuspidate. The crown of teeth is smooth, except along the transverse keel (Figure 12N1) and sometimes on the labial face (Figure 120) where it bears fine alveolar enameloid crests in occlusal view. The labial visor is extremely narrow in occlusal view, and the lingual border of the lingual face is primarily straight but also punctually sinuous (Figure 120) compared to previous taxa. The lateral depression of the lingual face can be relatively large (Figure 12N1), thereby indicating a close interlocking teeth in staggered file. The root is particularly well elongated lingually with two root lobes long, well-detached by a wide nutritive groove where a small circular foramen opens centrally in basal view (Figure 12N2).

\section{Remarks}

Relatively scarce in the sample, teeth of these undefined taxa are different from those of previous described Dasyatidae. For instance, it is distinct from Middle-Late Eocene " $D$ ". charlisae Case 1981 that possesses usual male teeth high crowned with strong ornamentation, conchoidal according Case (1981), covering completely the labial surface, from transversal keel to labial visor, and a narrower root compared to crown in lingual view. The presence of long and well-separated root lobes, a crown lingual face with marked articulate lateral depressions and lingual sinuous border could somewhat remind the dental traits characterizing teeth of the living Taeniurops (see Herman et al., 1998, 1999; Cappetta, 2012) or some Neogene representatives (CarriloBriceno et al., 2016, as cf. Taeniurops sp.). However, the latter always have crown with labial face coarsely ornamented and none of these representatives present this peculiar fine alveolar ornamentation of the transverse keel.

Family UROTRYGONIDAE McEachran, Dunn and Miyake, 1996 incertae sedis Genus ARECHIA Cappetta, 1983

Type species. Arechia arambourgi Cappetta, 1983 Arechia sp. Figure 12P-Q

2016 Arechia sp.; Merzeraud et al., p. 14-15, tab. 1.

Material. Sixty teeth, including those figured KEB 1-203, 1-204 (Figure 12P-Q) from the KEB-1 locality, Souar-Fortuna formations, Djebel el Kébar, Tunisia.

\section{Description}

Teeth are relatively large, reaching $3 \mathrm{~mm}$ long for the largest one. The dentition is characterized by a moderate gradient of monognathic heterodonty, with high-crowned teeth, which decrease in size toward the commissure. The enameloid of crown is entirely smooth, except the presence of soft wrinkles along the labial margin of the transversal keel in some teeth (Figure 12Q1). There is no detached cusp but the transversal keel can be substantially high, lingually oriented to vertically erected (e.g., Figure 12Q2), with rarely a minute cusp medially centred. The transversal keel, fine and cutting, never reaches the lateral angles of crown, the labial and lingual faces being fused laterally. On many teeth, the cutting transversal keel appears isolated from the rest of the crown in occlusal view. As a result, the lateral angles are well delimited from the transversal keel by angular notches in labial or lingual views (Figure 12Q2). The lingual face shows a triangular shape and is concave except near the median, vertical keel. The labial face is regularly concave or flat, depending on the file position of teeth. The lingual visor is medially sinuous in lingual view (Figure 12Q2). The root is poorly developed, lingually oriented with two 
short lobes separated by a shallow groove where a large principal foramen opens medially. A secondary foramen always opens labially near the crown/ root boundary.

\section{Remarks}

Only one species of Arechia is known to date: A. arambourgi Cappetta, 1983 from the Late Ypresian of Morocco. However, several reports of the genus indicate a more widespread geographical and stratigraphical ranges (e.g., Cappetta and Traverse, 1988; Tabuce et al., 2005; Cappetta, 2012; Sambou et al., 2017). The KEB-1 dental material is comparable to that figured by Cappetta (1983 pl. 2), but it seems somewhat different from Arechia arambourgi in having a higher cutting transversal keel with a slight ornamentation on its inner border, prefiguring the appearance of a real large cusp. However, these differences are tenuous, and this material is left in open nomenclature.

Murray et al. (2014, figure 4K-?M) figured several teeth of Dasyatis sp. from the Rupelian JQ, Fayum, the morphology of which is strongly reminiscent of that of Arechia, having non-continuous transversal keel from one lateral angle to the other. Some of them (Murray et al., 2014, figure 4M) possess a relatively long detached "cusp" that seemly derives from a high cutting transversal keel. Whatever the validity of the latter attribution, we provisionally attribute the genus Arechia to Urotrygonidae incertae sedis, rather than to Dasyatidae incertae sedis because the living representatives Urobatis jamaicensis (Herman et al., 2000; Hovestadt and Hovestadt-Euler 2010) seems to be the unique figured taxa with dasyatoid tooth design with teeth having a non-continuous transversal keel from both lateral angles of the crown. Arechia clearly differs from representatives of living or fossil Urobatis (Hoverstadt and Hovestadt-Euler 2010, Pimiento et al., 2013) in having no secondary crest on the labial face of the crown nor so developed cusp. The occurrences of Arechia in the middle Bartonian of Tunisia (Djebel el Kébar) and possibly until the Rupelian of Egypt (Murray et al., 2014) increase significantly the stratigraphical range of this possible urotrygonid, a family distributed today throughout the tropical Pacific and Western Atlantic realms.

\section{Super family DASYATOIDEA Whitley, 1939 incertae familiae Genus COUPATEZIA Cappetta, 1982}

Type species. Coupatezia woutersi Cappetta, 1982

\section{Coupatezia cristata nov. sp.} Figure 13A-E

zoobank.org/3BC6CE15-E4B3-412D-BFDC-5C64F6198255

2007 Coupatezia sp.; Strougo et al., p. 88-94, pl. 3, figs. 3-4.

2016 Coupatezia sp; Merzeraud et al., p. 14-15, tab. 1.

Etymology. Cristata, considering the peculiar labial extremity of crown that bear many enameloid crests.

Type locality and Stratum. KEB 1-205 (Figure 13A) from the KEB-1 locality, Souar-Fortuna formations in Djebel el Kébar, Tunisia.

Other material. Additional material, including figured KEB 1-206 to 1-209 (Figure 13B-E), principally consists of about 200 teeth from the KEB-1 locality, Souar-Fortuna formations, Djebel el Kébar, Tunisia.

Diagnosis. Species of Coupatezia characterized by large teeth (up to $5 \mathrm{~mm}$ mesiodistally wide) and only known by "female" tooth morphology, suggesting the lack of any gynandric heterodonty in this species. This species is also characterized by a combinations of many characters separately observed in "female" teeth of other species, as: teeth always broader than long (e.g., like C. bojoi, C. larivei, C. reniformis, C. wouterzi), crown having a deeply concave occlusal part of the labial face (e.g., like C. fallax, C. ambroggii), and sometimes of the lingual face; both surfaces of crown are finely ornamented with alveolar web of enameloid (e.g., like C. larivei); a labial visor strongly irregular in occlusal or labial view (e.g., like C. fallax).

\section{Description}

Almost all species of Coupatezia exhibit usually gynandric heterodonty, with male teeth (at least during the breeding period) having a cuspidate, triangular crown and with female teeth with uncuspidate, elliptic crown, as reported here. However, and as also observed in the Danian species C. melitiana Noubhani and Cappetta, 1997, there is no evidence of sexual dimorphism in the material of $C$. cristata nov. sp. from KEB which consists of 200 teeth, nor in the other contemporenous sample from Egypt where the new species occurs abundantly (EG). The crown seems never really cuspidate, assuming that some males were present in all or a part of all theses samples/localities. Of course, we cannot unambiguously exclude that lack of cuspidate teeth was due to male departure outside the lagoon during the breeding period. The teeth have a crown broader than long in occlusal view, and as broader as the root breadth. The out- 


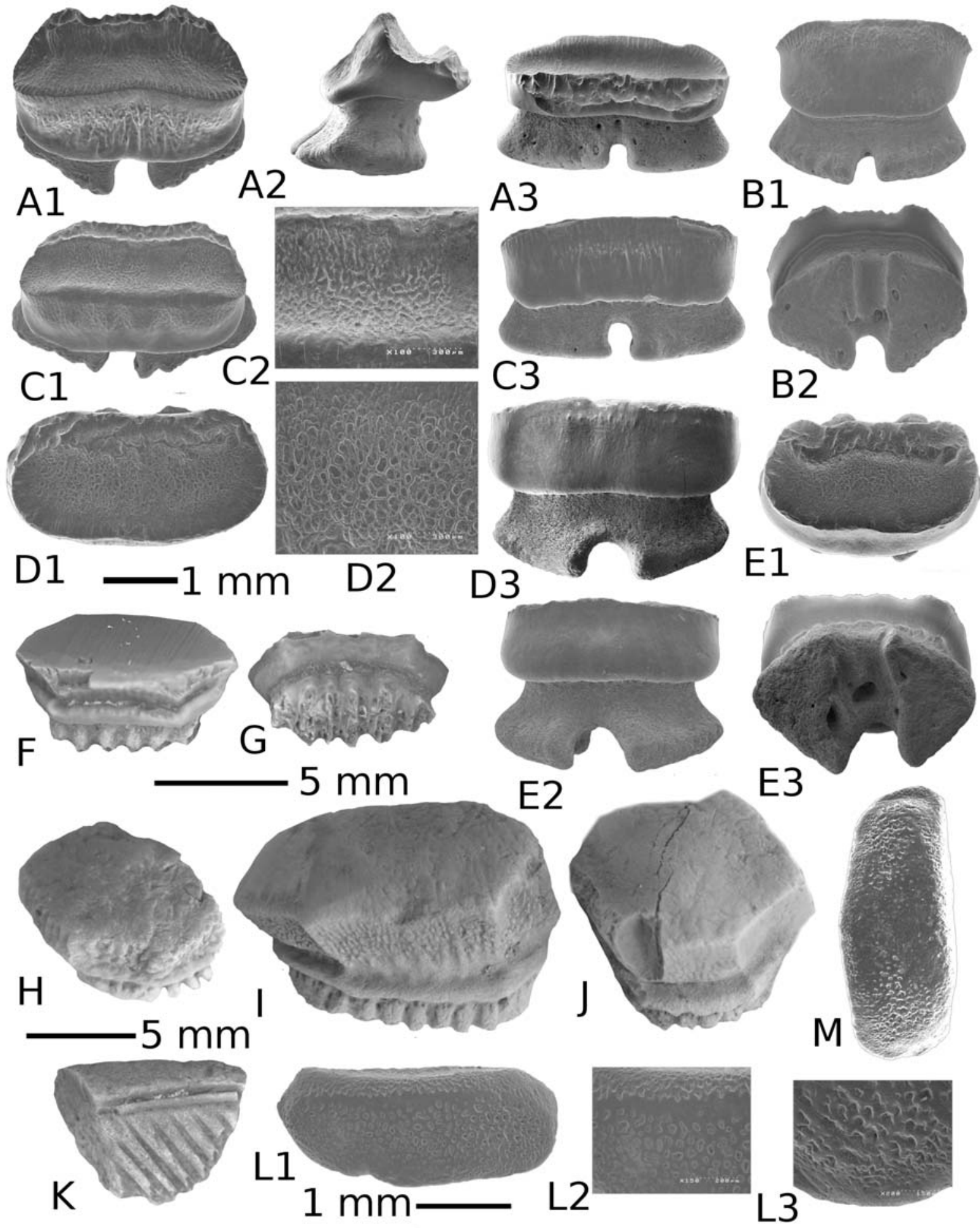

FIGURE 13. A-E. Coupatezia cristata nov. sp. A. antero-lateral tooth KEB 1-205, HOLOTYPE, A1.occlusal view, A2. Profile, A3. Labial view; B. Anterior tooth KEB 1-206, B1. Lingual view, B2. Basal view, C. lateral tooth KEB 1-207, C1. Occlusal view, C2. Magnificence of C1, C3. Lingual view; D. lateral tooth KEB 1-208, D1. Occlusal view, D2. Magnificence of D1, D3. Lingual view; E. lateral tooth KEB 1-209, E1. Occlusal view, E2., lingual view, E3. Basal view. F-G. Rhinoptera sp. F. medium tooth KEB 1-210, lingual view, G. medium tooth KEB 1-211, labial view; H-J. Myliobatis sp., $\mathrm{H}$. lateral tooth KEB 1-212, lingual view, I. medio-lateral tooth KEB 1-213, lingual view, J lateral tooth KEB 1-214, lingual view; K. Aetobatus sp. KEB 1-215, ligual view, L-M. Garabatis sp., L. KEB 1-216, occlusal view, M. KEB 1-217, L1. occlusal view, L2. Magnificence of central part, L3. Magnificence of marginal part of crown. 
line of the crown is elliptical (Figure 13C1, D1) or kidney-shaped (Figure 13A1, E1), with a labial concavity, more or less developed according to the file considered. The labial face of the crown is deeply concave, highlighted by a strong concavity in profile, as observable in the holotype (Figure 13A2). Lingually, this concavity is limited by a rather transverse keel, which reaches labially the irregular crests (Figure 13A1, E1). In the front of these labial crests, there is a narrow area all along the limit of the labial visor. The surface of this narrow area is strongly rugose with numerous transversal and vertical ridges that mark the upper part of the labial visor (Figure 13A1, C3). The surface of the labial face is covered by a fine but well-marked alveolar ornamentation of enameloid (Figure 13C2, D2); its lingual border, near the transverse keel, is sometimes highlighted by a series of regular short wrinkles (Figure 13A1). The lingual face is slightly concave and the enameloid is quite smooth (Figure 13E2) to well-ornamented (Figure 13A1). In lingual view, the margin of the crown is straight. The chopped labial visor clearly overhangs the root. The root is as high as the crown (Figure 13A2). Its labial profile is vertical when its lingual profile is oblique and slightly concave. The basal face is flat and the lobes are separated by a wide and deep furrow where foramina irregularly distributed open (Figure 13B2). The most lateral teeth are transversely elongated. The magnitude of enameloid ornamentation seems scalable on the material, particularly on the lingual face of the crown, which is smooth (Figure 13E2) to widely ornamented (Figure 13A1). Although it is unverified, this variability seems uncorrelated with tooth position or size, and thus, it could be related to a sexual heterodonty.

\section{Remarks}

Contrary to the Maastrichtian-Ypresian time window during which more than a dozen of species of Coupatezia occurred (e.g., Cappetta, 1983; Noubhani and Cappetta, 1997; Case and Cappetta, 1997), all of the Middle-Late Eocene reports of the genus have been attributed to the Belgian type species Coupatezia woutersi Cappetta, 1982, to the deepsea Coupatezia miretrainensis Adnet, 2006 , or more frequently to unnamed species. Cappetta and Case (2016) recently suggested that most of those attributed to $C$. woutersi and recovered in coastal deposits of Tropical realm during the Middle-Late Eocene (see Cappetta, 2012) document probably to other species. For instance, Case et al. (1996) have reported the occurrence of
C. woutersi in the Middle Eocene of Uzbekistan. The figured teeth seem closer to the Lutetian Coupatezia sp. from Lisbon Fm., Alabama, USA (Cappetta and Case, 2016, Ebersole et al., 2019), or those from the Lutetian of Aznag, Morocco (Tabuce et al., 2005) than to typical C. woutersi, mainly because the occlusal ornamentation of the crown is weak. Compared to typical teeth of $C$. woutersi from the Lutetian of Belgium (see Cappetta, 1982) and all the pre-Lutetian species, the teeth of the new species show clear differences as: an irregular and chopped labial visor coupled with a finer ornamented enameloid of the labial and lingual faces of the crown, and possibly a peculiar absence of sexual heterodonty (unverified). This new species is also distinct from $C$. miretrainensis Adnet, 2006, recovered in deep sea deposits of the Middle Eocene (Adnet, 2006, 2008a; Carslen and Cuny, 2014) in having no granular enameloid ornamentation.

Murray et al. (2010) also reported the occurrence of $C$. woutersi in the Priabonian freshwater deposits of the Fayum, Egypt (BQ-2). These authors, however, remarked that the seven specimens from BQ-2 do not present sexual heterodonty, and would then be identified as lateral positioned teeth of female Coupatezia. Considering the peculiar irregular labial visor (Murray et al., 2010 , figure $2 B$ ), the material from $B Q-2$ is quite similar to those of $C$. cristata nov. sp. However, the labial face of BQ-2 specimens (as those from KM in Adnet et al., 2011, and from QS in Underwood et al., 2011, figure 7D-E) is without any ornamentation. It makes sense to remain prudent about the attribution of the Priabonian specimens from Egypt to Coupatezia cristata nov. sp., even if we can nevertheless support affinities with the Bartonian KEB1 species. In addition, the Middle Eocene material attributed to Coupatezia sp. from EG (Strougo et al., 2007, plate 3, figures 3-4) could be now attributed to $C$. cristata nov. sp. without any doubt (pers. observ. SA, HC).

Specimens repositories. Holotype and Paratypes are deposited in the paleontological collections of the museum of the "Office National des Mines" of Tunis, 24 rue 8601, 2035 La Charguia, 1080 Tunis, Tunisia

Temporal range. Uppermost Lutetian-lowermost Bartonian (Egypt) to Middle Bartonian (Tunisia).

MYLIOBATIDAE Bonaparte, 1835 and RHINOPTERIDAE Jordan and Evermann, 1896 Figure $13 \mathrm{~F}-\mathrm{K}$

Many fragmentary myliobatid and rhinopterid teeth were collected in KEB-1 deposits. Often 
reduced to broken elongated teeth or hexagonal lateral teeth that constitute the usual tooth plate of these cruching taxa with pavement-like teeth, they mainly belong to the genera "Myliobatis" (abundant, large size; Figure 13H-J) Rhinoptera (abundant, small to medium size; Figure $13 \mathrm{~F}-\mathrm{G}$ ) and "Aetobatus" (extremely rare but distinguishable by its lingually extended root; Figure 13K). Accurate species identification is hard from isolated teeth, especially when they are damaged. Hovestadt and Hovestadt-Euler (2013) largely refigured numerous fossils myliobatids and some rhinopterids, including those usually recorded during the Paleogene. The main result of such a comprehensive comparative study is that the absence of complete or partial pavement-like jaw does not allow for a confident determination, explaining why we left them in open nomenclature.

\section{Genus GARABATIS Cappetta 1993}

Type species. Garabatis atlasi Cappetta 1993

\section{Garabatis sp.}

Figure 13L-M

2016 Garabatis sp; Merzeraud et al., p. 14-15, tab. 1. Material. Five small median teeth, partially abraded, from the KEB-1 locality, Souar-Fortuna sormations, Djebel el Kébar, Tunisia, including the two figured specimens KEB 1-216, -217 (Figure 13L-M)

\section{Description}

The small median teeth (no more than $5 \mathrm{~mm}$ long) show a myliobatid design with elongated crown of peculiar sigmoid outline in occlusal view, higher than the root of variable thickness in lingual view. The occlusal face of crown is slightly convex labiolingually. When not or slighty abraded by functional wear, the crown is entirely covered by a pitted enameloid, with depressions of circular or elliptic outline small but deep, especially on the margins of the crown (Figure 13L3). Contrary to what Hovestadt and Hovestadt-Euler (2013) advocated, pitted enameloid in Garabatis is not caused by marine organisms before or post depositional diagenesis. Comparatively to the unique species Garabatis atlasi Cappetta, 1993, the occlusal face of crowns seems more convex with sometimes the presence of a median crest abraded by functional wear, as observable in such crushing teeth (Figure 13L).

\section{Remarks}

Contrary to the large contemporenaous myliobatid Leidybatis with tooth crown showing quite similar enamel ornamentation, there is no elongated medial teeth with transversaly convex prominence in our sample. Moreover, the lingual face of crown is always smooth in Garabatis, at the contrary to that is observable in Leidybatis. This monospecific genus is known since the Thanetian in North African areas with the Moroccan species Garabatis atlasi (Cappetta 1993), and was already recorded in the Middle Eocene of Morocco (Tabuce et al., 2005), Egypt (EG: Strougo et al., 2007) until the Priabonian (Lower QS) of the Fayum area (Underwood et al., 2011), and Southwestern Morocco (Adnet et al., 2010).

Family MOBULIDAE Gill, 1893 incertae sedis Genus AMAMRIABATIS nov. gen

zoobank.org/93815E11-B349-4343-80C0-74B09CED6E79

Type species. Amamriabatis heni nov. sp. Etymology. Refers to Amamria, the hamlet located on the southeastern foothill of Djebel el Kébar, near the KEB-1 fossil-bearing locality, in recognition to the hospitality of the inhabitants of this hamlet, and Greek "batis" for rays.

Temporal. Middle Bartonian (Tunisia) to possibly Late Eocene (Egypt).

Diagnosis. Mobulid-like taxon known only by isolated teeth. Dentition of supposed alternating rows with teeth weakly joined. The dentition comprises teeth more or less elongated with roughly hexagonal-shaped to teeth bearing a median keel expended lingually. The tooth crown is relatively low, slightly displaced lingually with a smooth labial visor, particularly pinched, and a lingual face that could be, at the contrary, strongly ornamented, with sinuous folds and grooves under the developed lingual keel. The occlusal face of the crown is strongly flat and smooth. The root is narrow compared to the crown, and bears irregular lobes with rounded bases, widely separated by deep furrows.

\section{Amamriabatis heni nov. sp.}

Figure 14A-G

\section{zoobank.org/F335D187-C316-4079-8904-FC516106743A}

?2011 aff. Burhnamia sp.; Underwood et al., p. 53-62, fig. 7B.

2016 Burhnamia sp.; Merzeraud et al., p. 14-15, tab. 1.

Etymology. In Honour to Mister Kamel Heni, citizen of Soug-Jedid, for his considerable help during the field seasons in the Djebel el Kébar area.

Type locality and stratum. KEB 1-219 (Figure 14B) from the KEB-1 locality, Souar-Fortuna formations in Djebel el Kébar, Tunisia.

Other material. Additional material, including figured KEB 1-218, 1-220 to 1-224 (Figure 14A, C-G), 


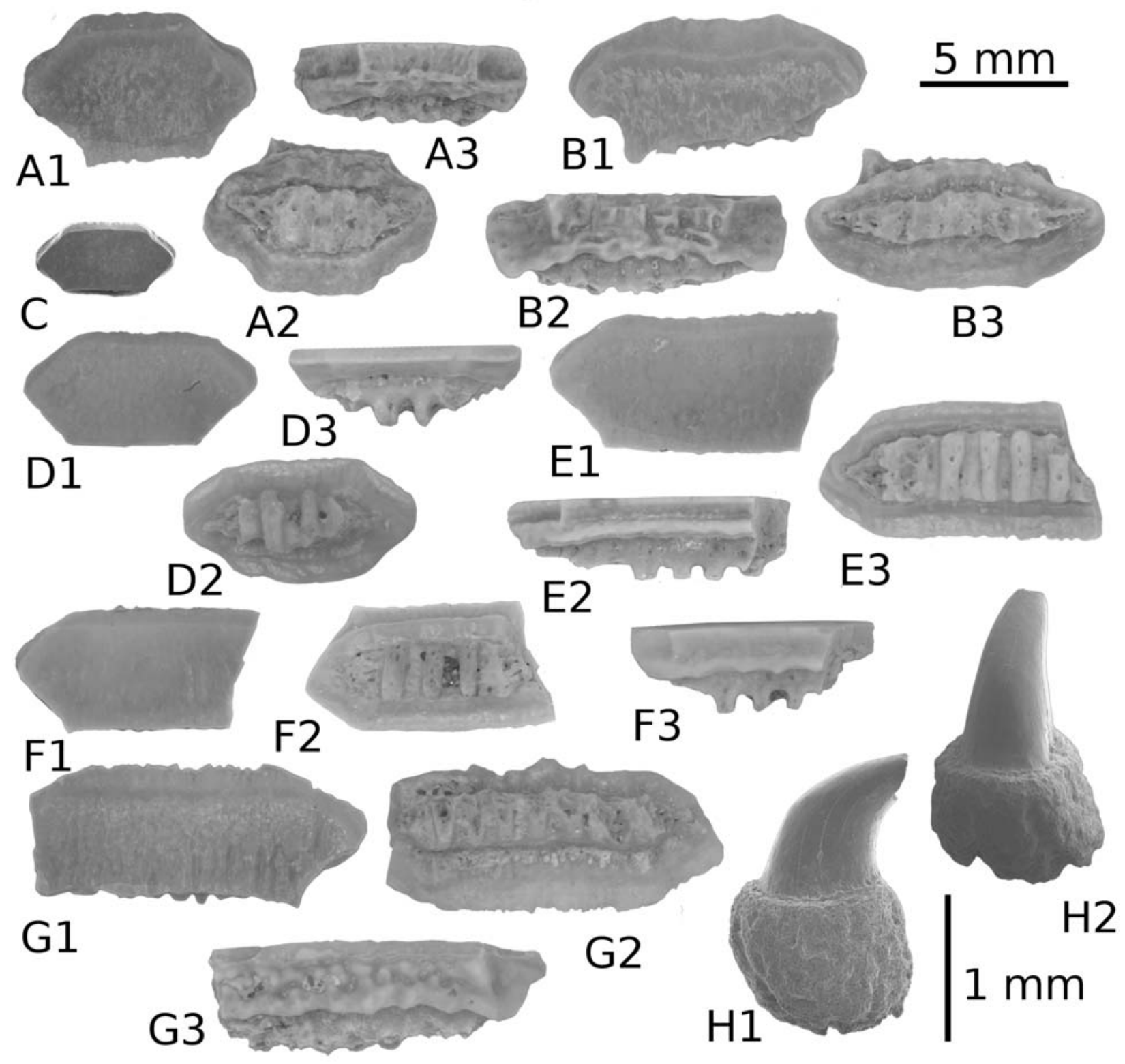

FIGURE 14. A-G. Amamriabatis heni nov gen. nov. sp. A. anterior tooth KEB 1-218, A1. Occlusal view, A2. Basal view, A3. Lingual view, B. antero-lateral tooth KEB 1-219 (Holotype), B1. Occlusal view, B2. Lingual view, B3. Basal view, C. juvenile tooth KEB 1-220, occlusal view, D. antero-lateral tooth KEB 1-221, D1. Occlusal view, D2. Basal view, D3. Labial view, E. lateral tooth KEB 1-222, E1. Occlusal view, E2. Lingual view, E3. Basal view, F. antero-lateral tooth KEB 1-223, F1. Occlusal view, F2. Basal view, F3. Labial view, G. lateral tooth KEB 1-224, G1. Occlusal view, G2. Basal view, G3. Lingual view; H. Archaeomanta sp. KEB 1-225, H1. Lateral view, H2. Labial view.

mainly consists of fifty teeth, most usually broken and particularly damaged, from the KEB-1 locality, Souar-Fortuna formations, Djebel el Kébar, Tunisia.

Diagnosis. As that as the monotypic new genus.

\section{Description}

Teeth are medium sized (no more than $1 \mathrm{~cm}$ long) with a sub-hexagonal shape in occlusal view, extremely fragile, and easily breakable. The dentition seems similar to that of rhinopterids and some stem mobulids with teeth regularly decreasing in width from the symphysis toward the lateral tooth files (Cappetta, 2012; Underwood et al., 2017). The roots are usually unpreserved, often rolled and broken. The holotype (Figure 14B) is most likely a tooth of the median tooth files, having a crown slightly wider than it is long. Its crown is relatively 
low, flattened and labiolingually extended with a possible surface wear, entirely flat and horizontal. The fine enameloid of the occlusal surface is almost smooth (Figure 14C1, B1, D1, E1) to finely wrinkled (Figure 14A1, F1). As observed in rhinopterid tooth plate, the labial visor and bulge are principally smooth and relatively sharp (Figure 14C3), except on some largest specimens (Figure 14F) where they can be irregular. However, and contrary to most of rhinopterids where the lingual face is regular and usually convex to fit the shape of the labial visor of incoming tooth row, the lingual face of Amamriabatis heni nov. gen. nov. sp. is narrower medially than laterally in lingual view (e.g., Figure 14B2, D2, F3). It is also noticeably ornamented with numerous, strong and sinuous folds and grooves, as observable in the holotype in lingual view (Figure 14B2). The deep ornamentation of this lingual face seems related to the moderate development of the transverse keel, which is oriented lingually as observable in some lateral teeth (Figure 14A3), median teeth (Figure 14B2), or anterior teeth (Figure 14F3). However, in some teeth (Figure 14D2, D3) with particularly low crowns, the lingual face lacks these folds of enameloid. The transverse keel is sometimes salient lingually as in the holotype (Figure 14B1), but it never extends toward the angular extremities of the crown, and it is often delimited by concave lateral borders, as particularly observed in the holotype (Figure 14B1). The lingual salient border of the transverse keel is most often straight to slightly sinuous in occlusal view (Figure 14B1, F1). The lower parts of the lingual and labial visors of the crown are relatively flat, horizontal, well developed, and form a continuous ring around the crown-root junction (Figure 14A2, B3, C2, D3, F2). The polyaulacorhize root is rather fine, never longer than the crown length, and seems as lower than the crown elevation. It is formed by an alternation of broad and deep furrows, "U" shaped in section, and with no more than eight lamina, asymmetrical in shape and size. There is often a visible foramen in the middle of some furrows (Figure 14A2, C2, F2).

\section{Remarks}

The tooth morphology of Amamriabatis nov. gen. is reminiscent to that of some basal mobulids, such as Burhnamia, Eoplinthicus, Oromobula and Argoubia (see Adnet et al., 2012; Underwood et al., 2017 for reviews). However, a suite of anatomical details allows for a clear distinction from the latter, which led us to propose this new genus. Contrary to the Middle Eocene Burhnamia, the occlusal face of the crown in Amamriabatis is flat and its enameloid is more smoothed. The transverse keel is more developed medio-lingually, and the labial visor is smooth and more regular where the lingual, labial and lateral faces of the crown in Burhnamia are somewhat concave and covered with fine, but well-developed granulations. Contrary to the Late Eocene Eoplinthicus, Plinthicus, Argoubia and Oromobula (and also the majority of the Recent Mobulidae with comb-like teeth), the crown of the teeth of Amamriabatis is lower, the transverse keel (when developed) is never dissected, and the labial visor is never deeply ornamented. With these characteristics, Amamriabatis displays an unusual dental pattern corresponding to a mosaic of characters observable in many rhinopterids (e.g., angular and smooth labial visor, flat occlusal surface of crown with sub-hexagonal outline) and many characters of stem mobulids (e.g., narrow root compared to crown, low number of irregular root lobes; presence of a transversal keel medially expensed on crown, irregular ornamentation of lingual face of crown limiting a strong interlocking of the tooth rows). The affinities with both families remain unclear, but considering that the majority of features are present in stem mobulids (like Burhnamia), we considered here that Amamriabatis nov. gen. belongs to the Mobulidae.

Another uncertainty concerns the monospecific genus Eomobula, which was originally described from a small tooth sample from the Lower Eocene of the Egem Fm. (Belgium), but was secondarily recorded by rare specimens in some Early-Middle Eocene localities (e.g., Kemp, 1994; Gheerbrant et al., 2003; Tabuce et al., 2005). Having very small teeth, this genus was attributed to a mobulid despite its teeth that show a very large occlusal face compared to the extremely reduced lingual and labial faces and a wide polyaulacorhize root as in myliobatids and rhinopterids. Herman et al. (1989), authors of Eomobula, themselves remarked that there was no real affinity in tooth morphology with other mobulids such as Burhnamia or Mobula, and suggested that this primitive mobulid probably represents an intermediate group between living representatives of the Myliobatidae and Mobulidae. Even if Enault et al. (2013) were not able to perform the enameloid histology of Eomobula to clarify its high-level taxonomical status among the Myliobatiformes, this genus is currently regarded as a peculiar Myliobatidae sensu stricto (Cappetta, 2006; Adnet et al., 2012; Hovestadt and Hovestadt-Euler, 2013), or possibly as a juvenile of an unknown myliobatid. 
Whatever the future valid status of this genus among the Myliobatidae, Amamriabatis nov. gen. is clearly distinct from Eomobula in having a low number of irregular root lobes, the presence of a transversal keel medially expended on the crown, and in displaying an irregular ornamentation of the lingual face of crowns, as observable in valid stem mobulids.

Underwood et al. (2011) reported in upper QS the presence of an unnamed genus that seems very similar in many respects to Burnhamia (Underwood et al., 2011, figure 7B as aff. Burhnamia sp.). Despite its surface wear, it differs in having a flat occlusal face showing some degree of wear, and could represent a secondarily macrophageous relative of Burnhamia. This preliminary comparison with other Burhnamia seems in accordance with the diagnosic features of the new KEB1 mobulid genus described here.

Specimens repositories. Holotype and Paratypes are deposited in the paleontological collections of the museum of the "Office National des Mines" of Tunis, 24 rue 8601, 2035 La Charguia, 1080 Tunis, Tunisia

Temporal range. Middle Bartonian (Tunisia) to possibly Late Eocene (Egypt).

Genus ARCHAEOMANTA Herman, 1979

Type species. Archaeomanta melenhorsti Herman, 1979

\section{Archaeomanta sp.}

Figure $14 \mathrm{H}$

2016 Archaeomanta sp.; Merzeraud et al., p. 14-15, tab. 1.

Material. Material consists of 11 fragmentary teeth, none with complete crown, from the KEB-1 locality, Souar-Fortuna formations, Djebel el Kébar, Tunisia, and includes the unique figured specimen KEB 1-225 (Figure 14H).

\section{Description}

Teeth of this genus are clearly distinctive in having a rather high crown, compressed mesio-distally with apex that bends strongly lingually. The cusp curves suddenly lingually at a certain distance from the ovoid base of the crown. Cusps do not bear the usual mediolabial cutting edge nor the mediolingual cutting edge on the apical region. The root is robust (Figure 14H1), globular with a basal face longer than broad, convex, with a heartshaped contour, and a narrow and shallow axial groove (sometimes with secondary labiolingually orientated grooves).

\section{Remarks}

This taxa is usually attributed to mobulids based on its peculiar tooth morphology reminding that of some Mobula with peg-like teeth, but the presence of a large pulp cavity extending to the tip of the cusp (Underwood et al., 2011) makes their supposed position within the mobulids very doubtful (see also Adnet et al., 2012). However, the enameloid of Archaeomanta (Enault et al., 2013) is very thin and closely resembles that of extant Mobulidae or fossil and extant Gymnuridae (e.g., Jacquhermania, Gymnura). Three species of Archaemanta are currently known in the fossil record. It concerns the Thanetian Archaeomanta priemi Herman and Crochard, 1979, the Ypresian Archaeomanta melenhorsti Herman and Crochard, 1979, and the Lutetian Archaeomanta hermani Kozlov, 2001. A morphological distinction between these chronospecies is evident, notably between the two firsts, known by numerous specimens. Indeed, teeth of $A$. melenhorsti have more mesiodistally compressed crowns with more elongated and distally oriented cusps and a deep, straight groove on roots compared with $A$. priemi that possesses a peculiar large collar at base of crowns (Herman and Crochard, 1979). In contrast, A. hermani shows an extreme long cusp strongly compressed mesiodistally compared with those observable in both older species. The morphology of the Bartonian KEB-1 specimens is clearly different from that of these three species in having more globular and robust roots (compared to $A$. melenhorsti and $A$. hermani), a tooth cusp without any median cutting edge (compared to $A$. melenhorsti, A. priemi, and ?A. hermani), and no marked collar (compared to A. priemi). However, the bad state of preservation of specimens does not allow to provide a detailed description of this unnamed species. Often rare in Paleogene deposits, this genus is nevertheless widely distributed in the MiddleLate Eocene of the peri-Tethysian realm (Cappetta, 2012), including in EG (Strougo et al., 2007), in the Priabonian of Egypt (upper GE to QS in Underwood et al., 2011), and in Southwestern Morocco (Adnet et al., 2010), even if the species status is always left in open nomenclature.

\section{CONCLUSIONS}

The fossil elasmobranchs from Tunisia have received little attention during the last century, except those from the Cretaceous deposits (e.g., Cuny et al., 2002, 2004, 2010). As the result, the Paleogene elasmobranch association has thus far 
only been documented from the Early Eocene phosphate layers of Metlaoui Fm. in the Gafsa basin, South Tunisia, at the beginning of the twentieth century (e.g., Sauvage 1889; Priem, 1903, 1907, 1909; synthetised by Arambourg, 1952). If Arambourg (1952) reported the presence of many Ypresian taxa that are similar to those recovered in the contemporaneous fossiliferous deposits of phosphate basins of Morocco (e.g., Arambourg, 1952; Noubhani and Cappetta, 1997), there are some intriguing data (e.g., presence of Cretolamna gafsana (White 1926)) indicating the occurence of an early Lutetian association in the Metlaoui Fm., a hypothesis recently confirmed with geochemical proxy and dated to 47.9 \pm 1.3 Ma according Kocsis et al. (2013). The elasmobranch assemblage reported here from the KEB-1 locality (Djebel el Kébar) then represents the unique Bartonian record of elasmobranchs from Tunisia. Remarkably, the occurence of $90 \%$ (30/33) of distinct elasmobranch taxa compared to those of the oldest deposits from Tunisia (Ypresian- Early Lutetian) demonstrates the existence of a well-marked elasmobranch turnover during the Middle Eocene in Tunisia. Recently, Sweydan et al. (2019) reported the presence of a reworked elasmobranch assemblage from Mebrouk in the Kasserine region of Tunisia. This assemblage, quite similar to those from KM, BQ (Sweydan et al., 2019) suggests an age ranging from the latest Priabonian up to the earliest Rupelian for the close marine deposits from where they were likely reworked. Despite major taxonomic differences with the KEB-1 association (e.g., presence of Galeocerdo eaglesomei, Abdounia, Negaprion, Carcharhinus perseus), the Mebrouk assemblage is also strongly dominated by Carcharhiniformes and Myliobatiformes with many common taxa recovered elsewhere along the western Tethys during the latest Bartonian-Priabonian time window, including those that first appeared at KEB-1 (e.g., Carcharhinus frequens, Misrichthys, Sphyrna, and Pastinachus). In that context, these two localities from central-West Tunisia testify a deep change in tropical shark communities during the Middle Eocene with postLutetian dominance of Carcharhiniformes compared to the early Paleogene where Lamniformes and Orectolobiformes were comparitively as well represented in Tunisia and Morocco for instance (Arambourg, 1952; Noubhani and Cappetta, 1997). This local trend also prefigures the worldwide decline of Lamniformes after the Paleogene in favour of the medium-large Carcharhiniformes (e.g., requiem and hammerhead sharks), which increased since the Eocene (Condamine et al., 2019).

More generally, our knowledge of the elasmobranch faunas documenting the tropical marine realm after the MECO event relied so far from the Late Eocene fossil records and some rare identified Bartonian localities found in Western Central Atlantic (Alabama, USA), Eastern Central Atlantic (Southwestern Morocco), and Southwestern Tethys (Western Desert and Wadi Al-Hitan, Egypt). This well-dated new KEB-1 elasmobranch assemblage from the Southwestern Tethys (North Tunisia) is therefore particularly critical for balancing the post MECO fossil record in tropical seas and for a better understanding of the paleobiogeography of elasmobranchs at that time.

In Egypt, Underwood et al. (2011) updated the elasmobranch fossil record from the Wadi Al-Hitan, Fayum area that was previously explored by numerous authors (Andrews, 1906; Dames, 1883, 1888; Leriche, 1922; Priem, 1897a-b, 1905, 1907, 1914; Stromer, 1903, 1905a-b; Case and Cappetta, 1990). Focusing on the numerous and historical Late Eocene series and samples (e.g., GE, BQ and QS), they reported the preliminary listing of 42 elasmobranch taxa from the Midawara Fm. (MI), a local formation that underlies south those of Late Eocene localities. The elasmobranch fauna from $\mathrm{MI}$ was also collected in a glauconitic sandstone that probably belongs to the lower part of the Midawara Fm., making the samples uppermost Lutetian and/or lowermost Bartonian in age (Underwood et al., 2011; King et al., 2014; Helal and Holcoval, 2017). The palaeoenvironment of MI is considered as representative of open but relatively shallow shelf (Underwood et al., 2011). Sharing a dozen taxa in common, KEB and $\mathrm{MI}$ recorded many typical Middle-Late Eocene genera (e.g., Moerigaleus, Misrichthys, Odontorhytis, Propristis, and Ouledia). Even if we cannot exclude that the distribution of taxa is most likely palaeoenvironmentally controlled, several other genera occurring in KEB surprisingly lack in shallow shelf of MI. It primarily concerns the benthic invertebrate feeders Stegostoma, Pastinachus, Pachygymnura, Arechia, Garabatis, Coupatezia, and Torpedo. Several presumably nectobenthic species are also different between MI and KEB (e.g., "Carcharhinus" frequens, Nebrius obliquus and possibly Carcharhinus kasserinensis nov. sp., Sphyrna guinoti nov. sp.) whereas some are encountered in younger levels of Wadi al-Hitan (GE, QS, and BQ). This taxonomic comparison with the unachieved listing of $\mathrm{MI}$ fauna (see also Figure 15) is in accordance with 


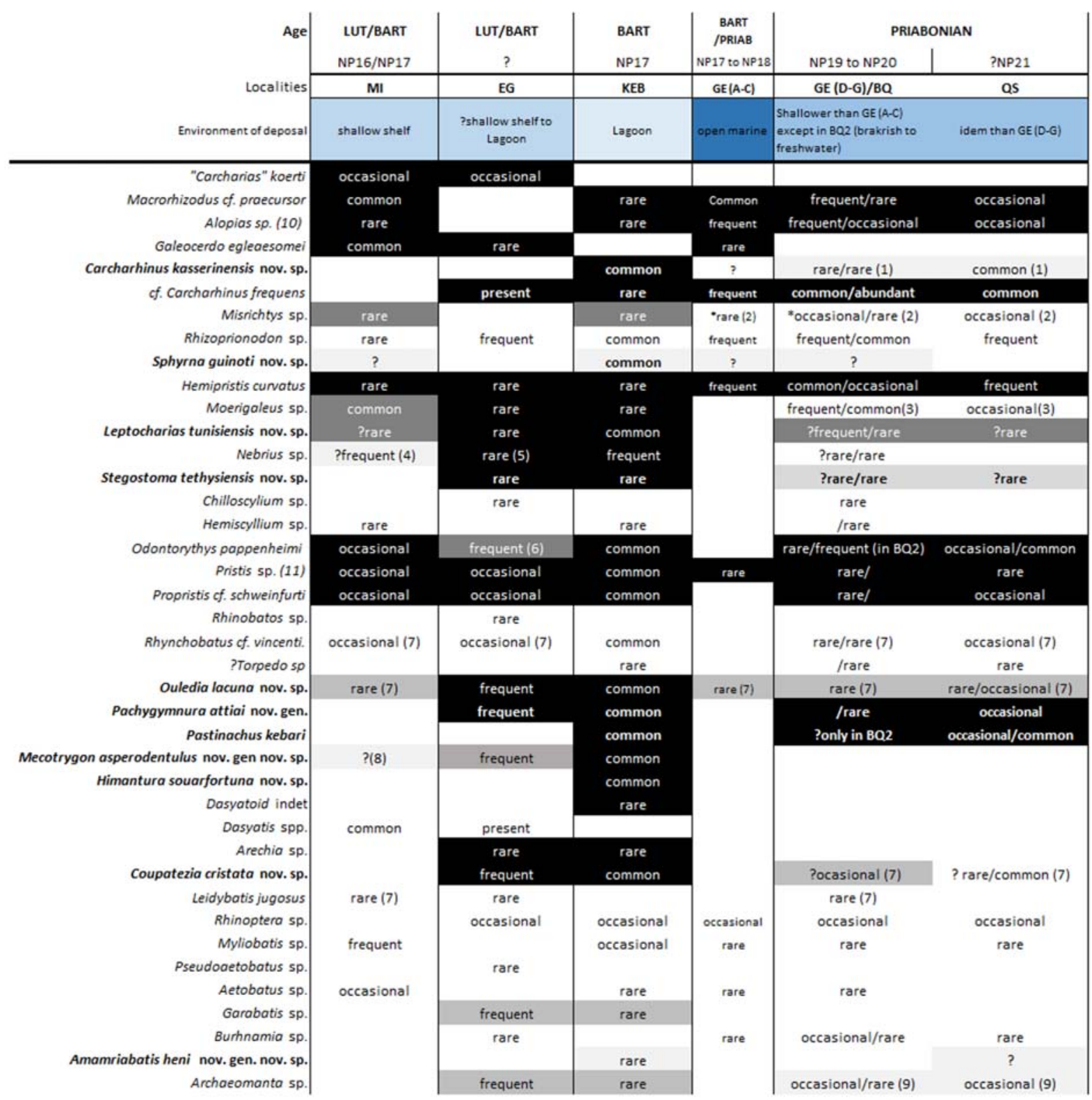

(1) large Carcharhinus with serrated teeth, (2) as M. stromeri, (3) as M. vitreodon, (4) as N. blankenhormi, (5) as N. obliquum, (6) refered to $O$. bahariensis, (7) unnnamed species, (8) as Taeniura sp., (9) two types in Fayum, (10) principally as A. alabamensis, (11) often as $P$. lathami

FIGURE 15. Distribution of Elasmobranch taxa within localities of KEB-1, Tunisia (KEB, this work) and El Gedida (EG), Baharia (Egypt, from Strougo et al., 2007 updated) with report of their occurences in the other late Middle Late Eocene tropical assemblages from Egypt (MI, GE, BQ, QS). Frequencies of taxa are somewhat subjective due to the different sources and/or sampling methods applied. Black-Grey intensity indicating the fossil completeness between KEB/EG and the other localities due to uncertainty/resolution of taxonomic attributions (See systematic palaeontology for detail, black: certain to light: possible). (1) Medium-Large Carcharhinus sp. with serrated teeth, (2) as Misrichtys stromeri, (3) as Moerigaleus vitreodon, (4) as Nebrius blankenhormi, (5) as Nebrius sp., (6) refered to Odontorhytis bahariensis, (7) unnnamed species, (8) possibly as Taeniura sp., (9) two types in Fayum. 
the age interpretation of Underwood et al. (2011) and supports that $\mathrm{MI}$ is somewhat older than KEB from the mid Bartonian. This also could indicate a renewal in elasmobranch fauna composition or the existence of a faunal migration eastward between times recorded in $\mathrm{MI}$ (Egypt) and KEB (Tunisa), and thus, during the early-mid Bartonian, with appearance of many taxa in Tunisia that became frequent in Egypt (e.g., "C". frequens, Pachygymnura, Pastinachus) during the Late Bartonian-Priabonian time window (e.g., GE, QS, BQ, KM).

In the West of the Fayum area, Egypt, Strougo et al. (2007) reported a preliminary listing including 25 elasmobranch taxa from glauconitic sandstones belonging to the ElHamra "group of Formations" of ElGedida mine (EG), near the Bahariya oasis, Libyan Desert, Egypt. The site is faulted and sedimentary deposits are often secondarily remineralised, and as such it has proven to be difficult to relate it to the surrounding stratigraphy. Imprecisely located stratigraphically among the ElHamra "group of Formations", the glauconitic horizon overlies the exploited iron of the Qazzum Fm. (Ypresian) and should be considered as "equivalent or younger" with that of the Sath ElHadid Fm. of the Fayum (for a discussion, see Strougo et al., 2007). The Sath ElHadid Fm. is considered as overlying the Midawara Fm. of Fayum (see also Abu Elgarh, 2012; King et al., 2014; Tawfik et al., 2016; Helal and Holcoval, 2017) and thus, be dated in fact to the early/mid Bartonian. However, Strougo et al. (2007) preliminary proposed a Lutetian age from available fossil assemblages at that time, arguing that the stratigraphical correlation of the glauconitic horizon with the Fayum formations remains unclear, and that the elasmobranch and bivalve assemblages show strong affinities with Lutetian faunas known from elsewhere (e.g., "Carcharias" koerti, Galeocerdo eaglesomei). After a re-examination of the material, including the new sampling during our 2009 field trip (pers. observ. SA, HC), it appears that several taxa occurring in KEB and $E G$ are seemingly close or conspecific (see systematics palaeontology and Figure 15). It particularly concerns the presence of taxa Leptocharias tunisiensis nov. sp., Stegostoma tethysiensis nov. sp., Ouledia lacuna nov. sp., Pachygymnura attiai, Coupatezia cristida, Mecotrygon asperodentulus nov. gen. nov. sp., in both localities. As previously stated by Underwood et al. (2011), we confirm that the EG fauna (Figure 15) is of similar age to MI and/or KEB with some taxonomic differences that could be indicative of paleoenvironmental differences. Nevertheless, we supect that EG could be somewhat intermediate in age between those of $\mathrm{MI}$ from the uppermost Lutetian and/or lowermost Bartonian (e.g., characterized by the absence of Pastinachus, large Carcharhinus, presence of " $C$ ". koerti, G. eaglesomei, Leidybatis) or those of KEB from the mid Bartonian (characterized by the presence of " $C$ " frequens, Pachygymnura, and $M$. asperodentatus nov. gen. nov. sp.). This new age range for EG (uppermost Lutetian to mid Bartonian) is in agreement with the former attribution of EG to the Sath ElHadid Fm. that is currently dated to the early-mid Bartonian.

Further East, Zouhri et al. (2017, in press) reported the fossil material from the Aridal Fm., Geran depression, southwestern Morocco, dating from the Bartonian (Gingerich and Zouhri, 2015). Including about 10 elasmobranch taxa preferentially encountered in open-shallow marine environments (Zouhri et al., in press), no precise comparison with the Tunisian KEB-1 fauna is possible due to the collection method consisting of picking the largest teeth in the vicinity of whale skeletons (Zouhri et al., 2017). For instance, and considering only sharks, the association mainly concerns the large ubiquitous pelagic predators that frequented the Middle Eocene seas (e.g., Otodus (Carcharocles), "Carcharias" koerti, Tethylamna cf. twiggsensis, Galeocerdo cf. eaglesomei), limiting the comparison with KEB that record none of the latter.

Comparison is more relevant with the Bartonian faunas recently synthetized by Ebersole et al. (2019) from the Upper Lisbon Fm. (NP16/NP17) and Gosport Sand (NP17) from the Claiborne Group in Alabama, USA. The faunal association of KEB-1 is clearly singular in having few large lamniforms fossil remains compared to the contemporenaous localities of Alabama that yielded numerous taxa (e.g., Odontaspis, Striatolamia, Otodus, Jaekelotodus, Hypotodus, Brachycarcharias, Tethylamna, Anomotodon). Bartonian carcharhiniforms and batoids of Alabama are more attractive because they are comprised of numerous taxa that were ubiquiteous in Atlantic and Tethys deposits during the warm Early-Middle Eocene (e.g., Abdounia, Negaprion, Galeorhinus, Galeocerdo, Physogaleus, Rhizoprionodon, Pristis, Myliobatis, Rhinoptera), plus some rare "unusual" taxa recorded in the Atlantic during the Middle Eocene (e.g., Hemipristis, requiem shark Carcharhinus mancinae, Propristis, Orectolobus, Tethylamna). However, only 10 genera and three species (Macrorhizodus praecursor, Hemipristis curvatus, and Propristis schweifurthi) are actually similar 
between the sub-contemporenaous localities of Alabama, USA, and that of Tunisia.

Finally, the faunal association of KEB (and to a lesser extent of EG and $\mathrm{MI}$ ) is particularly singular by of the presence of numerous "modern" tropical taxa, compared to those that frequented the tropical seas before the MECO event. For instance, it concerns the presence of the modern requiem shark of the genus Carcharhinus with enlarged serrated teeth (Carcharhinus kasserinensis nov. sp.) that prefigure, with the eastern coeval species Carcharhinus mancinae, the tooth design of numerous Neogene and living species, or carcharhinids with effiled teeth ("C". frequens, Misrichthys) that rapidly rise in southwestern Tethys during the Late Eocene. It also concerns the occurrences of Leptocharias, Sphyrna, Hemipristis, Stegostoma, Himantura, neotrygonins, and hypolophins that compose the modern fauna of tropical realm from the Late Eocene in western Tethys and until now in the Indo-Pacific area. As for the hypolophinins (Adnet et al., 2019) and urogymnins (Marrama et al., 2018), the spatial and temporal dynamics of most of the other tropical families or subfamilies recovered in KEB (e.g., hemigaleids, leptochariids, stegostomatids, neotrygonins, and ?urotygonids) appear to be also consistent with the 'hopping-hotspots' model hypothesized by Renema et al. (2008), who evidenced that the location of the main marine centre of palaeobiodiversity has moved across the globe during the last 50 million years, triggered by plate tectonics from the Tethys during the Eocene to the Indo-Australian Archipelago during the Miocene, before leaving a single hotspot in the Indo-Australian Archipelago in the present days (Renema et al., 2008; Leprieur et al.,
2016). We can also add that this moving seems toward the tropical western Atlantic, too, with the post-Eocene widespread of leptocharids from the Tethys to the Atlantic for instance. In fact, this suggests that the modern hotspots acted as regions of accumulation and survival from the Paleogene (including iterative warming events), before acting as centres of expansion and export from the recent time onward.

\section{ACKNOWLEDGEMENTS}

The authors are very grateful to Anusha Ramdarshan and Anthony Ravel, and Faouzi M'Nasri (ONM, Tunis) for their assistance during some of the field seasons in the Sidi-Bouzid region in Tunisia. We are indebted to the inhabitants of the Amamria hamlet (near Soug-Jedid village; Sidi Bouzid Township) for their hospitality and technical help during the fieldwork. We thank Etienne Steurbaut (Royal Belgian Institute of Natural Sciences, Leuven) for his examination of the sediment of the KEB-1 locality in search of nannoplancton. Many thanks to Johan Yans (University of Namur, NaGRIDD, Namur) for the K-Ar dating performed on glauconite grains from the glauconitic clays of the KEB-1 locality. We also want to thank Jürgen Kriwet and two anonymous reviewers for their constructive comments on earlier versions of the manuscript. This research was supported by the French ANR-ERC PALASIAFRICA Program (ANR08-JCJC-0017), a grant from the "Conseil Scientifique" (CS) of the "Université de Montpellier" (UM), and by the ONM of Tunis (AC-1785, 1234, 295 \& 1049).

\section{REFERENCES}

Abu El-Ghar, M.S. 2012. Sequence stratigraphy and cyclicity in the middle Eocene of the Fayoum range, Western Desert, Egypt: implications for regional sea level changes. Marine and Petroleum Geology, 29:276-292. https://doi.org/10.1016/j.marpetgeo.2011.01.008

Adnet, S. 2006. Nouvelles faunes de Sélaciens (Elasmobranchii, Neoselachii) de l'Eocène moyen des Landes (Sud-Ouest, France). Implication dans la connaissance des communautés de sélaciens d'eaux profondes. Palaeo Ichthyologica, 10:5-128.

Adnet, S., Antoine, P.-O., Hassan Baqri, S.R., Crochet, J.-Y., Marivaux, L., Welcomme, J.-L., and Métais, G. 2007. New tropical carcharhinids (Chondrichthyes, Carcharhiniformes) from the late Eocene-early Oligocene of Balochistan, Pakistan: paleoenvironmental and paleogeographic implications. Journal of Asian Earth Sciences, 30:303-323. https://doi.org/ 10.1016/j.jseaes.2006.10.002 
Adnet, S., Cappetta, H., and Reynders, J. 2008a. Contribution of Eocene sharks and rays from southern France to the history of deep-sea selachians. Acta Geologica Polonica, 58:257260.

Adnet, S., Cappetta, H., Beard, K.C., Marivaux, L., Marandat, B., Chaimanee, Y., Jaeger, J.-J., Tun, S.T., and Soe, A.N. 2008b. First myliobatiform teeth (Elasmobranchii, Neoselachii) from the Pondaung Formation (late middle Eocene) of Central Myanmar. Neues Jahrbuch für Geologie und Paläontologie - Abhandlungen, 247:335-340. https://doi.org/10.1127/00777749/2008/0247-0335

Adnet, S., Cappetta, H., and Tabuce, R. 2010. A Middle-Late Eocene vertebrate fauna (marine fish and mammals) from southwestern Morocco; preliminary report: age and palaeobiogeographical implications. Geological Magazine, 147:860-870. https://doi.org/ 10.1017/S0016756810000348

Adnet, S., Cappetta, H., Elnahas, S., and Strougo, A. 2011. A new Priabonian Chondrichthyans assemblage from the Western desert, Egypt: Correlation with the Fayum oasis. Journal of African Earth Sciences, 61:27-37. https://doi.org/10.1016/j.jafrearsci.2011.04.005

Adnet, S., Cappetta, H., Guinot, G., and Notarbartolo Di Sciara, G. 2012. Evolutionary history of the devilrays (Chondrichthyes: Myliobatiformes) from fossil and morphological inference. Zoological Journal of the Linnean Society, 166:132-159. https://doi.org/10.1111/j.10963642.2012.00844.x

Adnet, S., Mouana, M., Charruault, A.-L., Essid, E.M., Ammar, H.K., Marzougui, W., Merzeraud, G., Tabuce, R., Vianey-Liaud, M., and Marivaux, L. 2019. Teeth, fossil record and evolutionary history of the cowtail stingray Pastinachus Rüppell, 1829. Historical Biology, 31:1213-1222. https://doi.org/10.1080/08912963.2018.1431779

Agassiz, L. 1843. Recherches sur les Poissons fossiles. Atlas Neuchâtel, Switzerland 3, viii + $390+32$

Andrews, C.W. 1906. A Descriptive Catalogue of the Tertiary Vertebrata of the Fayûm, Egypt. Based on the Collection of the Egyptian government in the Geological museum, Cairo, and on the Collection in the British Museum (Natural History), London. F.R.S. Printed by order of the Trustees of the British Museum, London. https://doi.org/10.5962/bhl.title.55134

Applegate, S.P. 1972. A revision of the higher taxa of Orectoloboids. Journal of the Marine Biological Association of India, 14:743-751.

Arambourg, C., 1952. Les vertébrés fossiles des gisements de phosphates (Maroc-AlgérieTunisie). Notes et Mémoires du Service Géologique du Maroc, 92:1-372.

Averianov, A.O. and Udovinchenko, N. 1993. Age of vertebrates from the Andarak Locality (Southern Fergana). Stratigraphy and Geological Correlation, 1:139-141.

Beaufort, L.F., de 1926. On a collection of marine fishes from the Miocene of South Celebes. Jaarboek van het Mijnwezen in Nederlandsch Oost-Indië, 1:117-148.

Benoit, J., Adnet, S., El Mabrouk, E., Khayati, H., Ben Haj Ali, M., Marivaux, L., Merzeraud, G., Merigeaud, S., Vianey-Liaud, M., and Tabuce, R. 2013. Cranial remain from Tunisia provides new clues for the origin and evolution of Sirenia (Mammalia, Afrotheria) in Africa. Plos One, 8:e54307. https://doi.org/10.1371/journal.pone.0054307

Berg, L.S. 1958. System der Rezenten und Fossilen Fischartigen und Fische. Hochschulbücher für Biologie, Deutscher Verlag Wissenchaft, Berlin.

Bijl, P.K., Houben, A.J.P., Schouten, S., Bohaty, S.M., Sluijs, A., Reichart, G., Damsté, J.S.D., and Brinkhuis, H. 2010. Transient middle Eocene atmospheric CO2 and temperature variations. Science, 330:819-821. https://doi.org/10.1126/science.1193654

de Blainville, H.M. 1816. Prodrome d'une nouvelle distribution systématique du règne animal. Bulletin de la Société philomatique de Paris, 8:105-124.

Bloch, M.E. and Schneider, J.G. 1801. Blochii Systema Ichthyologiae iconibus ex illustratum. Post obitum auctoris opus inchoatum absolvit, correxit, interpolavit. J.G. Schneider, Saxo. https://doi.org/10.5962/bhl.title.5750

Bohaty, S.M. and Zachos J.C. 2003. Significant Southern Ocean warming event in the late middle Eocene. Geology, 31:1017-1020. https://doi.org/10.1130/G19800.1

Bohaty, S.M., Zachos, J.C. Florindo, F., and Delaney, M.L. 2009. Coupled greenhouse warming and deep-sea acidification in the middle Eocene. Paleoceanography, 24:PA2207. https:// doi.org/10.1029/2008PA001676

Böhm, J. 1926. Über tertiäre Versteinerungen von den Bogenfelser Diamantfeldern. Die Diamantenwüste Südwestafrikas, Bulletin, 2:55-87 
Bonaparte, C.L. 1832. Iconografia della fauna italica per le quattro classi degli animali vertebrati. Tomo III. Pesci. Roma, 1:1-6. https://doi.org/10.5962/bhl.title.70395

Bonaparte, C.L. 1835. Iconografia della fauna italica per le quattro classi degli animali vertebrati. Tomo III. Pesci. Roma, 12-14:59-79.

Bonaparte, C.L. 1838. Iconografia della fauna italica per le quattro classi degli animali vertebrati. Tomo III. Pesci. Roma, 24-26:121-135.

Bonnaterre, J.P. 1788. Tableau encyclopédique et méthodique des trois règnes de la Nature. Ichthyologie. Tableau encyclopédique et méthodique des trois règnes de la nature. Ichthyologie, Paris.

Boscolo Galazo, F.B., Giusberti, L., Luciani, V., and Thomas, E. 2013. Paleoenvironmental changes during the Middle Eocene Climatic Optimum (MECO) and its aftermath: The benthic foraminiferal record from the Alano section (NE Italy). Palaeogeography, Palaeoclimatology, Palaeoecology, 378:22-35. https://doi.org/10.1016/j.palaeo.2013.03.018

Briggs, J.C. 1995. Global Biogeography. Elsevier, Amsterdam. https://doi.org/10.1016/s09205446(06)x8049-4

Cappetta, H. 1970. Les Sélaciens du Miocène de la région de Montpellier. Palaeovertebrata, Mémoire Extraordinaire 1970:1-139. https://doi.org/10.18563/pv.3.ext.1-139

Cappetta, H. 1982. Révision de Cestracion duponti Winkler, 1874 (Selachii, Batomorphii) du Bruxellien de Woluwe-Saint-Lambert (Eocène moyen de Belgique). Mededelingen van de Werkgroep voor Tertiaire en Kwartaire Geologie, 19:113-125.

Cappetta, H. 1983. Additions à la faune de sélaciens fossiles du Maroc. 2: Révision de Raja praealba Arambourg, 1952, espèce de l'Yprésien des Ouled Abdoun. Tertiary Research, 5:18.

Cappetta, H. 1986. Myliobatidae nouveaux (Neoselachii, Batomorphii) de I'Yprésien des Ouled Abdoun, Maroc. Geologica et Paleontologica, 20:185-207.

Cappetta, H. 1988. Les Torpediniformes (Neoselachii, Batomorphii) des Phosphates du Maroc. Observations sur la denture des genres Actuels. Tertiary Research, 10:21-52.

Cappetta, H. 1993. Sélaciens nouveaux (Chondrichthyes, Neoselachii) du Paléocène supérieur de la région d'Ouarzazate, Maroc. Paläontologishe Zeitshrift, 67:109-122.

Cappetta, H. 2006. Elasmobranchii Post-Triadici (Index specierum et generum), Fossilium Catalogus I: Animalia. Backhuys Publishers, Leiden.

Cappetta, H. 2012. Chondrichthyes: Mesozoic and Cenozoic Elasmobranchii: teeth. Handbook of Palaeoichthyology. Volume 3E. Schultze, H.-P (ed.), Verlag Dr. Friedrich Pfeil, München.

Cappetta, H. and Case, G.R. 2016. A selachian fauna from the Middle Eocene (Lutetian, Lisbon Formation) of Andalusia, Covington County, Alabama, USA. Palaeontographica Abteilung A, 307:43-103.

Cappetta, H. and Cavallo, O. 2006. Les selaciens du Pliocene de la région d'Alba (Piémont, Italie Nord-ouest). Estratto da "Rivista Piemontese di Storia Naturale", 27:33-76.

Cappetta, H. and Traverse, M. 1988. Une riche faune de sélaciens dans le bassin à phosphate de Kpogamé-Hahotoé (Eocène moyen du Togo): Note préliminaire et précisions sur la structure et l'âge du gisement. Geobios, 21:359-365. https://doi.org/10.1016/s00166995(88)80058-5

Carrillo-Briceño, J., Aguilera, O., De Gracia, C., Aguirre-Fernandez, G., Kindlimann, R., and Sánchez-Villagra, M. 2016. An early Neogene elasmobranch fauna from the southern Caribbean (Western Venezuela). Palaeontologia Electronica, 19.2.27A:1-32. https://doi.org/ $10.26879 / 664$

Carslen, A.W. and Cuny, G. 2014. A study of the sharks and rays from the Lillebælt Clay (EarlyMiddle Eocene) of Denmark, and their palaeoecology. Bulletin of the Geological Society of Denmark, 62:39-88.

Case, G.R. 1981. Late Eocene selachians from south-central Georgia. Palaeontographica Abteilung A, 176:52-79.

Case, G.R. 1994. Fossil fish remains from the Late Paleocene Tuscahoma and Early Eocene Bashi Formations of Meridian, Lauderdale County, Mississippi. Part I. Selachians. Palaeontographica Abteilung A, 230:97-138.

Case, G.R. and Borodin, P.D. 2000. A middle Eocene selachian fauna from the Castle Hayne Limestone Formation of Duplin County, North Carolina. Münchner Geowissenschassiche Abhandlungen, 39:17-34.

Case, G.R. and Cappetta, H. 1990. The Eocene selachians fauna from the fayum depression in Egypt. Palaeontographica Abteilung A, 212:1-30. 
Case, G.R. and Cappetta, H. 1997. A new selachian fauna from the Late Maastrichtian of Texas (Upper Cretaceous/Navarroan; Kemp Formation). Münchner Geowissenschaftliche abhandlungen reihe a geologie und paläentologie, 34:131-189.

Case, G.R. and West, R.M. 1991. Geology and paleontology of the Eocene Drazinda Shale Member of the Khirthar Formation, central Western Pakistan, Part II Late Eocene fishes. Tertiary Research,12:105-120.

Case, G.R., Udovichenko, N.I., Nessov, L.A., Averianov, A.O., and Borodin, P.D. 1996. A middle Eocene selachian fauna from the White Mountain formation of the Kizylkum desert, Uzbekistan, C.I.S. Palaeontographica Abteilung A, 242:99-126.

Casier, E. 1946. La faune ichthyologique de l'Yprésien de la Belgique. Mémoires du Musée royal d'Histoire naturelle de Belgique, 104:1-267.

Casier, E. 1971. Sur un matériel ichthyologique des "Midra (and Saila) Shales" du Qatar (Golfe Persique). Bulletin de l'Institut Royal des Sciences Naturelles de Belgique, 47(2):1-9.

Cicimurri, D.J. 2007. A partial rostrum of the sawfish Pristis lathami Galeotti, 1837, from the Eocene of South Carolina. Journal of Paleontology, 81:597-601. https://doi.org/10.1666/ 05086.1

Cicimurri, D.J. and Knight, J.L. 2009. Late Oligocene sharks and rays from the Chandler Bridge Formation, Dorchester County, South Carolina, USA. Acta Palaeontologica Polonica, 54:627-647. https://doi.org/10.4202/app.2008.0077

Cicimurri, D.J. and Knight, J.L. 2019. Late Eocene (Priabonian) elasmobranchs from the Dry Branch Formation (Barnwell Group) of Aiken County, South Carolina, USA. PaleoBios, 36:131.

Collareta, A., Lambert, O., Landini, W., Di Celma, C., Malinverno, E., Varas-Malca, R., Urbina, M., and Bianucci, G. 2017. Did the giant extinct shark Carcharocles megalodon target small prey? Bite marks on marine mammal remains from the late Miocene of Peru. Palaeogeography, Palaeoclimatology, Palaeoecology, 469:84-91. https://doi.org/10.1016/ j.palaeo.2017.01.001

Compagno, L.J.V. 1973. Interrelationships of living elasmobranchs. Zoological Journal of the Linnean Society, 53(Supplement 1):15-61.

Compagno, L.J.V. 1977. Phyletic relationships of living sharks and rays. American Zoologist, 17:303-322. https://doi.org/10.1093/icb/17.2.303

Compagno, L.J.V. 1988. Sharks of the Order Carcharhiniformes. Princeton University Press (Edt), Princeton, New Jersey.

Compagno, L.J.V. and Roberts, T.R. 1982. Freshwater stingrays (Dasyatidae) of Southeast Asia and New Guinea, with description of a new species of Himantura and reports of unidentified species. Environmental Biolology of Fishes, 7:321-339. https://doi.org/10.1007/bf00005567

Compagno, L.J.V. and Roberts, T.R. 1984. Marine and freshwater stingrays (Dasyatidae) of West Africa, with description of a new species. Proceedings of the California Academy of Sciences, 43:283-300.

Condamine, F.L., Romieu, J., and Guinot, G. 2019. Climate cooling and clade competition likely drove the decline of lamniform sharks. Proceedings of the National Academy of Sciences USA, 116:20584-20590. https://doi.org/10.1073/pnas.1902693116

Cope, E.D. 1869. Descriptions of some extinct fishes previously unknown. Proceedings of the Boston Society of Natural History, 12:310-317.

Coxall, H., Wilson, P., Pälike, H., Lear, C., and Backman, J. 2005. Rapid stepwise onset of Antarctic glaciation and deeper calcite compensation in the Pacific Ocean. Nature, 433:53-7. https://doi.org/10.1038/nature03135

Cramwinckel, M.J., Huber, M., Kocken, I.J., Agnini, C., Bijl, P.K., Bohaty, S.M., Frieling, J., Goldner, A., Hilgen, F.J., Kip, E.L., Peterse, F., van der Ploeg, R., Röhl, U., Schouten, S., and Sluijs, A. 2018. Synchronous tropical and polar temperature evolution in the Eocene. Nature, 559:382-386. https://doi.org/10.1038/s41586-018-0272-2

Cuny, G., Ouaja, M., Srarfi, D., Schmitz, L., Buffetaut, E., and Benton, M.J. 2004. Fossil sharks from the Early Cretaceous of Tunisia. Revue de Paleobiologie, 23:127-142.

Cuny, G., Buffetaut, E., Benton, M.J., and Srarfi, D. 2002. Les hybodontes (Chondrichthyens : Elasmobranchii) du Crétacé tunisien, p. 36-38. In ONF (ed.) Huitième journée de géologie tunisienne, résumés des communications et guide de l'excursion, Office National des Mines, Tunis. 
Cuny, G., Cobbett, A.M., Meunier, F.J., and Benton, M.J. 2010. Vertebrate microremains from the Early Cretaceous of southern Tunisia. Geobios, 43:615-628. https://doi.org/10.1016/ j.geobios.2010.07.001

Dames, V.W. 1883. Über eine tertiäre Wirbelthierfauna von der westlichen Insel des Birket-elQurun im Fajum (Aegypten). Sitzungsber der Bayerishe Akademie der Wissenschaften, 6:129-153.

Dames, W. 1888. Amblypristis cheops nov. gen. nov. sp. aus dem Eocän Aegyptens. Sitzungsberichte der Gesellschaft naturforschender Freunde zu Berlin, 106-108.

de Blainville, H.M. 1816. Prodrome d'une nouvelle distribution systématique du règne animal. Bulletin de la Société philomatique de Paris, 8:105-124.

de Buen, F. 1926. Catalogo ictiologico del Mediterraneo Español y de Marruecos, recopilando lo publicado sobrepeces de las costas mediterraneas y proximas del Atlantico (Mar de España). Resultados de las ampafias Realizadas por Acuerdos Internacionales. Instituto Español de Oceanografia, 2:1-221.

DeConto, R.M. and Pollard, D. 2003. Rapid Cenozoic glaciation of Antarctica induced by declining atmospheric $\mathrm{CO}_{2}$. Nature, 421:245-249. https://doi.org/10.1038/nature01290

Donovan, S.K. and Gunter, G.C. 2001. Fossil sharks from Jamaica. Bulletin of the Mizunami Fossil Museum, 28:211-215.

Duméril, A.M.C. 1806. Zoologie analytique, ou méthode naturelle de classification des animaux. Allais, Paris.

Ebersole, J.A., Ebersole, S.M., and Cicimurri, D.J. 2017. The occurrence of early Pleistocene marine fish remains from the Gulf Coast of Mobile County, Alabama, USA. Palaeodiversity, 10:97-115. https://doi.org/10.18476/pale.v10.a6

Ebersole, J.A., Cicimurri, D.J., and Stringer, G.L. 2019. Taxonomy and biostratigraphy of the elasmobranchs and bony fishes (Chondrichthyes and Osteichthyes) of the lower-to-middle Eocene (Ypresian to Bartonian) Claiborne Group in Alabama, USA, including an analysis of otoliths. European Journal of Taxonomy, 585:1-274. https://doi.org/10.5852/ejt.2019.585

Edgar, K.M., Wilson, P.A., Sexton, P.F., Gibbs, S.J., Roberts, A.P., and Norris, R.D. 2010. New biostratigraphic, magnetostratigraphic and isotopic insights into the Middle Eocene Climatic Optimum in low latitudes. Palaeogeography, Palaeoclimatology, Palaeoecology, 297:670682. https://doi.org/10.1016/j.palaeo.2010.09.016

Ehret, D.J., Hubbell G., and Macfadden B.J. 2009. Exceptional preservation of the white shark Carcharodon (Lamniformes, Lamnidae) from the early Pliocene of Peru. Journal of Vertebrate Paleontology, 29:1-13. https://doi.org/10.1671/039.029.0113

Ehret, D.J., Macfadden B.J., Devries, T., Foster, D., and Salas-Gismondi, R. 2012. Origin of the White Shark Carcharodon (Lamniformes: Lamnidae) based on recalibration of the Upper Neogene Pisco Formation of Peru. Palaeontology, 55:1139-1153

Enault, S., Cappetta, H., and Adnet, S. 2013. Simplification of the enameloid microstructure of large stingrays (Chondrichthyes: Myliobatiformes): a functional approach. Zoological Journal of the Linnean Society, 169:144-155. https://doi.org/10.1111/zoj.12059

Engelbrecht, A., Mörs, T., Reguero, M.A., and Kriwet, J. 2016. Revision of Eocene Antarctic carpet sharks (Elasmobranchii, Orectolobiformes) from Seymour Island, Antarctic Peninsula. Journal of Systematic Palaeontology, 15:969-990. https://doi.org/10.1080/ 14772019.2016.1266048

Föllmi, K.B. 1996 The phosphorous cycle, phosphogenesis and marine phosphate deposits. Earth Sciences Reviews, 40:55-124. https://doi.org/10.1016/0012-8252(95)00049-6

Forsskål, P. 1775. Descriptiones animalium, avium, amphibiorum, piscium, insectorum, vermium; quae in itinere orientali observavit Petrus Forskål. Post mortem auctoris edidit Carsten Niebuhr. Adjuncta est materia medica kahirina atque tabula maris Rubri geographica. Mölleri, Hauniae.

Fowler, H.W. 1934. Descriptions of new fishes obtained 1907 to 1910 , chiefly in the Philippine Islands and adjacent seas. Proceedings of the Academy of Natural Sciences of Philadelphia, 85:233-367.

Gallo V., Cavalcanti, M.J., Da Silva, R.F.L., Da Silva, H.M.A., and Pagnoncelli, D. 2010. Panbiogeographical analysis of the shark genus Rhizoprionodon (Chondrichtyes, Carcharhniformes, Carcharhinidae). Journal of Fish Biology, 76:1696-1713. https://doi.org/ 10.1111/j.1095-8649.2010.02609.x

Garman, S. 1913. The Plagiostomia (sharks, skates and rays). Memoirs of the Museum of Comparative Zoology, Harvard, 36:1-528. https://doi.org/10.5962/bhl.title.43732 
Garrick, J.A.F. 1985 Additions to a revision of the shark genus Carcharhinus: synonymy of Aprionodon and Hypoprion, and description of a new species of Carcharhinus (Carcharhinidae). NOAA Technical Report NMFS, 34:1-26.

Genault, B. 1993. Contribution à l'étude des elasmobranches oligocène du Bassin de Paris 2. Découverte de deux horizons à Elasmobranches dans le Stampien (Sables de Fontainebleau) de la feuille géologique de Chartres. Cossmanniana, 2:13-36.

Gheerbrant, E., Sudre, J., Cappetta, H., Mourer-Chauvire, C., Bourdon, E., Larochene, M. Amaghzaz, M., and Bouya, B. 2003. Les localités à mammifères des carrières de Grand Daoui, Bassin des Ouled Abdoun, Maroc, Yprésien: premier état des lieux. Bulletin de la Société Géologique de France, 174:279-293.

Gill, T. 1862. Analytical synopsis of the Order of Squali and revision of the nomenclature of the genera. Annals of the Lyceum of Natural History of New York, 7:367-408. https://doi.org/ 10.1111/j.1749-6632.1862.tb00166.x

Gill, T. 1872. Arrangement of the families of fishes, or classes Pisces, Marsupiobranchii, and Leptocardii. Smithsonian Miscellaneous Collections, 11:1-49. https://doi.org/10.5962/ bhl.title.18974

Gill, T. 1893. Families and subfamilies of fishes. Memoirs of the National Academy of Sciences, 6:125-138. https://doi.org/10.5962/bhl.part.6303

Gingerich, P.D. and Zouhri, S. 2015. New fauna of archaeocete whales (Mammalia, Cetacea) from the Bartonian middle Eocene of southern Morocco. Journal of African Earth Sciences, 111:273-286. https://doi.org/10.1016/j.jafrearsci.2015.08.006

Gingerich, P.D., Zalmout, I.S., Antar, M.S.M., Williams, E.M., Carlson, A.E., Kelly, D.C., and Peters, S.E. 2012. Large-scale glaciation and deglaciation of Antarctica during the late Eocene: forum reply. Geology, 40(3):e255. https://doi.org/10.1130/g33046y.1

Gmelin, J.F. 1789. Systema Naturae per regna tria naturae, secundum classes, ordines, genera, species; cum characteribus, differentiis, synonymis, locis p. 1033-1516. In Lipsiae, 1788-93. Caroli a Linné. Systema Naturae per regna tria naturae, secundum classes, ordines, genera, species. Editio decimo tertia, aucta, reformata.

Gray, J.E. 1851. List of the specimens of fish in the collection of the British Museum. Part I. Chondropterygii. British Museum (Natural History), London. https://doi.org/10.5962/ bhl.title.20819

Guinot, G., Adnet, S., Shimada, K., Shimada, K., Underwood, C.J., Siversson, M., Ward, D.J., Kriwet, J., and Cappetta, H. 2018. On the need of providing tooth morphology in descriptions of extant elasmobranch species. Zootaxa, 4461:118-126. https://doi.org/10.11646/ zootaxa.4461.1.8

Günther, A. 1870. Catalogue of the fishes in the British Museum. London, British Museum (Natural History), 8:1- 549. https://doi.org/10.5962/bhl.title.8329

Hasse, J.C.F. 1879. Das Natürliche System der Elasmobranchier auf Grundlage des Baues and der Entwicklung ihrer 1879-85 Wirbelsäule. Eine morphologische and paläntologische Studie. Gustav Fisher Verlag, Jena, besonderer Theil, 2:99-109. https://doi.org/10.5962/ bhl.title.8431

Helal, S. and Holcová, K. 2017. Response of foraminiferal assemblages on the middle Eocene climatic optimum and following climatic transition in the shallow tropical sea (the south Fayoum area, Egypt). Arabian Journal of Geosciences, 10:1-21. https://doi.org/10.1007/ s12517-016-2818-7.

Herman, J. 1977. Les sélaciens des terrains néocrétacés et paléocènes de Belgique et des contrées limitrophes. Eléments d'une biostratigraphique inter-contientale. Mémoire pour servir à l'explication des Cartes géologiques et minérales de Belgique, Séries Géologie, 15:1-401.

Herman, J. and Crochard, M. 1979. Additions to the Eocene fish fauna of Belgium 4. Archaeomanta, a new genus from the Belgian and North African Palaeogene. Tertiary Research, 2:61-67.

Herman, J., Hovestadt-Euler, M., and Hovestadt, D.C. 1989. Additions to the Eocene fish fauna of Belgium. 9. Discovery of Eomobula gen. et spec. nov. (Mobulidae, Chondrichthyes) from the Ypresian. Tertiary Research, 10:175-178. 
Herman, J., Hovestadt-Euler, M., and Hovestadt, D.C. 1991. Contributions to the study of the comparative morphology of teeth and other relevant ichthyodorulites in living supraspecific taxa of chondrichthyan fishes. Part A: Selachii. $\mathrm{N}^{\circ} 2 \mathrm{c}$. Order: Carcharhiniformes. Families : Proscylliidae, Hemigaleidae, Pseudotriakidae, Leptochariidae and Carcharhinidae. Bulletin de l'Institut Royal des Sciences Naturelles de Belgique, 61:73-120.

Herman, J., Hovestadt-Euler, M., and Hovestadt, D.C. 1992. Contributions to the study of the comparative morphology of teeth and other relevant ichthyodorulites in living supraspecific taxa of chondrichthyan fishes. Part A: Selachii. N4 . Order: Orectolobiformes. Families : Brachaeluridae, Ginglymostomatidae, Hemiscylliidae, Orectolobidae, Parascylliidae, Rhiniodontidae, Stegostomatidae. Order Pristiophoriformes-Family: Pristiophoridae. Order Squatiniformes-Family Squatinidae. Bulletin de I'Institut Royal des Sciences Naturelles de Belgique, 62:193-254.

Herman, J., Hovestadt-Euler, M., Hovestadt, D.C., and Stehmann, M. 1997. Contributions to the study of the comparative morphology of teeth and other relevant ichthyodorulites in living supraspecific taxa of chondrichthyan fishes. Part B: Batomorphii. $\mathrm{N}^{\circ} 2$. Order Rajiformes Suborder Pristoidei-Family: Pristidae -Genera: Anoxypristis and Pristis. N³: Suborder Rajoidei -Superfamily Rhinobatoidea -Families Rhinidae -Genera: Rhina and Rhynchobatus and Rhinobatidae -Genera: Aptychotrema, Platyrhina, Platyrhinoidis, Rhinobatos, Trigonorrhina, Zanobatus and Zapteryx. Bulletin de l'Institut Royal des Sciences Naturelles de Belgique, 67:107-162.

Herman, J., Hovestadt-Euler, M., Hovestadt, D.C., and. Stehmann, M. 1998. Contributions to the study of the comparative morphology of teeth and other relevant ichthyodorulites in living supraspecific taxa of chondrichthyan fishes. Part B: Batomorphii. N4a. Order Rajiformes Suborder Myliobatoidei-Superfamily: Dasyatoidea-Family Dasyatidae-Subfamily DasyatinaeGenera: Amphotistius, Dasyatis, Himantura, Pastinachus, Pteroplatytrygon, Taeniura, Urogymnus and Urolophoides (inc. supraspecific taxa of uncertain status and validity). Superfamily Myliobatoidea-Family Gymnuridae-Genera: Aetoplatea and Gymnura. Superfamily Plesiobatoidea-Family Hexatrygonidae-Genus: Hexatrygon. Bulletin de I'Institut Royal des Sciences Naturelles de Belgique, 68:145-197.

Herman, J., Hovestadt-Euler, M., Hovestadt, D.C., and. Stehmann, M. 1999. Contributions to the study of the comparative morphology of teeth and other relevant ichthyodorulites in living supraspecific taxa of chondrichthyan fishes. Part B: Batomorphii. $\mathrm{N}^{\circ} 4 \mathrm{~b}$. Order Rajiformes Suborder Myliobatoidei-Superfamily: Dasyatoidea-Family Dasyatidae-Subfamily DasyatinaeGenera: Taeniura, Urogymnus, Urolophoides -Subfamily Potamotrygoninae -Genera: Disceus, Paratrygon, Plesiotrygon and Potamotrygon (incl. supraspecific taxa of uncertain status and validity). Family Urolophidae -Genera: Trygonoptera, Urolophus and Urotrygon Superfamily Myliobatoidea-Family Gymnuridae-Genus Aetoplatea. Bulletin de I'Institut Royal des Sciences Naturelles de Belgique, 69:161-200.

Herman, J., Hovestadt-Euler, M., Hovestadt, D.C., and Stehmann, M. 2000. Contributions to the study of the comparative morphology of teeth and other relevant ichthyodorulites in living supraspecific taxa of chondrichthyan fishes . Part B: Batomorphii 4c: Order: Rajiformes Suborder Myliobatoidei - Superfamily Dasyatoidea - Family Dasyatidae - Subfamily Dasyatinae - Genus: Urobatis, Subfamily Potamotrygoninae - Genus: Pomatotrgon, Superfamily Plesiobatoidea - Family Plesiobatidae - Genus: Plestiobatis, Superfamily Myliobatoidea - Family Myliobatidae Subfamily Myliobatinae - Genera: Aetobatus, Aetomylaeus, Myliobatis and Pteromylaeus, Subfamily Rhinopterinae - Genus: Rhinoptera and Subfamily Mobulinae - Genera: Manta and Mobula. Addendum 1 to 4a: erratum to Genus Pteroplatytrygon. Bulletin de l'Institut Royal des Sciences Naturelles de Belgique, 70:5-67.

Hermann, J. 1783. Tabula affinitatum animalium olim academico specimine edita, nunc uberiore commentario illustrata com annotationibus ad historiam naturalem animalium augendam facientibus. Treuthel, J.G., Argentorati.

Hollis, C.J., Jones, T.D., Anagnostou, E., Bijl, P.K., Cramwinckel, M.J., Cui, Y., Dickens, G.R., Edgar, K.M., Eley, Y., Evans, D., Foster, G.L., Frieling, J., Ingls, G.N., Kennedy, E.M., Kozdon, R., Lauretano, V., Lear, C.H., Littler, K., Lourens, L., Meckler, A.N., Naafs, B.D.A., Palike, H., Pancost, R.D., Pearson, P.N., Rohl, U., Royer, D.L., Salzmann, U., Schubert, B.A., Seebeck, H., Sluijs, A., Speijer, R.P., Stassen, P., Tierney, J., Tripati, A., Wade, B., Westerhold, T., Witkowski,C., Zachos, J., Ehang, Y.G., Huber, M., and Lunst, D.J. 2019. The DeepMIP contribution to PMIP4: methodologies for selection, compilation and analysis of latest 
Paleocene and early Eocene climate proxy data, incorporating version 0.1 of the DeepMIP database. Geoscientific Model Development, 1:3149-3206. https://doi.org/10.5194/gmd-123149-2019

Hovestadt, D.C. and Hovestadt-Euler, M. 2010. Urobatis molleni nov. sp. (Chondrichthyes, Myliobatiformes, Urolophidae) in the Eocene of Belgium. Geominpal Belgica Découvertes Géologiques, Minéralogiques et Paléontologiques en Belgique, 1:67-69.

Hovestadt, D.C. and Hovestadt-Euler, M. 2013. Generic assessment and reallocation of Cenozoic Myliobatinae based on new information of tooth, tooth plate and caudal spine morphology of extant taxa. Palaeontos, 24:1-66.

Huxley, T.H. 1880. On the application of the laws of evolution to the arrangement of the Vertebrata, and more particularly of the Mammalia. Proceedings of the Zoological Society of London, 1880:649-662.

Jaekel, O. 1894. Die eocänen Selachier vom Monte Bolca : ein Beitrag zur Morphogenie des Wirbelthiere. Springer, J., Berlin.

Joleaud, L. 1912. Géologie et paléontologie de la Plaine du Comtat et de ses abords. Description des terrains néogènes. Montpellier: Imprimerie Montane, Sicardi et Valentin, 2:255-285.

Jordan, D.S. and Evermann, B.W. 1896. The fishes of North and Middle America: a descriptive catalogue of the species of fish-like vertebrates found in the waters of North America, north of the Isthmus of Panama. Bulletin of the United States National Museum, 47:1-1240. https:/ /doi.org/10.5962/bhl.title.39714

Jordan D.S. and Gilbert, C.H. 1879. Notes on the fishes of Beaufort Harbor, North Carolina. Proceedings of the United States National Museum, 1:365-388. https://doi.org/10.5479/ si.00963801.1-55.365

Kajiura, S. and Tricas, T. 1996. Seasonal dynamics of dental sexual dimorphism in the Atlantic stingray Dasyatis sabina. Journal of Experimental Biology, 199:2297-2306.

Katz, M.E., Miller, K.G., Wright, J.D., Wade, B.S., Browning, J.V., Cramer, B.S., and Rosenthal, Y. 2008. Stepwise transition from the Eocene greenhouse to the Oligocene icehouse. Nature Geoscience, 1:329-334. https://doi.org/10.1038/ngeo179

Kemp, D. 1994. Fossil chondrichthyes from the lower Barton and Bracklesham Groups of the Hampshire Basin: their taxonomy, stratigraphical distribution and palaeobiology. Unpublished PhD Thesis, Department Geology, Portsmouth, UK.

Kent, B.W. 1999. Part 2. Sharks from the Fisher/Sullivan Site, p. 11-38. In Weems, R.E. and Grimsley, G.J. (eds.), Early Eocene Vertebrates and Plants from the Fisher/Sullivan Site (Nanjemoy Formation) Stafford County, Virginia. Commonwealth of Virginia, Virginia Division of Mineral Resources, Charlottesville.

King, C., Underwood, C.J., and Steurbaut, E. 2014. Eocene stratigraphy of the Wadi Al-Hitan World Heritage Site and adjacent areas (Fayum, Egypt). Stratigraphy, 11:185-234.

Klunzinger, C.B. 1871. Synopsis der Fische des Rothen Meeres II. Theil. Verhandlungen der Königlischen Zoologischen-Botanischen Gesellschaft in Wien, 21:441-688.

Kocsis, L., Ounis, A., Chaabani, F., and Salah, N.M., 2013. Paleoenvironmental conditions and strontium isotope stratigraphy in the Paleogene Gafsa Basin (Tunisia) deduced from geochemical analyses of phosphatic fossils. International Journal of Earth Sciences, 102:1111-1129. https://doi.org/10.1007/s00531-012-0845-5

Kozlov, V.A. 2001. Additions to the Paleogene elasmobranch fauna of western Kazakhstan. Turania, a new shark genus (Odontaspididae) and a new ray species (genus Archaeomanta, Mobulidae). Materialy po Stratigrafii i Paleontologii Urala, 4:83-86. (In Russian)

Kruckow, T. and Thies, D. 1990. Die Neoselachier der Paläokaraib (Pisces: Elasmobranchii). Courier Forschungsinstitut Senckenberg, 119:1-102.

Kumar, K. and Loyal, A.S. 1987. Eocene ichthyofauna from the Subathu Formation, northwestern Himalaya, India. Journal of the Palaeontogical Society of India, 32:64-84.

Last, P.R., Naylor, G.J.P., and Manjaji-Matsumoto, B.M. 2016. A revised classification of the family Dasyatidae (Chondrichthyes: Myliobatiformes) based on new morphological and molecular insights. Zootaxa, 4139:345-368. https://doi.org/10.11646/zootaxa.4139.3.2

Laurito Mora, C.A. 1999. Los selaceos fosiles de la localidad de Alto Guayacan (y otros ictiolitos associados). Mioceno Superior-Plioceno Inferior de Limon, Costa Rica. Guila Imprenta, San José. 
Lear, C.H., Elderfield, H., and Wilson, P. 2008. Cenozoic deep-sea temperatures and global ice volumes from Mg/Ca in benthic foraminiferal calcite. Science, 287:269-272. https://doi.org/ 10.1126/science.287.5451.269

Leidy, J., 1877. Description of vertebrate remains, chiefly from the phosphate beds of South Carolina. Journal of the Academy of Natural Sciences of Philadelphia, 8:209-261.

Leprieur, F., Descombes, P., Gaboriau, T., Cowman, P.F., Parravicini, V., Kulbicki, M., Melian, C.J., de Santana, C.N, Heine, C., Mouillot, D., Bellwood, D.R., and Pellisier, R. 2016. Plate tectonics drive tropical reef biodiversity dynamics. Nature Communications, 7:1-8. https:// doi.org/10.1038/ncomms11461

Leriche, M. 1905 Les poissons éocènes de la Belgique. Mémoires du Musée Royal d'Histoire Naturelle de Belgique, 3(11):49-228.

Leriche, M. 1922. Note sur des Poissons de l'Eocène du Mokattam, près du Caire (Egypte). Bulletin de la Société Belge de Géologie, de Paléontologie et d'Hydrologie, 31:202-210.

Lesson, R.P. 1831. Poissons, p. 66-238. In Duperrey, L.I. (ed.), 1826-1830, Voyage autour du Monde, exécuté par Ordre du Roi, sur la Corvette de la Majeste, La Coquille, pendant les anneés 1822, 1823, 1824, et 1825. Arthus Bertrand, Paris.

Linck, H.F. 1790. Versuch einer Eintheilung der Fische nach den Zähnen. Magazin für das Neueste aus der Physik und Naturgeschichte, 6:28-38.

Linnaeus, C. 1758. Systema Naturae per regna tria naturae, regnum animale, secundum classes, ordines, genera, species, cum characteribus differentiis synonymis, locis. Ed. X. L. Salvius, Stockholm.

Liu, Z., Pagani, M., Zinniker, D., DeConto, R., Huber, M., Brinkhuis, H., and Pearson, A. 2009. Global cooling during the Eocene-Oligocene climate transition. Science, 323:1187-1190. https://doi.org/10.1126/science.1166368

Long, D.J. 1992. Sharks from the La Meseta Formation (Eocene), Seymour Island, Antarctic Peninsula. Journal of Vertebrate Paleontology, 12:11-32. https://doi.org/10.1080/ 02724634.1992.10011428

Louterbach, M., Roddaz, M., Bailleul, J., Antoine, P.-O., Adnet, S., Kim, J.H., van Soelen, E., Parra, F., Gérard, J., Calderon, Y., Gagnaison, C., Sinninghe Damsté, J.S., and Baby, P. 2014. Evidences for a Paleocene marine incursion in southern Amazonia (Madre de Dios Sub-Andean Zone, Peru). Palaeogeography, Palaeoclimatology, Palaeoecology, 414:451471. https://doi.org/10.1016/j.palaeo.2014.09.027

Luciani, V., Giusberti, L., Agnini, C., Fornaciari, E., Rio, D., Spofforth, D.J., and Pälike, H. 2010. Ecological and evolutionary response of Tethyan planktonic foraminifera to the middle Eocene climatic optimum (MECO) from the Alano section (NE Italy). Palaeogeography, Palaeoclimatology, Palaeoecology, 292:82-95. https://doi.org/10.1016/j.palaeo.2010.03.029

Marivaux, L., Essid, E.M., Marzougui, W., Khayati Ammar, H., Adnet, S., Marandat, B., Merzeraud, G., Ramdarshan, A., Tabuce, R., Vianey-Liaud, M., and Yans, J. 2014a. A morphological intermediate between eosimiiform and simiiform primates from the late middle Eocene of Tunisia: Macroevolutionary and paleobiogeographic implications of early anthropoids. American Journal of Physical Anthropology, 154:387-401. https://doi.org/ 10.1002/ajpa.22523

Marivaux, L., Essid, E.M., Marzougui, W., Khayati Ammar, H., Adnet, S., Marandat, B., Merzeraud, G., Tabuce, R., and Vianey-Liaud, M., 2014b. A new and primitive species of Protophiomys (Rodentia, Hystricognathi) from the late middle Eocene of Djebel el Kébar, Central Tunisia. Palaeovertebrata, 38:1-17. https://doi.org/10.18563/pv.38.1.e2

Marrama, G., Klug, S., Vos, J.D., and Kriwet, J. 2018. Anatomy, relationships and palaeobiogeographic implications of the first Neogene holomorphic stingray (Myliobatiformes: Dasyatidae) from the early Miocene of Sulawesi, Indonesia, SE Asia. Zoological Journal of the Linnean Society, 184:1142-1168. https://doi.org/10.1093/ zoolinnean/zly020

McEachran, J.D., Dunn, K.A., and Miyake, T. 1996. Interrelationships of the batoid fishes (Chondrichthyes: Batoidei), p. 63-84. In Stiassny, M.L.J., Parenti, L.R., and Johnson, G.D. (eds.), Interrelationships of Fishes. Academic Press, San Diego, London. https://doi.org/ 10.1016/b978-012670950-6/50005-9 
Merzeraud, G., Essid, E.M., Marzougui, W., Ammar, H.K., Adnet, S., Marivaux, L., Tabuce, R., and Vianey-Liaud, M. 2016. Stratigraphie et sédimentologie des dépôts marins et continentaux d'âge éocène moyen à miocène en Tunisie centrale (région du Djebel el Kébar). Bulletin de la Société géologique de France, 187:11-25. https://doi.org/10.2113/ gssgfbull.187.1.11

Miller, K.G., Fairbanks R.G., and Mountain G.S. 1987. Tertiary oxygen isotope synthesis, sea level history, and continental margin erosion. Paleoceanography, 2:1-19. https://doi.org/ 10.1029/PA002i001p00001

Miller, K.G., Kominz, M.A., Browning, J.V., Wright, J.D., Mountain, G.S., Katz, M. E., and Pekar, S.F. 2005. The Phanerozoic record of global sea-level change. Science, 310:1293-1298. https://doi.org/10.1126/science.1116412

Mitchell, S.F. 2016. Geology of the western margin of the Benbow Inlier-implications for the relationship between the Yellow Limestone and White Limestone groups (with the description of the Litchfield Formation, new name). Caribbean Journal of Earth Science, 48:19-25.

Mitchill, S.L.1815. The fishes of New York described and arranged. Transactions of the Literary and Philosophical Society of New York, 1:355-492.

Müller, J. and Henle, F.G.J. 1837. Gattungen der Haifische und Rochen nach einer von inm mit Hrn. Henle unternommenen gemeinschaftlichen Arbeit über die Natugeschiste der Knorpelfishe. Berishte des Königlischen Preussischen Akademie der Wissenschaften zu Berlin, 1837:111-118

Müller, J. and Henle, F.G.J. 1838. Ueber die Gattungen der Plagiostomen. Archiv fur Naturgeschichte, 4:83-85.

Müller, J. and Henle, F.G.J. 1839-1841. Systematische Beschreibung der Plagiostomen. Berlin bei Veit and Comp 1841, 22:1-200. https://doi.org/10.5962/bhl.title.6906

Murray, A.M. 2004. Late Eocene and early Oligocene teleost and associated ichthyofauna of the Jebel Qatrani Formation, Fayum, Egypt. Palaeontology, 47:711-724. https://doi.org/10.1111/ j.0031-0239.2004.00384.x

Murray, A.M., Cook, T.D., Attia, Y.S., Chatrath, P., and Simons, E.L. 2010. A freshwater ichthyofauna from the late Eocene Birket Qarun Formation, Fayum, Egypt. Journal of Vertebrate Paleontology, 30:665-680. https://doi.org/10.1080/02724631003758060

Murray, A.M., Argyriou, T., and Cook, T.D. 2014. Palaeobiogeographic relationships and palaeoenvironmental implications of an earliest Oligocene Tethyan ichthyofauna from Egypt. Canadian Journal of Earth Sciences, 51:909-918. https://doi.org/10.1139/cjes-2014-0097

Musick, J.A., Harbin, M.M., and Compagno, L.J.V. 2004. Historical zoogeography of the Selachii, p. 33-78. In Carrier, J.C., Musick, J.A., and Heithaus, M.R. (eds.), Biology of Sharks and Their Relatives, Edition 2. CRC Press, Boca Raton, Florida.

Mustafa, H. and Zalmout, I.S. 2002. Elasmobranchs from the late Eocene Wadi Esh-Shallala Formation of Qa'Faydat ad Dahikiya, east Jordan. Tertiary Research, 21:77-94.

Naylor, G.J.P. 1990. A morphometric approach to distinguish between the Upper dentitins of Carcharhinus limbatus and C. brevipinna with comments on its application to tracing shark phylogenies through their fossil teeth. NOAA Technical Report, 90:381-387.

Naylor, G.J.P. and Marcus, L.F. 1994. Identifying isolated shark teeth of the genus Carcharhinus to species: relevance for tracking phyletic change through the fossil record. American Museum Novitates, 3109:1-53.

Naylor, G.J.P., Caira, J.N., Jensen, K., Rosana, K.A.M., Straube, N., and Lakner, C. 2012. Elasmobranch phylogeny: a mitochondrial estimate based on 595 species, p. 31-56. In Carrier, J.C., Musick, J.A., and Heithaus, M.R. (eds.), Biology of Sharks and Their Relatives, Edition 2. CRC Press, Boca Raton, Florida. https://doi.org/10.1201/b11867-9

Notholt, J.G., Sheldon R.P., and Davidson D.F. 1989. Phosphate Deposits of the World: International Geological Correlation Programme Project: 156. Volume 2. Phosphate Rock Resources. Cambridge University Press, Cambridge. https://doi.org/10.1002/gj.3350270219

Noubhani, A. and Cappetta, H. 1997. Les Orectolobiformes, Carcharhiniformes et Myliobatiformes (Elasmobranchii, Neoselachii) des bassins à phosphate du Maroc (Maastrichtien-Lutétien basal). Systématique, biostratigraphie, évolution et dynamique des faunes. Palaeo Ichthyologica, 8:1-327. 
Nyberg, K.G., Ciampaglio, C.N., and Wray, G.A. 2006. Tracing the ancestry of the great white shark, Carcharodon carcharias, using morphometric analyses of fossil teeth. Journal of Vertebrate Paleontology, 26:806-814. https://doi.org/10.1671/02724634(2006)26[806:ttaotg]2.0.co;2

Pawellek, T., Adnet, S., Cappetta, H., Metais, E., Salem, M., Brunet, M., and Jaeger, J.-J. 2012. Discovery of an earliest Pliocene relic tropical fish fauna in a newly detected cliff section (Sabratah Basin, NW Libya). Neues Jahrbuch für Geologie und Paläontologie, Abhandlungen, 266:93-114. https://doi.org/10.1127/0077-7749/2012/0272

Peters, S.E., Antar, M.S.M., Zalmout, I.S., and Gingerich, P.D. 2009. Sequence stratigraphic control on preservation of late Eocene whales and other vertebrates at Wadi Al-Hitan, Egypt. Palaios, 24:290-302. https://doi.org/10.2110/palo.2008.p08-080r

Peters, S.E., Carlson, A.E., Kelly, D.C., and Gingerich, P.D. 2010. Large-scale glaciation and deglaciation of Antarctica during the Late Eocene. Geology, 38:723-726. https://doi.org/ 10.1130/g31068.1

Pimiento, C., González-Barba, G., Ehret, D.J., Hendy, A.J.W., MacFadden, B.J., and Jaramillo, C. 2013. Sharks and rays (Chondrichthyes, Elasmobranchii) from the Late Miocene Gatun Formation of Panama. Journal of Paleontology, 87:755-774. https://doi.org/10.1666/12-117

Priem, M.F. 1897a. Sur les poissons de l'Eocène du Mont Mokattam (Egypte). Bulletin de la Société géologique de France (Serie 3), 25:212-227.

Priem, M.F. 1897b. Note sur Propristis Dames, du Tertiaire inférieur d'Égypte. Bulletin de la Société géologique de France (Serie 3), 25:228-232.

Priem, M.F. 1903. Sur les Poisson fossiles des phosphates d'Algérie et de Tunisie. Extrait du Bulletin de la société Géologique de France (Serie 4), 3:393-406.

Priem, M.F. 1905. Sur les poissons fossiles de l'Eocène moyen d'Egypte. Bulletin de la Société géologique de France (Serie 4), 5:633-641.

Priem, M.F. 1907. Sur des vertébrés de l'Eocène d'Egypte et de Tunisie. Bulletin de la Société géologique de France (Serie 4), 7:412-419.

Priem, M.F. 1908. Etude des poissons fossiles du Bassin Parisien. Annales de Paléontologie, 1144.

Priem, M.F. 1909. Note sur les poissons fossiles des phosphates de Tunisie et d'Algérie. Bulletin de la société Géologique de France (Serie 4), 9:315-324.

Priem, M.F. 1914. Sur les vertébrés du Crétacé et de l'Eocène d'Egypte. Bulletin de la Société géologique de France (Serie 4), 14:366-382.

Probst, J. 1877. Beiträge zur Kenntniss der fossilen Fische aus der Molasse von Baltringen. II: Batoidei A. Günther. Jahreshefte des Vereins für vaterländische Naturkunde in Württemberg, 33:69-103.

Purdy, R.W., Schneider, V.P., Applegate, S.P., Mclellan, J.H., and Slaughter, R.L. 2001. The Neogene sharks, rays, and bony fishes from Lee Creek Mine, Aurora, North Carolina. Smithsonian Contributions to Paleobiology, 90:71-202.

Quoy J.R.C. and Gaimard, J.P. 1824. Description des Poissons, Chapitre 9, p. 1-328. In de Freycinet, L. (ed.), Voyage autour du Monde exécuté sur les corvettes de L. M. "L'Uranie" et "La Physicienne," pendant les années 1817, 1818, 1819 et 1820. Paris.

Rafinesque, C.S. 1810. Indice d'ittiologia siciliana ossia catalogo metodico dei nomi latini, italiani, e siciliani, e siciliani dei pesci, che si rinvengono in Sicilia disposti secondo un metodo naturale eseguito da un appendice che contiene la descrizione di alcuni nuovi pesci siciliani. III Opuscolo del signore C.S. Rafinesque Schmaltz. Giovanni del Nobolo, Messina.

Renema, W., Bellwood, D.R., Braga, J.C., Bromfield, K., Hall, R., Johnson, K.G., Lunt, P., Meyer, C.P., McMonagle, L.B., Morley, R.J., O'Dea, A., Todd, J.A., Wesselingh, F.P., Wilson, M.E.J., and Pandolfi, J.M. 2008. Hopping hotspots: global shifts in marine biodiversity. Science, 321:654-657. https://doi.org/10.1126/science.1155674

Rüppell, W.P.E.S.E. 1835-1938. Neue Wirbelthiere zu der Fauna von Abyssinien gehörig: Fische des rothen Meeres. Frankfurt am Main. https://doi.org/10.5962/bhl.title.53778

Sahni, A. and Mehrotra, D.K. 1981. The Elasmobranch fauna of coastal Miocene sediments of Peninsular India. Biological Memoirs Lucknow, 5:83-121.

Salame, I. and Asan, A. 2019. A new Odontorhytis species (Chondrichtyes) from the Middle Eocene of ElGedida Mine, Bhahriya Oasis, Egypt. Egyptian Journal of Geology, 63:407-415. 
Sambou, B.S., Sarr, R., Hautier, L., Cappetta, H., and Adnet, S., 2017. The selachian fauna (sharks and rays) of the phosphate series of Ndendouri-Ouali Diala (Matam, Western Senegal): Dating and paleoenvironmental interests. Neues Jahrbuch für Geologie und Paläontologie, Abhandlungen 283:205-219. https://doi.org/10.1127/njgpa/2017/0637

Sambou, B.S., Hautier, L., Sarr, R., Tabuce, R., Lihoreau, F., Thiam, M., Lebrun, R., Martin, J.E., Cappetta, H., and Adnet, S. 2020. Contribution to the reappraisal of the mid Paleogene ichtyofauna of Western Africa with three new enigmatical elasmobranchs from ThanetianLutetian of Senegal. Annales de Paléontologie, 106:102400. https://doi.org/10.1016/ j.annpal.2020.102400

Samonds, K.E., Andrianavalona, T.H., Wallett, L.A., Zalmout, I.S., and Ward, D.J. 2019. A middle - late Eocene neoselachian assemblage from nearshore marine deposits, Mahajanga Basin, northwestern Madagascar. Plos One, 14:e0211789. https://doi.org/10.1371/ journal.pone.0211789

Sauvage, H.E. 1889. Note sur quelques poissons fossiles de Tunisie. Bulletin de la Société géologique de France (Serie 3), 17:560-562.

Springer, V.G. 1964. A revision of the carcharhinid shark genera Scoliodon, Loxodon, and Rhizoprionodon. Proceedings of the United States National Museum, 115:559-632. https:// doi.org/10.5479/si.00963801.115-3493.559

Stickley, C., St John, K., Koç, N., Jordan, R.W., Passchier, S., Pearce, R.B., and Kearns, L.E. 2009. Evidence for middle Eocene Arctic sea ice from diatoms and ice-rafted debris. Nature, 460:376-379. https://doi.org/10.1038/nature08163

Strömer, E. 1903. Haifischzähne aus dem unteren Mokattam bei Wasta in Egypten. Neues Jahruch, 1:29-41.

Strömer, E. 1905a. Die Fischreste des Mittleren und Oberen Eocäns von Ägypten. I. Teil: Selachii, B. Squaloidei, und II. Teil: Teleostomi, A. Ganoidei. Beiträge zur Paläontologie und Geologie Österreich-Ungarns, 18:163-185.

Strömer, E. 1905b. Die Fischreste des Mittleren und Oberen Eocäns von Ägypten. I. Teil: Die Selachier, A. Myliobatiden und Pristiden. Beiträge zur Paläontologie und Geologie Österreich-Ungarns, 18:37-58.

Strougo, A. 2008. The Mokattamian stage: 125 years later. Earth Science Series, Middle East Research Center, Ain Shams University, 22:47-108.

Strougo, A., Cappetta, H., and Elnahas, S. 2007. A remarkable Eocene ichthyofauna from the Elgedida glauconitic sandstone, Bahariya oasis, Egypt, and its stratigraphic implications. Earth Science Series, Middle East Research Center, Ain Shams University, 21:81-98.

Sweydan, S., Merzeraud, G., Essid, E.M., Marzougui, W., Temani, R., Ammar, H.K., Marivaux, L., Vianey-Liaud, M., Tabuce, R., and Adnet, S. 2019. A reworked elasmobranch fauna from Tunisia providing a snapshot of Eocene-Oligocene Tethyan faunas. Journal of African Earth Sciences, 149:194-206. https://doi.org/10.1016/j.jafrearsci.2018.08.008.

Tabuce, R., Adnet, S., Cappetta, H., Noubhani, A.B., and Quillevéré, F. 2005. Aznag (bassin d'Ouarzazate, Maroc), nouvelle localité à sélaciens et mammifères de l'Eocène moyen (Lutétien) d'Afrique. Bulletin de la Société géologique de France, 176(4):381-400. https:// doi.org/10.2113/176.4.381

Tawfik, M. and Moussa M. 2016. Relationships between sequence stratigraphy and diagenesis of corals and foraminifers in the Middle Eocene, northern Egypt. Turkish Journal of Earth Sciences, 26:10.3906/yer-1602-2. https://doi.org/10.3906/yer-1602-2

Toffanin, F., Agnini, C., Fornaciari, E., Rio, D., Giusberti, L., Luciani, V., Spofforth, D.J.A., and Pälike, H. 2011. Changes in calcareous nannofossil assemblages during the Middle Eocene Climatic Optimum: Clues from the central-western Tethys (Alano section, NE Italy). Marine Micropaleontology, 81(1-2):22-31. https://doi.org/10.1016/j.marmicro.2011.07.002

Underwood, C.J. and Gunter, G.C. 2012. The shark Carcharhinus sp. from the Middle Eocene of Jamaica and the Eocene record of Carcharhinus. Caribbean Journal of Earth Science, 44:25-30.

Underwood, C.J. and Ward, D.J. 2008. Sharks of the Order Carcharhiniformes from the British Coniacian, Santonian and Campanian (Upper Cretaceous). Palaeontology, 51:509-536. https://doi.org/10.1111/j.1475-4983.2008.00757.x

Underwood, C.J. and Ward, D.J. 2011. New hemigaleid shark from the late Eocene of Wadi AlHitan, Egypt. Journal of Vertebrate Paleontology, 31:707-711. https://doi.org/10.1080/ 02724634.2011.563763 
Underwood, C.J., Ward, D.J., King, C., Antar, S.M., Zalmout, I.S., and Gingerich, P.D. 2011. Shark and ray faunas in the middle and late Eocene of the Fayum area, Egypt. Proceedings of the Geologists' Association, 122:47-66. https://doi.org/10.1016/j.pgeola.2010.09.004

Underwood, C.J., King, C., and Steurbaut, E. 2012. Large-scale glaciation and deglaciation of Antarctica during the Late Eocene: Comment. Geology, 40:e253-e254. https://doi.org/ 10.1130/G31820C.1

Underwood, C.J., King, C., and Steurbaut, E. 2013. Eocene initiation of Nile drainage due to East African uplift. Palaeogeography, Palaeoclimatology, Palaeoecology, 392:138-145. https:// doi.org/10.1016/j.palaeo.2013.09.014

Underwood, C.J., Kolmann, M.A., and Ward, D.J. 2017. Paleogene origin of planktivory in the Batoidea. Journal of Vertebrate Paleontology, 37:e1293068. https://doi.org/10.1080/ 02724634.2017.1293068

Van Vliet, H.J., Schulp, A., Abu El-Kheir, G., Paijmans, T., and Bosselaers, M. 2017. A new site with Oligocene terrestrial mammals and an Oligocene selachian fauna from Minqar Tibaghbagh, the Western Desert of Egypt. Acta Palaeontologica Polonica, 62:509-525. https://doi.org/10.4202/app.00341.2017

Voigt, M. and Weber, D. 2011. Field guide for sharks of the genus Carcharhinus. Verlag Dr. F. Pfeil, München.

Ward, D.J. and Wiest, R.L. 1990. A checklist of Palaeocene and Eocene sharks and rays (Chondrichthyes) from the Pamunkey Group, Maryland and Virginia, USA. Tertiary Research, 12:81-88.

Westerhold, T., Röhl, U., Donner, B., and Zachos, J.C. 2018. Global extent of early Eocene hyperthermal events: a new Pacific benthic foraminiferal isotope record from Shatsky Rise (ODP Site 1209). Paleoceanography and Paleoclimatology, 33:626-642. https://doi.org/ 10.1029/2017PA003306

White, E.I. 1926. Eocene fishes from Nigeria. Bulletin of the Geological Survey of Nigeria, 10:182.

White, E.I. 1956. The Eocene fishes of Alabama. Bulletins of American Paleontology, 36:123150.

Whitley, G.P. 1929. Additions to the check-list of the fishes of New South Wales, No. 2. Australian Zoologist, 5:353-357.

Whitley, G.P. 1939. Taxonomic notes on sharks and rays. Australian Zoologist, 9:227-262.

Witkowski, J., Bohaty, S.M., McCartney, K., and Harwood, D.M. 2012. Enhanced siliceous plankton productivity in response to middle Eocene warming at Southern Ocean ODP Sites 748 and 749. Palaeogeography, Palaeoclimatology, Palaeoecology, 326-328:78-94. https:// doi.org/10.1016/j.palaeo.2012.02.006

Zachos, J.C., Quinn, T.M., and Salamy, K.A. 1996. High-resolution (10 years) deep-sea foraminiferal stable isotope records of the Eocene-Oligocene climate transition. Paleoceanography, 11:251-266. https://doi.org/10.1029/96PA00571

Zachos, J.C., Pagani, M., Sloan, L., Thomas, E., and Billups, K. 2001. Trends, rhythms, and aberrations in global climate 65 Ma to present. Science, 292:686-693. https://doi.org/ 10.1126/science.1059412

Zachos, J.C., Dickens, G.R., and Zeebe, R.E. 2008. An early Cenozoic perspective on greenhouse warming and carbon-cycle dynamics. Nature, 451:279-283. https://doi.org/ 10.1038/nature06588

Zalmout, I.S., Antar, M.S.M., Shafy, E.A., Metwally, M.H., Hatab, E.E., and Gingerich, P.D. 2012. Priabonian sharks and rays (late Eocene: Neoselachii) from Minqar Tabaghbagh in the Western Qattara Depression, Egypt. Contributions from the Museum of Paleontology, University of Michigan, 32:71-90.

Zouhri, S., Khalloufi, B., Bourdon, E., De Lapparent De Broin, F., Rage, J.-C., M'HaïDrat, L., Gingerich, P.D., and Elboudali, N. 2017. Marine vertebrate fauna from the late Eocene Samlat Formation of Ad-Dakhla, southwestern Morocco. Geological Magazine, 155:15961620. https://doi.org/10.1017/S0016756817000759

Zouhri, S., Gingerich, P., Khalloufi, B., Bourdon, E., Adnet, S., Jouve, S., Bouzarzarz, W., Rage, J.C., Tabuce, R., Amane, A., and De Lapparent De Broin, F. In press. Bartonian middle Eocene vertebrate fauna from the Aridal Formation, Sabkha of Gueran, southern Morocco. Geodiversitas. 


\section{APPENDIX 1.}

Half lower (top) and upper (down) jaws of Female (UM REC285M) and Male (UM REC284M) of Leptocharias smithii (Sénégal). S. symphyseal teeth.

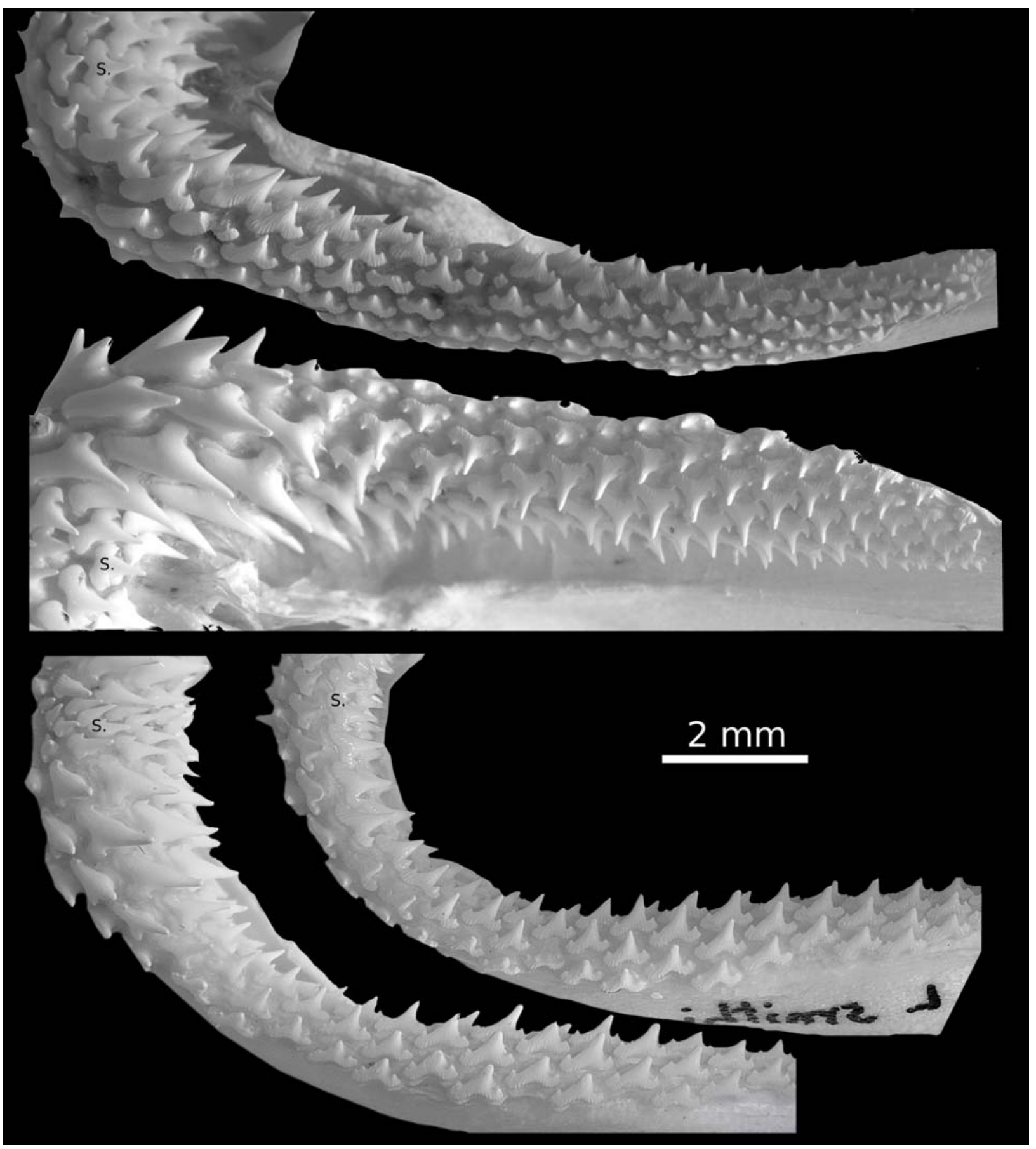




\section{APPENDIX 2.}

A: Sphyrna media. A1. Upper (left) and lower (right) half jaw of Female (UM REC142M), A2. Magnificience of upper teeth, A3. Magnificience of lower teeth; B: Sphyrna tudes. B1. Upper (left) and lower (right) half jaw of Female (UM REC144M), B2. Magnificience of upper teeth, B3. Magnificience of lower teeth; C: Rhizoprionodon acutus. Upper (left) and lower (right) half jaw of Male (UM REC1237M); D: Rhizoprionodon lalandis. Upper (left) and lower (right) half jaw of Female (UM REC279M); E: Rhizoprionodon porosus. Upper (left) and lower (right) half jaw of Male (UM REC277M).
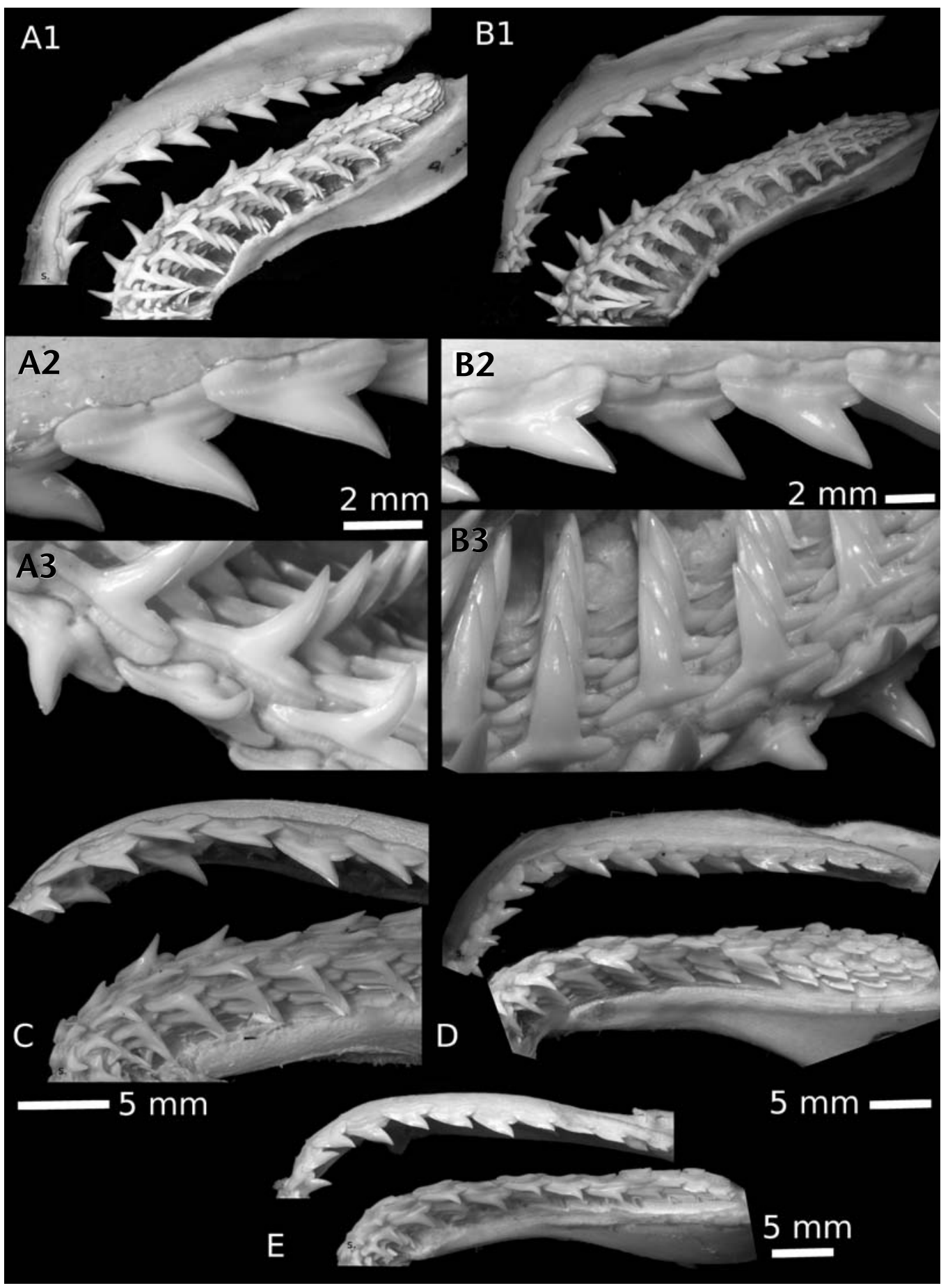